\title{
Single-Atom Catalysts: From Design to Application
}

\author{
Niancai Cheng ${ }^{1,2} \cdot$ Lei Zhang $^{1} \cdot$ Kieran Doyle-Davis $^{1} \cdot$ Xueliang Sun $^{1}$ \\ Received: 19 February 2019 / Revised: 17 April 2019 / Accepted: 12 July 2019 / Published online: 28 August 2019 \\ (c) The Author(s) 2019
}

\begin{abstract}
Single-atom catalysis is a powerful and attractive technique with exceptional performance, drastic cost reduction and notable catalytic activity and selectivity. In single-atom catalysis, supported single-atom catalysts contain isolated individual atoms dispersed on, and/or coordinated with, surface atoms of appropriate supports, which not only maximize the atomic efficiency of metals, but also provide an alternative strategy to tune the activity and selectivity of catalytic reactions. This review will highlight the attributes of single-atom catalysis and summarize the most recent advancements in single-atom catalysts with a focus on the design of highly active and stable single atoms. In addition, new research directions and future trends will also be discussed.
\end{abstract}

Keywords Single-atom $\cdot$ Synchrotron radiation $\cdot$ Electrocatalytic reactions $\cdot$ Heterogeneous catalysis $\cdot$ DFT calculations

\section{Introduction}

Supported nanocatalysts have been widely studied due to high activities in different chemical reactions [1-3]. In addition, the size of metal particles is one of the most important factors dictating catalytic performance [4]. Therefore, to achieve high specific activity and reduce cost, reductions in the size of catalyst particles are necessary, especially in the case of noble metal catalysts. Noble metals such as Pt, $\mathrm{Pd}, \mathrm{Ru}, \mathrm{Rh}$ and $\mathrm{Ir}$ are superior heterogeneous catalysts that are used in the petrochemical industry, medicine production, environmental protection and new energy applications. However, due to high costs and low natural abundances, noble metal catalysts cannot meet increasing demands and the minimization of the use of such expensive catalysts and the simultaneous retention in catalytic activity levels are significant and consistent challenges in this field [5, 6] (Scheme 1).

To address these issues, the downsizing of noble metals from nanoclusters to isolated single atoms is the most

Niancai Cheng and Lei Zhang have contributed equally to this work.

Xueliang Sun

xsun@eng.uwo.ca

1 Department of Mechanical and Materials Engineering, University of Western Ontario, London, ON N6A 5B9, Canada

2 College of Materials Science and Engineering, Fuzhou University, Fuzhou 350108, China effective method to provide optimal active sites in corresponding catalysts to maximize metal atom efficiency and maintain necessary catalytic performances [7-9]. Here, single-atom catalysts (SACs), a class of catalysts in which catalytically active individual and isolated metal atoms are anchored to supports, have emerged as a novel class of catalysts that can exhibit optimal metal utilization, with all metal atoms being exposed to reactants and available for catalytic reactions [9]. Furthermore, the unique properties of SACs have attracted great attention from researchers due to distinct behaviors in comparison with metal nanoparticles (NPs) and mononuclear metal compounds in which extraordinary catalytic activity, selectivity and stability for various reactions including oxidation, water-gas shift and hydrogenation have been demonstrated and can be attributed to the low-coordination environment of metal atoms as well as the high atom utilization and improved strong metal-support interactions [10]. And since the first practical $\mathrm{SAC}\left(\mathrm{Pt}_{1} / \mathrm{FeO}_{x}\right)$ was reported by Zhao et al. [11], significant progress has been made in this rapidly emerging field, with various supported SACs with different metals being designed and tested to exhibit excellent catalytic performances in various chemical reactions [12, 13]. We summarized the important developments of SACs for several typical catalytic reactions in Scheme 1.

Despite the observed performances for various reactions however, significant challenges associated with the synthesis and stabilization of SACs exist as well in which a key challenge in the application of SACs is the stabilization of isolated metals on supports without the compromise of 
Scheme 1 Timeline of important developments of singleatom catalysts

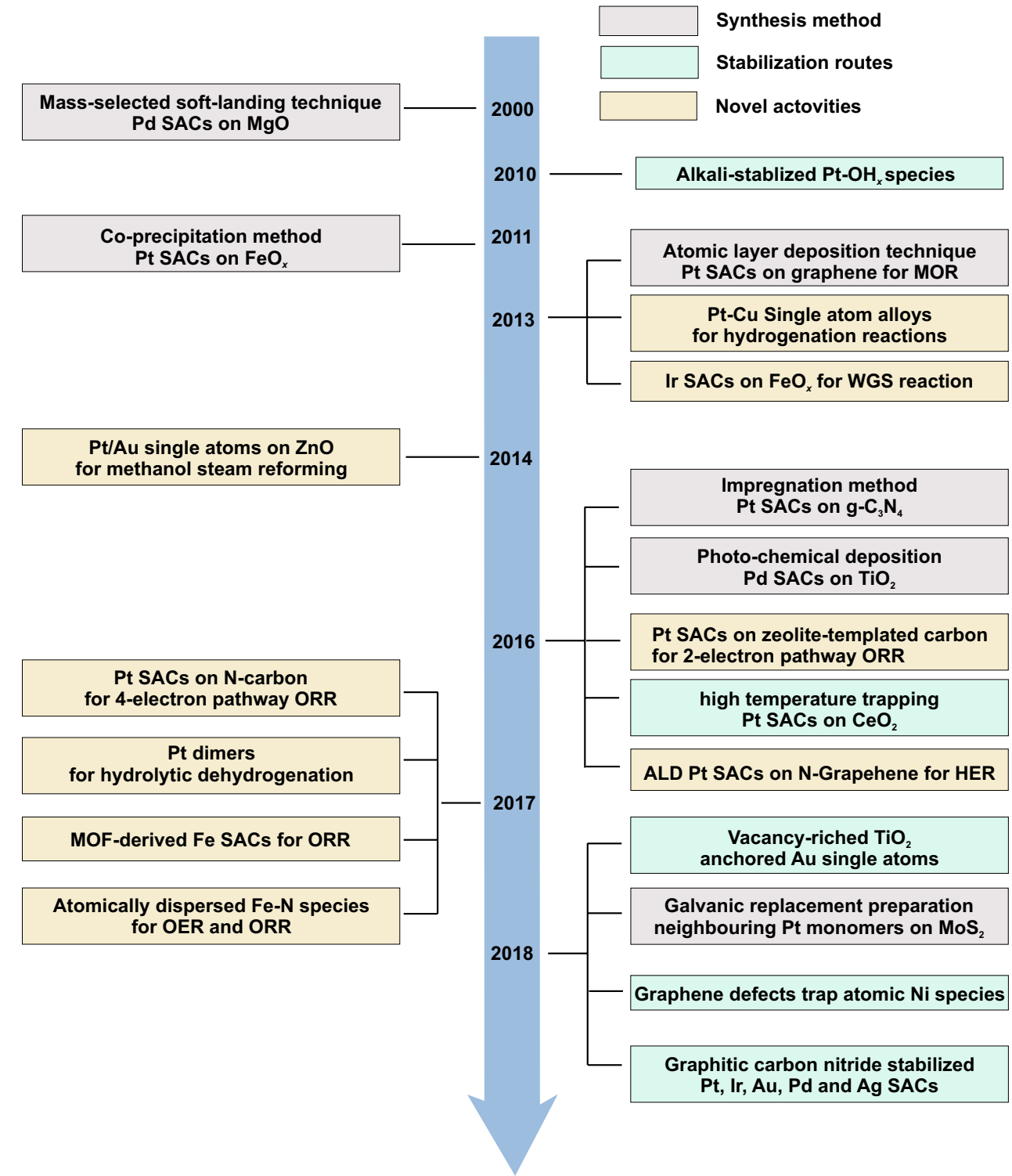

catalytic activity, especially at high temperatures or under harsh reaction conditions [14-17]. This is because single metal atoms tend to become more mobile and form aggregates as the surface energies of single metal atoms become higher than corresponding metal clusters and nanoparticles. To address this, metal loadings are currently kept at low levels to minimize agglomeration during synthesis; however, the high loading of SACs remains a challenge for practical application. Therefore, this review will focus on the design of highly stable and active SACs for practical application in which the performance of state-of-the-art SACs is summarized. This review will also provide an overview of the mechanisms of single-atom catalysis and the stabilization of single atoms to provide insights into the design of highperformance catalytic systems. Overall, this review will be a useful guideline for industrial catalyst development.

\section{Synthesis Methods for Single-Atom Catalysts}

A prerequisite of SACs is the dispersal of isolated single metal atoms onto appropriate support surfaces. However, SAC fabrication is challenging due to the energetically preferential aggregation of metal atoms during synthesis or subsequent treatment processes. Therefore, single metal atom materials require the development of advanced synthetic methods to gain wider adoption. Here, researchers have proposed several strategies such as atomic layer deposition (ALD), wet impregnation and co-precipitation for SAC synthesis, and in this review, several methods are discussed. 
Fig. 1 HAADF-STEM images of Pt single atoms on different substrates: a g- $\mathrm{C}_{3} \mathrm{~N}_{4}$, b TiN, c LSC, d HSC. a Adapted with permission from Ref. [19]. Copyright 2016, Wiley-VCH. b Adapted with permission from Ref. [20]. Copyright 2016, Wiley-VCH. c, d Adapted with permission from Ref. [22]. Copyright 2016, Nature Publishing Group
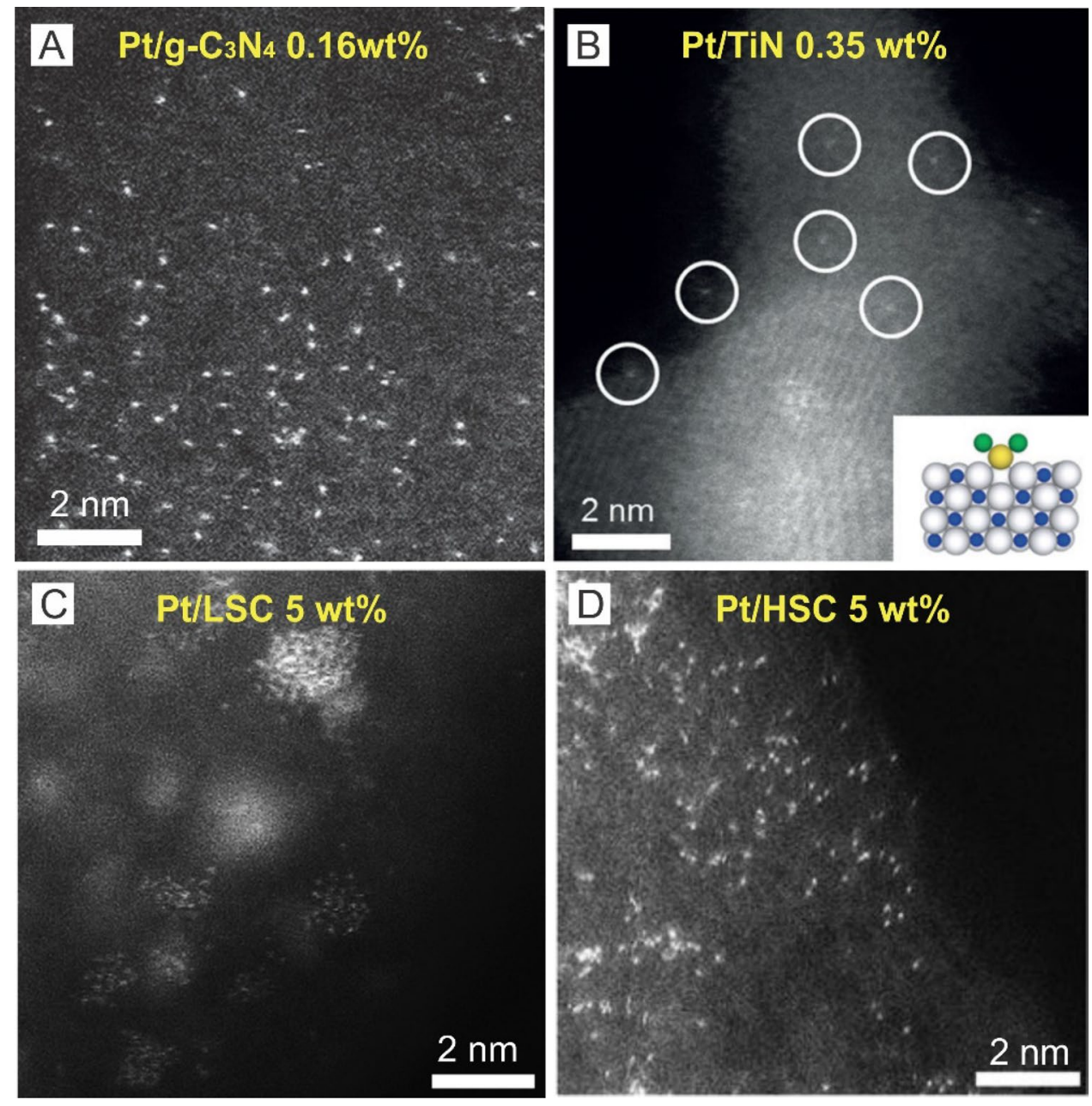

\subsection{Impregnation}

Impregnation is a simple method to prepare supported catalysts in which typically, a certain volume of solution containing active metal precursors is mixed with a catalyst support to allow the active metal precursors to anchor onto the support through an ion-exchange/adsorption process. As a result, the quality of SACs prepared using impregnation depends heavily on precursor-support interactions. For example, g- $\mathrm{C}_{3} \mathrm{~N}_{4}$ (graphitic carbon nitride) with N/Ccoordinating frameworks in a $\mathrm{g}-\mathrm{C}_{3} \mathrm{~N}_{4}$ matrix can facilitate interactions with metal precursors [18] in which $\mathrm{Li}$ et al. [19] anchored single $\mathrm{Pt}$ atoms onto $\mathrm{g}-\mathrm{C}_{3} \mathrm{~N}_{4}$ through the addition of $\mathrm{Pt}$ precursors $\left(\mathrm{H}_{2} \mathrm{PtCl}_{6}\right)$ into a $\mathrm{g}-\mathrm{C}_{3} \mathrm{~N}_{4}$ aqueous dispersion followed by stirring at $70{ }^{\circ} \mathrm{C}$ for $4-10 \mathrm{~h}$ (Fig. 1a). Here, the researchers washed the resulting product with distilled water and ethanol several times to remove Pt precursors without interacting with the $\mathrm{g}-\mathrm{C}_{3} \mathrm{~N}_{4}$ support and dried the residual powder in vacuum at $60{ }^{\circ} \mathrm{C}$ overnight followed by annealing at $125^{\circ} \mathrm{C}$ for $1 \mathrm{~h}$ in $\mathrm{Ar}$ atmosphere.

Supported SACs can also be prepared through a dry impregnation method in which precursors can generally be applied to the surface of supports with weak precursor-support interactions. For example, Lee et al. [20] used dry impregnation to deposit single $\mathrm{Pt}$ atoms onto a TiN support (Fig. 1b) in which the Pt precursor solution was finely mixed with acid-treated TiN nanoparticles and dried in a vacuum oven at $50{ }^{\circ} \mathrm{C}$. These researchers subsequently reduced the resulting powder at $100{ }^{\circ} \mathrm{C}$ for $1 \mathrm{~h}$ under a $\mathrm{H}_{2} / \mathrm{N}_{2}$ flow at a flow rate of $200 \mathrm{sccm}$ and reported that single Pt atom catalysts could only be achieved at low Pt loadings of less than $0.35 \mathrm{wt} \%$ and that Pt clusters and nanoparticles would form if Pt loadings were higher than $0.35 \mathrm{wt} \%$. Here, the researchers suggested that the formation of $\mathrm{Pt}$ nanoparticles at $\mathrm{Pt}$ loadings of higher than $0.35 \mathrm{wt} \%$ was a result of the severe redistribution of impregnated species due to the weakness of the precursor-support interaction during impregnation [21].

Overall, impregnation is an economical and simple method for the synthesis of SACs. However, it is difficult to produce high-loading SACs using this method due to the limited number of functional groups and defects on the surface of supports that can interact with metal precursors. To address this, Choi et al. [22] recently used sulfur-doped zeolite-templated carbon with low and high sulfur content 
(4 wt\% and $17 \mathrm{wt} \% \mathrm{~S}$ ) as templates (LSC and HSC) to synthesize single $\mathrm{Pt}$ atom catalysts through a wet-impregnation method and reported that the loading of single Pt atoms can reach as high as $5 \mathrm{wt} \%$ (Fig. 1c, d). Here, the researchers attributed the good dispersion of Pt single atoms to the formation of four-coordinated mononuclear $\mathrm{Pt}-\mathrm{S}_{4}$ complexes [22].

\subsection{Co-precipitation}

Co-precipitation is a traditional and widely used method to synthesize nanoparticle materials [23-25]. However, Zhang's group have successively used this method to synthesize a series of SACs for CO oxidation, hydrogenation and water-gas shift reactions [26-30]. For example, Qiao et al. [11] prepared $\mathrm{FeO}_{x}$-supported single $\mathrm{Pt}$ atom catalysts using co-precipitation with an aqueous solution of chloroplatinic acid $\left(\mathrm{H}_{2} \mathrm{PtCl}_{6}\right)$ and ferric nitrate $\left[\mathrm{Fe}\left(\mathrm{NO}_{3}\right)_{3}\right]$ as the metal precursors and sodium carbonate $\left(\mathrm{Na}_{2} \mathrm{CO}_{3}\right)$ as the precipitation agent at $50{ }^{\circ} \mathrm{C}$ in which the resulting solution possessed a fixed $\mathrm{pH}$ of $\sim 8$. Here, the resultant precipitate was filtered, washed thoroughly with deionized water, dried at $60{ }^{\circ} \mathrm{C}$ overnight and calcined at $400{ }^{\circ} \mathrm{C}$ for $5 \mathrm{~h}$. In addition, the sample was reduced with $10 \% \mathrm{H}_{2} / \mathrm{He}$ at $200{ }^{\circ} \mathrm{C}$ for $30 \mathrm{~min}$ and HAADF-STEM images were obtained to confirm that the Pt atoms were located on the surface or near subsurface of the nanocrystallites rather than inside the iron oxide, which can reduce the Ir utilization and catalytic activity. As a result, this SAC demonstrated excellent stability and high activity for $\mathrm{CO}$ oxidation and the preferential oxidation of $\mathrm{CO}$ in $\mathrm{H}_{2}$. The researchers in this study also reported that much like the impregnation methods, low metal loadings were required to achieve isolated Pt atoms in which uniformly dispersed individual $\mathrm{Pt}$ atoms can be observed on $\mathrm{FeO}_{x}$ support surfaces with a low Pt loading of 0.17 wt\% (Fig. 2a), whereas individual Pt atoms, 2D Pt rafts with fewer than ten Pt atoms and 3D Pt clusters $\leqslant 1 \mathrm{~nm}$ can be observed with a Pt loading of $2.5 \mathrm{wt} \%$ (Fig. 2b). Wei et al. [31] also reported that reduction temperatures can affect the morphology of $\mathrm{Pt}$ on $\mathrm{FeO}_{x}$ surfaces in co-precipitation in which at a Pt loading of $0.08 \mathrm{wt} \%$ and a reduction temperature of $200{ }^{\circ} \mathrm{C}$, all $\mathrm{Pt}$ species on $\mathrm{FeO}_{x}$ were found to be in the form of isolated single atoms with no sub-nanometer clusters or nanoparticles being detected, whereas at higher
Fig. 2 HAADF-STEM images of $\mathbf{a}, \mathbf{b}$ Pt single atoms on $\mathrm{FeO}_{x}$ and $\mathbf{c}, \mathbf{d}$ Ir single atoms on $\mathrm{FeO}_{x}$. a, b Adapted with permission from Ref. [11]. Copyright 2011, Nature Publishing Group. c, d Adapted with permission from Ref. [27]. Copyright 2013, American Chemical Society
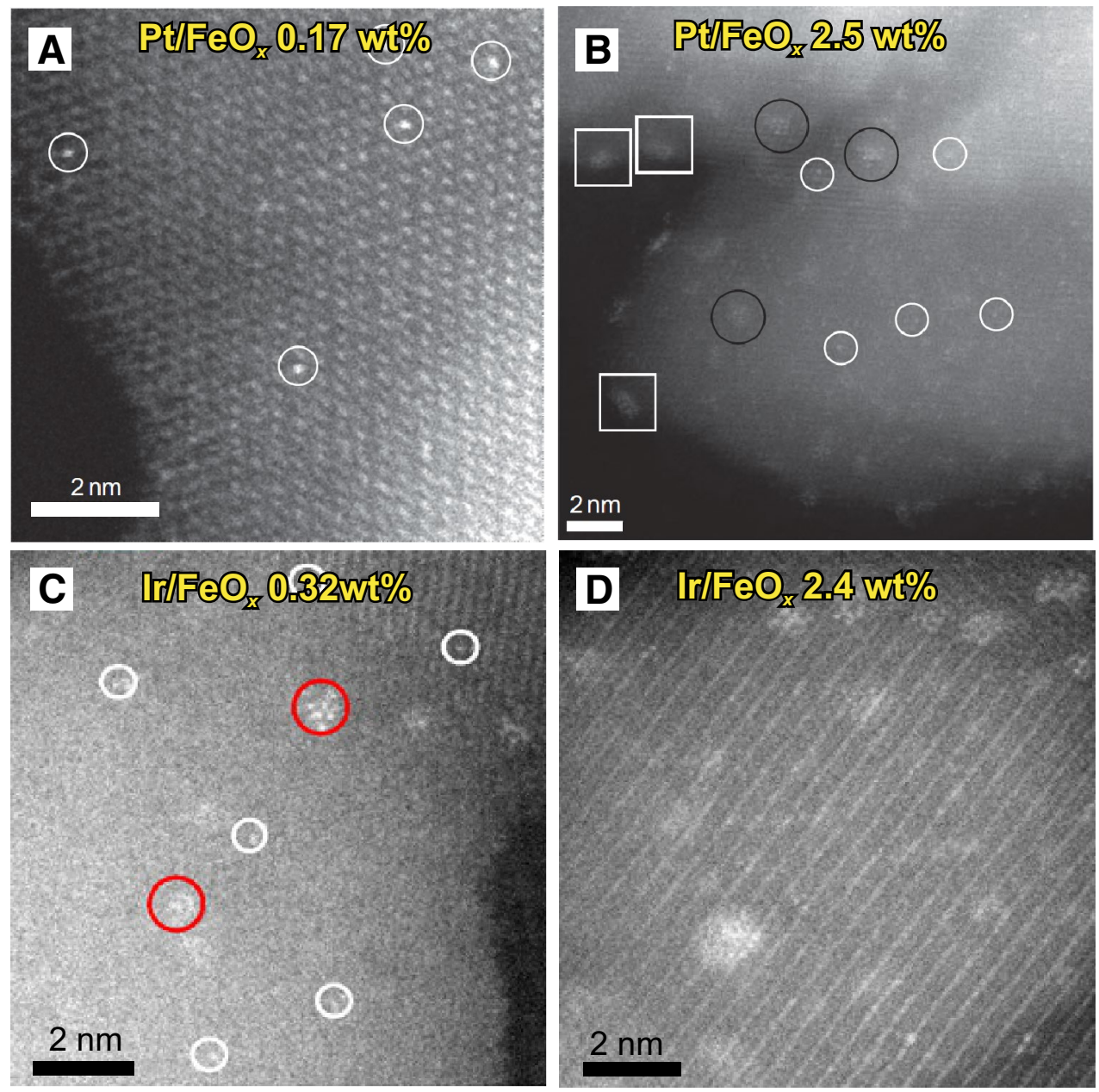
reducing temperatures $\left(250^{\circ} \mathrm{C}\right.$ or above) at the same Pt loading, clustering of single atoms can be observed with small clusters composed of loose and random ensembles of several to tens of Pt atoms being found. Furthermore, Zhang et al. $[27,28]$ also prepared single Ir atoms anchored on $\mathrm{FeO}_{x}$ catalysts using co-precipitation (Fig. 2c, d) in which a higher precipitation temperature $\left(80^{\circ} \mathrm{C}\right)$ was chosen to guarantee that all $\mathrm{H}_{2} \mathrm{IrCl}_{6}$ in the solution was precipitated and loaded onto the $\mathrm{FeO}_{x}$ support. As a result, the synthesized single Ir atoms anchored onto $\mathrm{FeO}_{x}$ exhibited an exceptionally high activity for water-gas shift reactions (WGS) that was almost 1 order of magnitude higher than its cluster or nanoparticle counterparts.

Overall, co-precipitation is a simple, rapid and economical method for the synthesis of SACs. And in the future, further optimizations of synthesis parameters are necessary to increase the loading of single atoms. However, co-precipitation is only suitable for the synthesis of single atoms on metal oxide supports. In addition, the use of co-precipitation to synthesize metal SACs can lead to the burial of metal atoms in the interfacial regions of support agglomerates and in the bulk of support crystallites, leading to the lack of accessibility to these buried single atoms by reactant molecules, significantly compromising the effectiveness and efficiency of corresponding SACs.

\subsection{Atomic Layer Deposition}

Atomic layer deposition (ALD) is gaining attention as a technique for the deposition of noble metals and metal oxides because of the ability to deposit uniform and conformal thin films of distributed particles ranging from single atoms to sub-nanometer clusters to NPs in high-aspect-ratio structures and porous materials [32-36]. In general, the process of ALD consists of four steps [37]: (1) exposure to the first precursor; (2) purge of the reaction chamber; (3) exposure to the second reactant precursor; and (4) a further purge of the reaction chamber, in which the morphology, size, density and loading of deposited materials on supports can be precisely controlled through the simple adjustment of ALD cycles. For example, Sun et al. [38] first reported the practical synthesis of isolated single $\mathrm{Pt}$ atoms anchored onto graphene nanosheets (GNS) using ALD based on the following reaction mechanism (Fig. 7):

$$
\begin{aligned}
& \mathrm{Pt}-\mathrm{O}^{*}+(\mathrm{MeCp}) \mathrm{Pt}\left(\mathrm{CH}_{3}\right)_{3} \rightarrow\left(\mathrm{CH}_{3}\right)_{2} \mathrm{Pt}(\mathrm{MeCp}) \\
& +\mathrm{CO}_{2} \uparrow+\mathrm{H}_{2} \mathrm{O} \uparrow+\text { fragments } \\
& \left(\mathrm{CH}_{3}\right)_{2} \mathrm{Pt}(\mathrm{MeCp})^{*}+\mathrm{O}_{2} \uparrow \rightarrow \mathrm{Pt}-\mathrm{O}^{*} \\
& \quad+\mathrm{CO}_{2} \uparrow+\mathrm{H}_{2} \mathrm{O} \uparrow+\text { fragments }
\end{aligned}
$$

Here, high-angle annular dark-field STEM (HAADF-STEM) images (Fig. 3a, b) of the resulting Pt deposited onto GNS and N-doped GNS were obtained in which after 50 cycles of ALD, numerous individual $\mathrm{Pt}$ atoms as well as very small $\mathrm{Pt}$ clusters $(<1 \mathrm{~nm})$ consisting of a few atoms were observed. And after 100 cycles, Pt clusters were observed to have grown larger, forming NPs with average sizes between 1 and $2 \mathrm{~nm}$. Furthermore, after 150 cycles, existing clusters and particles from the 50 and 100 cycle samples were observed to have grown to be as large as $4 \mathrm{~nm}$ with new 1 to $2 \mathrm{~nm}$ clusters forming. These researchers also reported that the optimal single Pt atom catalyst (ALD50-Pt/GNS) exhibited significantly enhanced methanol oxidation catalytic activities (up to 10 times) in comparison with state-of-the-art commercial $\mathrm{Pt} / \mathrm{C}$ catalysts and that the increased methanol oxidation activity of the ALD50-Pt/GNS can be attributed to the smaller particle sizes that resulted in the improved utilization of Pt atoms. Furthermore, X-ray absorption fine structure (XAFS) analysis in this study also revealed that the low-coordination and partially unoccupied $5 \mathrm{~d}$ orbitals of the $\mathrm{Pt}$ atoms in the ALD50-Pt/GNS can contribute to enhanced performances as well. Aside from Pt single atoms, Lu et al. [39] also reported that $\mathrm{Pt}_{2}$ dimers can be fabricated using a bottom-up approach on graphene through the creation of proper nucleation sites followed by $\mathrm{Pt}_{1}$ single-atom deposition and the selective attachment of a secondary Pt atom to the preliminary one (Fig. $3 \mathrm{c}$ ). Here, the $\mathrm{Pt}_{2}$ dimers were in an oxidized form with a structure of $\mathrm{Pt}-\mathrm{O} / \mathrm{C}-\mathrm{Pt}$ due to the ozone exposure step. Moreover, Lu et al. [40] obtained single $\mathrm{Pd}$ atom catalysts through a single cycle of ALD with prolonged $\mathrm{Pd}(\mathrm{hfac})_{2}$ exposure to allow Pd precursors to completely react with graphene functional groups (Fig. 3d) in which the researchers reported that single Pd atoms on graphene showed remarkable performance in the selective hydrogenation of 1,3-butadiene and $\sim 100 \%$ butene selectivity with $95 \%$ conversion at a mild reaction temperature of $50{ }^{\circ} \mathrm{C}$. More importantly, the $\mathrm{Pd}$ single atoms demonstrated excellent durability against deactivation through metal atom aggregation or carbonaceous deposition during $100 \mathrm{~h}$ of reaction time.

Overall, the properties of the support play an important role in the stabilization and loading of deposited materials using ALD [37, 41-43]. To develop stable, high loading and isolated noble metal atoms on catalyst supports, the understanding of ALD and the nature of the interactions between deposited materials and supports is crucial. In addition, the development of cheaper precursors to synthesize SACS using ALD is vital.

\subsection{Wet-Chemical Synthesis}

Wet-chemical synthesis is a facile preparation method that is promising for the large-scale production of SACs. Aside from common wet-chemical synthetic methods such as impregnation and co-precipitation that have already been discussed, other novel wet-chemical synthetic methods have 
Fig. 3 SACs obtained through ALD. a, b HAADF-STEM images of Pt single atoms on a graphene and $\mathbf{b} \mathrm{N}$-doped graphene. c HAADF-STEM images of Pt dimers on graphene. d HAADF-STEM images of Pd single atoms on graphene. a Adapted with permission from Ref. [38]. Copyright 2013, Nature Publishing Group. b Adapted with permission from Ref. [109]. Copyright 2016, Nature Publishing Group. c Adapted with permission from Ref. [39]. Copyright 2017, Nature Publishing Group. d Adapted with permission from Ref. [40]. Copyright 2015, American Chemical Society
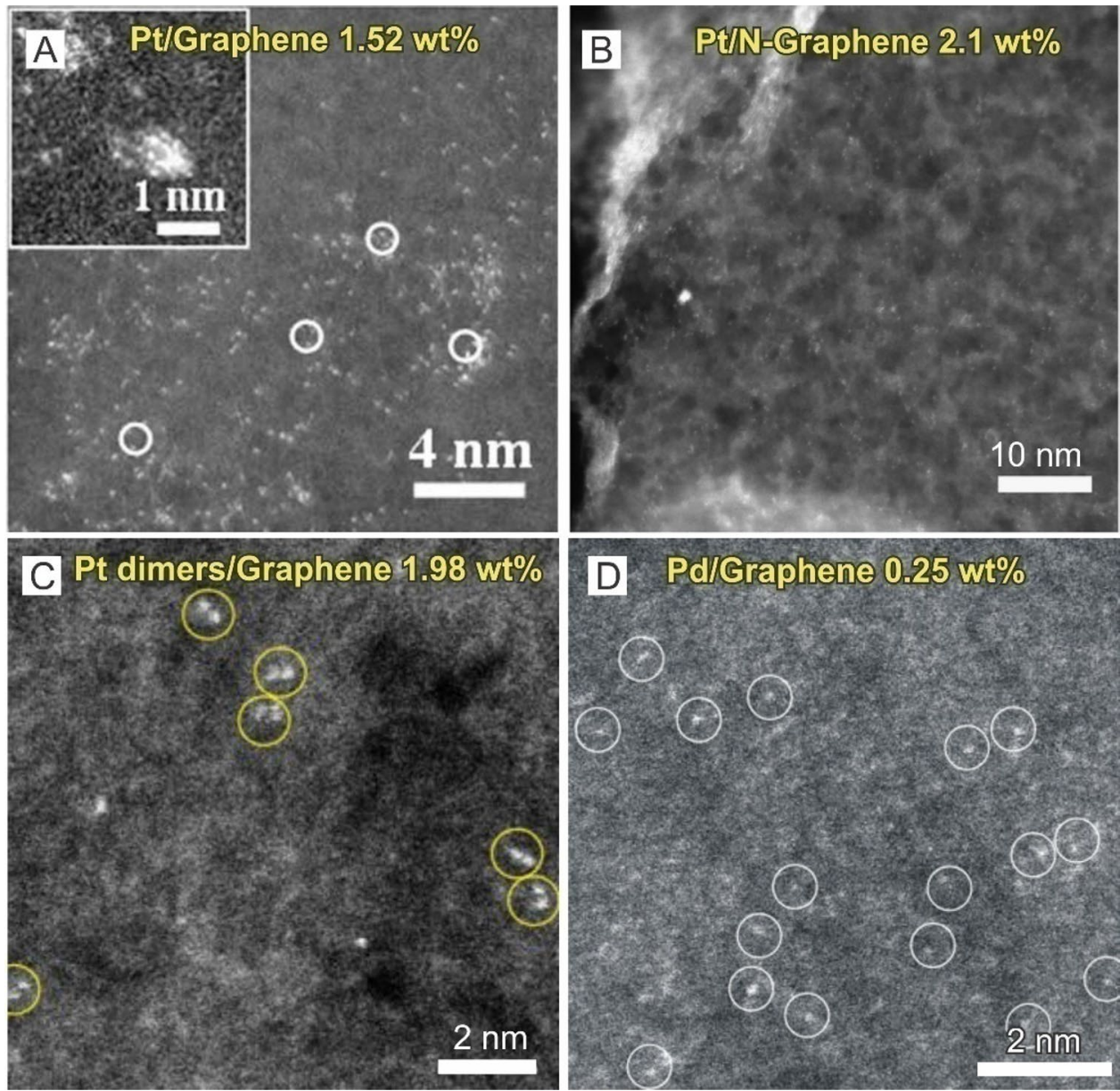

recently been applied in the preparation of SACs. For example, Zheng et al. [44] used a photochemical route to fabricate a stable atomically dispersed $\mathrm{Pd}-\mathrm{TiO}_{2}$ catalyst with $1.5 \%$ Pd loading (Fig. 4a, b) in which the Pd species was first adsorbed on $\mathrm{TiO}_{2}$ and irradiated under 10 min of UV to form Pd single atoms. Here, the researchers reported that in the extended X-ray absorption fine structure (EXAFS) spectrometry results, no peaks in the $2-3 \AA$ range from Pd-Pd contributions were observed, indicating the sole presence of dispersed $\mathrm{Pd}$ atoms in the $\mathrm{Pd}_{1} / \mathrm{TiO}_{2}$ catalyst and that in the hydrogenation of benzaldehyde, the $\mathrm{Pd}_{1} / \mathrm{TiO}_{2}$ catalyst readily converted all benzaldehyde into benzyl alcohol in $3.5 \mathrm{~h}$ at room temperature with a TOF of $1002 \mathrm{~h}^{-1}$. In addition, the researchers reported that the single Pd atoms maintained their dispersion after five cycles.

Aside from photochemical strategies, galvanic replacement reactions can also be used to fabricate SACs. For example, Zeng et al. [45] prepared single Pt atoms on $\mathrm{MoS}_{2}$ by injecting a $\mathrm{K}_{2} \mathrm{PtCl}_{6}$ solution into a mixture of water, ethanol and $\mathrm{MoS}_{2}$ nanosheets using a syringe pump (Fig. 4c-e) in which during the subsequent reaction, $\mathrm{Pt}$ atoms replaced Mo atoms in the $\mathrm{MoS}_{2}$ nanosheets with Pt loading being tunable from $0.2 \%$ to $7.5 \%$ in which at $7.5 \%$, the ratio of neighboring Pt monomers was counted as $65.5 \%$. Here, the researchers found that on neighboring Pt monomers, $\mathrm{CO}_{2}$ can successively hydrogenate into formic acid followed by methanol in which the neighboring Pt monomers worked in synergy to vary reaction barriers, making these atoms highly active toward $\mathrm{CO}_{2}$ hydrogenation.

In general, reaction kinetics during wet-chemical synthesis needs to be precisely controlled to achieve SACs in which the atomically dispersed separation and isolation of precursors on substrates are vital for the formation of single atoms. In addition, metal precursors should be reduced at relatively slow reaction rates to protect as-formed single atoms from migration and agglomeration.

\subsection{MOF-Derived Single-Atom Catalysts}

Spatial confinement is considered to be another effective method to synthesize SACs in which the separation and encapsulation of suitable mononuclear metal precursors with porous materials can prevent the agglomeration of single atoms. Based on this, several different carbon porous materials including zeolite [46, 47], MOFs [48-50] and covalentorganic frameworks [51-53] have been used as templates for 
Fig. 4 a STEM-EDS elemental mapping and b HAADF-STEM image of a single $\mathrm{Pd}_{1} / \mathrm{TiO}_{2}$ nanosheet. c HAADF-STEM image of $7.5 \% \mathrm{Pt} / \mathrm{MoS}_{2}$. d, e Magnified HAADF-STEM image of $7.5 \% \mathrm{Pt} / \mathrm{MoS}_{2}$ and its corresponding structural model showing one type of neighboring Pt monomers. a, b Adapted with permission from Ref. [44]. Copyright 2016, American Association for the Advancement of Science. $\mathbf{c}-\mathbf{e}$ Adapted with permission from Ref. [45]. Copyright 2018, Nature Publishing Group
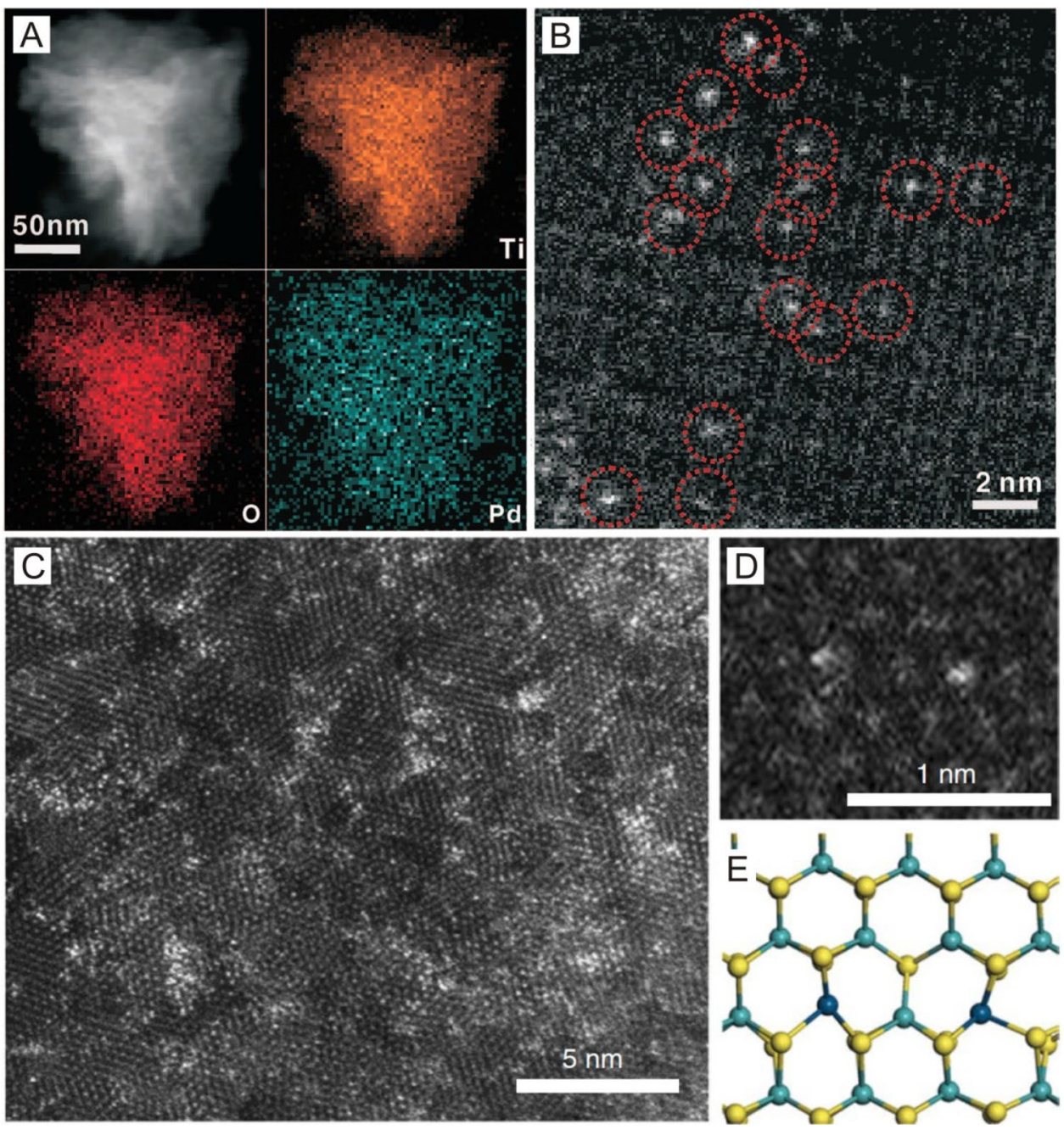

the preparation of SACs, and among these, MOF-derived SACs have been widely developed in recent years. MOFs are constructed through the periodic coordination of metal ions and organic ligands to form one- to three-dimensional networks. The organic linkers in MOFs are enormously diverse and possess a variety of configurations. In addition, MOFs possess ordered pore structures, uniform pore sizes and high specific surface areas, making them ideal substrates for the deposition of single atoms.

For the preparation of single atoms, the pyrolysis of MOFs can serve as an important route to fabricate $\mathrm{N}$-doped carbon materials, which are ideal substrates for the dispersion and stabilization of SACs. In a typical example, Li et al. [54] prepared $\mathrm{Zn} / \mathrm{Co}$ bimetallic MOFs (BMOF) with a homogeneous distribution of $\mathrm{Zn}$ and $\mathrm{Co}$ in which after pyrolysis at $800^{\circ} \mathrm{C}$, Co can be evaporated due to its low boiling point, resulting in the formation of single Co atoms on nitrogen-doped porous carbon. In addition, researchers have reported that the coordination number of $\mathrm{Co}-\mathrm{N}$ can be tuned by changing pyrolysis temperatures in which three atomically dispersed Co catalysts with different Co@N numbers $\left(\mathrm{Co}-\mathrm{N}_{4}, \mathrm{Co}-\mathrm{N}_{3}\right.$ and $\left.\mathrm{Co}-\mathrm{N}_{2}\right)$ can be selectively prepared at 800,900 and $1000{ }^{\circ} \mathrm{C}$ [55]. Furthermore, Li et al. [56] prepared Fe(acac) @ ZIF-8 molecular-scale cages by assembling $\mathrm{Zn}^{2+}, 2$-methylimidazole and $\mathrm{Fe}(\mathrm{acac})_{3}$ molecules (Fig. 5a) in which after pyrolysis at $900{ }^{\circ} \mathrm{C}$ under Ar atmosphere, ZIF-8 can transform into nitrogen-doped porous carbon, whereas $\mathrm{Fe}(\mathrm{acac})_{3}$ can be reduced through the carbonization of organic linkers, leading to the formation of Fe single atoms (Fig. 5b, c). These researchers also fabricated single $\mathrm{Ni}$ atoms through ionic exchange between $\mathrm{Zn}$ nodes and adsorbed $\mathrm{Ni}$ ions within the cavities of ZIF- 8 followed by pyrolysis at $1000{ }^{\circ} \mathrm{C}$ [57]. Aside from non-noble metals, single $\mathrm{Ru}$ atoms were also synthesized on MOF-derived carbon supports in which Wang et al. [58] used well-defined $\mathrm{Ru}_{3}(\mathrm{CO})_{12}$ as a precursor for the suitable molecular-scale cages of zeolitic imidazolate frameworks (ZIFs). Here, the researcher reported that the $\mathrm{Ru}_{3}(\mathrm{CO})_{12}$ can be encapsulated in the cages of ZIF-8 in which after pyrolysis at $800{ }^{\circ} \mathrm{C}$, uniform $\mathrm{Ru}_{3}$ clusters stabilized by nitrogen species $\left(\mathrm{Ru}_{3} / \mathrm{CN}\right)$ can be formed. 
Fig. 5 a Schematic of the formation of isolated single $\mathrm{Fe}$ atoms $/ \mathrm{N}$-doped porous carbon from the pyrolysis of MOFs. b, c HAADF-STEM images and enlarged image of the $\mathrm{Fe}$ single atoms derived from the MOF structure. $\mathbf{d}$ Schematic of the transformation of nanoparticles to single atoms and the structural characterization of Pd single atoms. a-c Adapted with permission from Ref. [56]. Copyright 2017, Wiley-VCH. d Adapted with permission from Ref. [59]. Copyright 2018, Nature Publishing Group
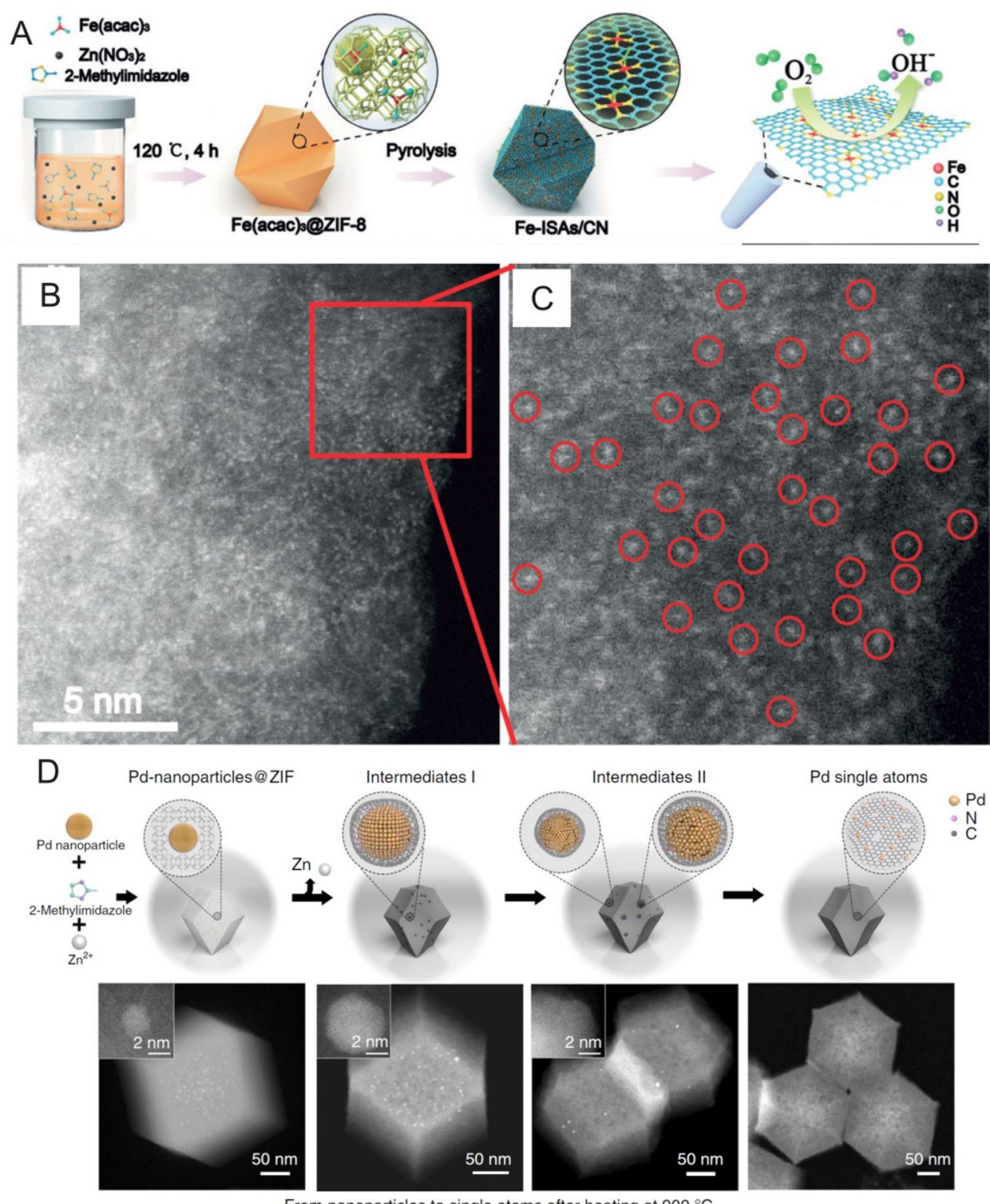

From nanoparticles to single atoms after heating at $900{ }^{\circ} \mathrm{C}$

More recently, Li et al. [59] reported that noble metal nanoparticles can transform into well-dispersed stable single atoms at temperatures above $900{ }^{\circ} \mathrm{C}$ in inert atmospheres in which Pd nanoparticles can transform into single atoms after Pd@ZIF-8 nanoparticle composites are heated at $900{ }^{\circ} \mathrm{C}$ for $3 \mathrm{~h}$ (Fig. 5d). Here, X-ray absorption near-edge spectroscopy (XANES) measurements revealed that the resulting Pd single atoms possessed only one dominant peak at $1.5 \AA$ that can be attributed to $\mathrm{Pd}-\mathrm{N}$ bonds and that at the early stages of the reaction process, Pd particles grew larger due to disorderly movement and intensive collision within the support. The size of these Pd particles subsequently decreases through the collision and coordination of surface $\mathrm{Pd}$ with $\mathrm{CN}$ in which the continued emission and capture of Pd atoms can act as a principal pathway for transformation from nanoparticles to single atoms. The researchers in this study also conducted density functional theory (DFT) calculations, which revealed that the high-temperature formation of single atoms is driven by the formation of more thermodynamically stable $\mathrm{Pd}-\mathrm{N}_{4}$ structures as mobile Pd atoms are captured on the defects of nitrogen-doped carbon. Aside from noble metals, Wu et al. [60] reported that supported Ni metal nanoparticles can also be transformed into thermally stable single $\mathrm{Ni}$ atoms on the surface of pyrolysis treated ZIF-8 in which their transformation process involves Ni nanoparticles being mixed with a carbon support and thermally treated at $900{ }^{\circ} \mathrm{C}$ in $\mathrm{Ar}$ to obtain single $\mathrm{Ni}$ atoms. Here, the researchers proposed that the $\mathrm{Ni}$ particles can break surface $\mathrm{C}-\mathrm{C}$ bonds and create a porous structure and that as $\mathrm{Ni}$ particles diffuse within the $\mathrm{N}$-doped carbon matrix, $\mathrm{Ni}$ atoms can bind to $\mathrm{N}$-rich defects. 


\section{Characterization Techniques for Single-Atom Catalysts}

By definition, SACs contain only isolated single atoms acting as the centers of catalytically active sites. Therefore, the confirmation of the existence of isolated single metal atoms and the determination of their spatial distribution are critical to the development SACs. Here, advanced characterization techniques can reveal the structures and chemical states of single atoms and assist in the study of single-atom catalytic mechanisms and the design of stable single-atom structures. And overall, the most intuitive approach for the characterization of SACs is the direct imaging of single metal atoms dispersed on high surface-area supports, with XANES and EXAFS being able to provide information concerning the dispersion of single atoms, the nature of neighboring atomic species and corresponding oxidation states.

\subsection{Electron Microscopy}

Transmission electron microscopy (TEM) is a useful method to image deposited catalyst particles to characterize stability on various supports and under diverse conditions and atomic-resolution TEM is one of the most direct methods to study detailed atomic-scale structural information of SACs and the interactions between metals and supports, which is essential for the understanding of catalytic activity and degradation mechanisms. And recently, aberrationcorrected TEM (AC-TEM), in both phase contrast TEM and sub-angstrom resolution high-angle annular dark-field STEM (HAADF-STEM) modes, has been widely utilized to directly image SACs [61-65] in which high spatial resolutions allow for the precise determination of the size and distribution of individual metal atoms and provide local structural information concerning metal species on supports [66]. Furthermore, interactions between single noble metal atoms and graphene edges have been investigated using aberration-corrected and mono-chromated TEM [67]. For example, Robertson et al. [68] used AC-TEM to study the real-time dynamics of $\mathrm{Fe}$ atoms filling vacancy sites in graphene with atomic resolution and reported that once incorporated into the graphene lattice, $\mathrm{Fe}$ atoms can transition to adjacent lattice positions and reversibly switch their bonding between three and four nearest neighbors in which the $\mathrm{C}$ atoms adjacent to the $\mathrm{Fe}$ atoms were found to be more susceptible to Stone-Wales-type bond rotations due to changes in the dopant bonding configuration. Rümmeli et al. [69] also investigated single $\mathrm{Fe}$ atoms at graphene edges using in situ AC-TEM and reported that individual $\mathrm{Fe}$ atoms were able to diffuse along the graphene edge either through the removal or addition of carbon atoms in which the experimental observations of the catalytic behavior of the single $\mathrm{Fe}$ atoms were in excellent agreement with supporting theoretical studies.

One primary advantage of HAADF-STEM is that the imaging is based on Rutherford scattering in which image intensity for given atoms is roughly proportional to the square of the atomic number $\left(Z^{2}\right)$ of the element [70, 71], allowing heavy metal atoms to brightly contrast against low background supports. For example, single gold atoms $(Z=79)$ appear as bright centers in zeolite frameworks consisting of light atoms of $\mathrm{Si}(Z=14), \mathrm{Al}(Z=13), \mathrm{Na}(Z=11)$ and $\mathrm{O}(Z=8)$ [46]. In addition, to unravel the interfacial interactions between metal atoms and $\mathrm{TiO}_{2}$ surfaces at the atomic level, Shibata et al. [72] directly imaged individual $\mathrm{Pt}$ atoms adsorbed on $\mathrm{TiO}_{2}$ (110) surfaces using aberrationcorrected STEM (Fig. 3) in which many of the Pt atoms were found to be single isolated atoms on the surface of $\mathrm{TiO}_{2}$. Here, the $Z$-contrast image characteristics of HAADF allowed Pt atoms $(Z=78)$ to stand out as brighter spots above the $\mathrm{TiO}_{2}$ support ( $\mathrm{Ti}, Z=22 ; \mathrm{O}, Z=8$ ) and the subangstrom level spatial resolution enabled the identification of five different stable Pt adsorption sites on the $\mathrm{TiO}_{2}(110)$ surface. Furthermore, a combination of STEM with DFT calculations conducted in this study revealed that the most favorable Pt adsorption sites were the vacancy sites of basal subsurface oxygen atoms located in the subsurface positions relative to the top surface bridging oxygen atoms.

Another important advantage of HAADF-STEM is the ability to provide atomic level local structural and chemical information, allowing for deeper understandings into the stabilization of single atoms. For example, enlarged HAADF-STEM images can show the stabilization of $\mathrm{Ni}$ atoms on nanoporous graphene through a substitutional $\mathrm{Ni}$ atom occupying a carbon site in the graphene lattice [73]. In addition, the structure of single Fe centers can be revealed by sub-angstrom resolution HAADF-STEM images to clearly show the atomic size and homogeneous distribution of $\mathrm{Fe}$ atoms within the graphene matrix [74]. Furthermore, electron energy loss spectroscopy (EELS) atomic spectra can be used to reveal the presence of both $\mathrm{Fe}$ and $\mathrm{N}$ elements in single Fe centers (one bright dot), suggesting the formation of $\mathrm{Fe}-\mathrm{N}_{x}$ bonds. In another study, Botton et al. [43] utilized HAADF-STEM to determine the structural information of ALD deposited Pt on nitrogen-doped graphene, revealing that individual $\mathrm{Pt}$ atoms and clusters were uniformly dispersed on the surface of nitrogen-doped graphene up to 150 ALD cycles along with a detailed mapping of $\mathrm{Pt}$ on the nitrogen-doped graphene support in which most Pt atoms and clusters were revealed to be located at the edge instead of the surface of nitrogen-doped graphene. These results were also consistent with the results obtained by Chang et al. [75], who reported that single atoms preferred to remain at the atomic step edges of few-layer reduced graphene and evolved with the steps. Researchers have also reported the 
necessity to examine single atoms at lower operating voltages to prevent single atoms from radiation damage in the use of STEM [76-78].

Overall, electron microscopy enables the direct imaging of supported particles to reveal structural and interfacial information of metals and supports. However, electron microscopy images can only provide local information for specific positions and lack broader sample-wide context. Furthermore, electron microscopy can mainly examine sample surfaces and the investigation of single atoms encapsulated in limited spaces such as small pores, cavities or layers inside bulk using electron microscopy is difficult.

\subsection{Synchrotron Radiation Investigations}

Due to the available high flux of X-rays and the versatility of beam lines, synchrotron radiation has become a valuable tool in the investigation of deposited, size-selected clusters and even single atoms. In addition, synchrotron radiation allows for the investigation of bulk materials and in combination with the aforementioned electron microscopy techniques, the elucidation of the overall structure of single metal atoms rather than just local and surface information [7, 79]. In synchrotron radiation investigations, the absence of metal-metal interactions is a clear indication of the absence of particles in which in general, single supported atoms are oxidized and if metal-metal interactions are not observed after the reduction in samples at high temperatures, the presence of rafts can be ruled out. For example, in a study by Yang et al. [20], EXAFS data of Pt/TiN samples (Fig. 6a, b) revealed that the $0.35 \mathrm{wt} \% \mathrm{Pt} / \mathrm{TiN}$ sample exhibited a strong peak at $\sim 2 \AA$ and smaller wiggles at 2-3 $\mathrm{\AA}$. Here, the researchers attributed the strong peak at $\sim 2 \AA$ to $\mathrm{Pt}-\mathrm{Cl}$ interactions and the smaller wiggles at 2-3 $\AA$ to the smaller Pt-Ti and Pt-Pt interactions in which the coordination number of the $0.35 \mathrm{wt} \% \mathrm{Pt} / \mathrm{TiN}$ sample was 3.038 for $\mathrm{Pt}-\mathrm{Cl}, 0.583$ for $\mathrm{Pt}-\mathrm{Pt}$ and 0.573 for $\mathrm{Pt}-\mathrm{Ti}$, indicating that single $\mathrm{Pt}$ atoms were primarily stabilized by chlorine ligands. Furthermore, the Pt-Pt coordination number found in this study was much smaller than that of typical Pt nanoparticles, confirming the presence of isolated $\mathrm{Pt}$ atoms on the TiN support. In addition, the observed small interactions between $\mathrm{Pt}$ and $\mathrm{Ti}$ indicate the anchoring effect of the TiN surface. Moreover, these researchers also reported that as Pt weight percentages increased, structural features changed significantly in which the coordination number of $\mathrm{Pt}-\mathrm{Cl}$ decreased from 3.038 for the $0.35 \mathrm{wt} \%$ $\mathrm{Pt} / \mathrm{TiN}$ sample to 0.166 for the $5 \mathrm{wt} \% \mathrm{Pt} / \mathrm{TiN}$ sample and the coordination number of Pt-Pt increased from 0.583 for the $0.35 \mathrm{wt} \% \mathrm{Pt} / \mathrm{TiN}$ sample to 8.310 for the $5 \mathrm{wt} \% \mathrm{Pt} / \mathrm{TiN}$ sample, suggesting that the $5 \mathrm{wt} \% \mathrm{Pt} / \mathrm{TiN}$ sample primarily contained Pt nanoparticles.
The use of electron microscopy to examine the size of catalyst particles anchored into small pores, cavities or layers of supports such as MOF, zeolite and graphitic layers is difficult because electron microscopy is mainly used to examine surface information for supported catalysts. However, synchrotron analysis is an effective strategy to examine these types of catalysts. For example, Ye et al. [50] used synchrotron radiation to investigate single cobalt atoms implanted in a MOF based on EXAFS detected $\mathrm{Co}-\mathrm{N}$ bonding (rather than $\mathrm{Co}-\mathrm{Co}$ ) and reported that their HAADFSTEM measurements revealed that the atomic dispersion of Co atoms was stabilized by the $\mathrm{N}$-doped porous carbon of MOFs for Co SACs/N-C obtained at $800^{\circ} \mathrm{C}$ [54]. However, the obtained HAADF-STEM images could only provide structural information of Co atoms on MOF surfaces and could not reveal the structure of particles inside the support. Despite this, EXAFS measurements confirmed the dispersed Co single atoms in the MOF with a $\mathrm{Co}-\mathrm{N}$ coordination peak at $1.60 \AA$ and no Co-Co signals. Furthermore, by combining synchrotron analysis with HAADF-STEM images, the researchers suggested that Co SACs distributed in a highly dispersed 3D fashion on $\mathrm{N}$-doped carbon rather than just on the surface [54].

Another important advantage of synchrotron analysis is the ability to provide insights into the chemical nature and stabilization structure of single atoms on supports. For examples, Choi et al. [22] used EXAFS to analyze the chemical nature of $\mathrm{Pt}$ species on three different carbon supports (ZTC: zeolite-templated carbon, LSC: low S content ZTC, HST: high S content ZTC) in which EXAFS fittings showed a dominant peak at $2.75 \AA$ corresponding to $\mathrm{Pt}-\mathrm{Pt}$ coordination with a coordination number $(\mathrm{CN})$ of 9.2 for the $\mathrm{Pt} / \mathrm{ZTC}$ sample and 3.3 for the Pt/LSC sample (Fig. 6c),with no appreciable $\mathrm{Pt}-\mathrm{Pt}$ coordination being detected for the $\mathrm{Pt} /$ HSC sample. In addition, the researchers also found dominant Pt-S peaks at 2.29 $\AA$ with a CN of 3.8 and 2.4 for Pt/ $\mathrm{HSC}$ and $\mathrm{Pt} / \mathrm{LSH}$, respectively, indicating that Pt on HSC was predominantly in the form of atomically dispersed $\mathrm{Pt}$ ligated by approximately four $S$ moieties (Fig. 6d). Yin et al. [54] also used the stabilization structure obtained from EXAFS analysis to explain the stabilization of Co SAs with high metal concentration on highly porous structures in which EXAFS data showed that the coordination numbers of Co-N for Co SAs/N-C obtained at 800 and $900{ }^{\circ} \mathrm{C}$ were 4 and 2 , respectively. In addition, these researchers reported that increasing pyrolysis temperatures can lead to the bond breakage of $\mathrm{Co}-\mathrm{N}$ coordination, allowing Co SAs to be stabilized in $\mathrm{Co}-\mathrm{N}_{4}$ and $\mathrm{Co}-\mathrm{N}_{2}$ moieties for Co SAs/N-C pyrolyzed at 800 and $900{ }^{\circ} \mathrm{C}$, respectively.

X-ray absorption spectroscopy (XAS) can also be used to study the local electronic structure of metal catalysts and their interaction with support materials [80, 81]. For example, Sun et al. [38] used XANES analyses to reveal 
Fig. 6 a, b Pt L3 edge k3-weighted FT-EXAFS spectra of the samples: $0.35 \mathrm{wt} \%$, $2 \mathrm{wt} \%$ and $5 \mathrm{wt} \% \mathrm{Pt} / \mathrm{TiN}, 5 \mathrm{wt} \%$ $\mathrm{Pt}$ NP/TiN prepared using the EG method, $20 \mathrm{wt} \% \mathrm{Pt} / \mathrm{C}$ and $\mathrm{Pt}$ foil. c Fourier transforms of k3-weighted Pt LIII-edge EXAFS confirming that $\mathrm{Pt}$ species in Pt/HSC exhibited only $\mathrm{Pt}-\mathrm{S}$ coordination. $\mathbf{d}$ Proposed atomistic structure of the Pt/HSC based on the bucky bowl-like structure of zeolitetemplated carbon (C: gray, $\mathrm{H}$ : white, S: yellow and Pt: purple). e Normalized XANES spectra at the Pt L3 edge of ALDPt/ NGNs, Pt/C catalysts and Pt foil. f Normalized XANES spectra at the $\mathrm{Pt} \mathrm{L} 3$ edge of $\mathrm{Pt}$ single atoms on $\mathrm{FeO}_{x}, \mathrm{PtO}_{2}$ and $\mathrm{Pt}$ foil. a, b Adapted with permission from Ref. [20]. Copyright 2016, Wiley-VCH. c, $\mathbf{d}$ Adapted with permission from Ref. [22]. Copyright 2016, Nature Publishing Group. e Adapted with permission from Ref. [109]. Copyright 2016, Nature Publishing Group. f Adapted with permission from Ref. [11]. Copyright 2011, Nature Publishing Group
A
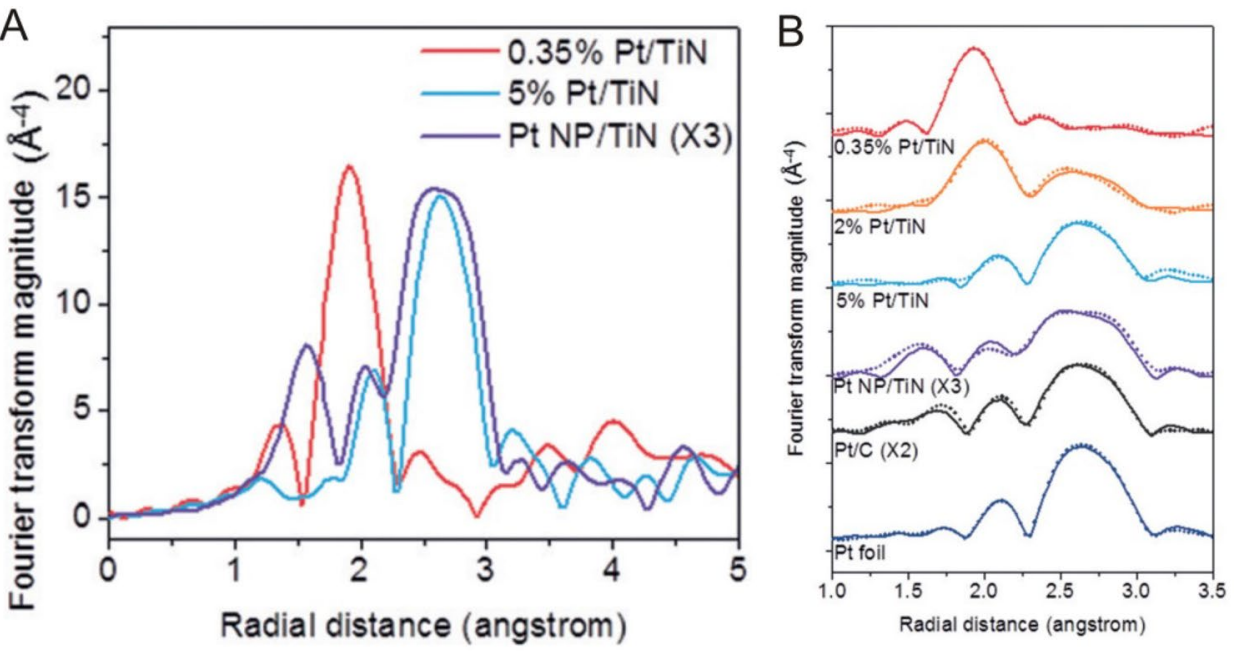

D
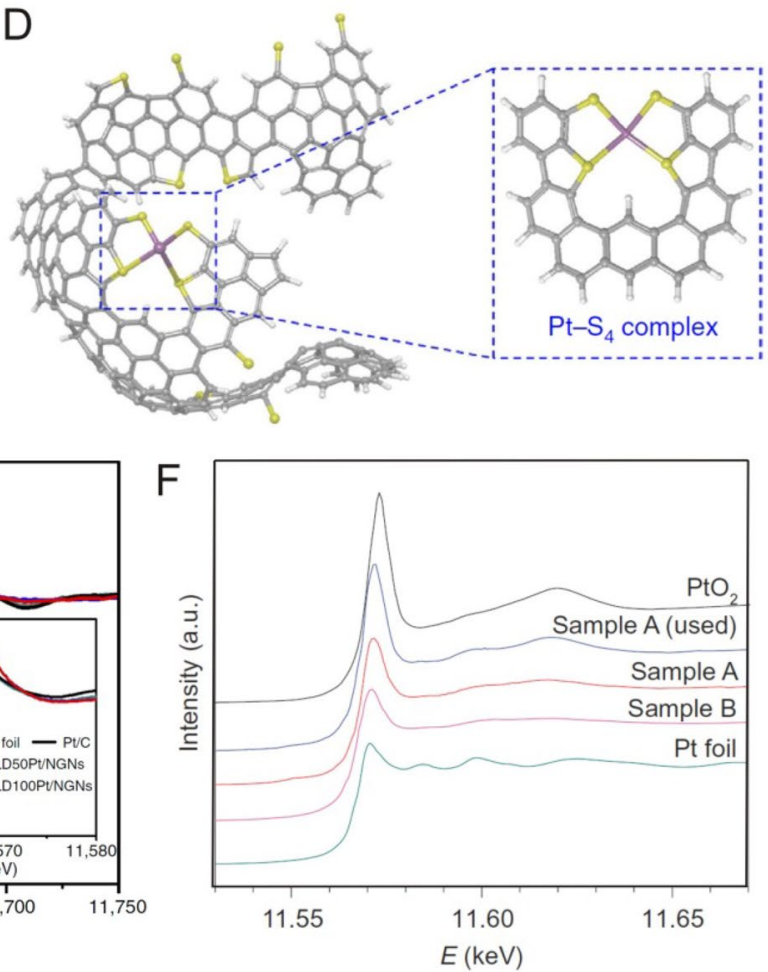

that single Pt atoms prepared by ALD possessed the highest total unoccupied Pt 5d orbitals as compared with small clusters and nanoparticles (Fig. 6e) leading to excellent performances for the corresponding SACs. Similar conclusions were also drawn by Zhang et al. [11] for single Pt atoms on $\mathrm{FeO}_{x}$ in which the more vacant d orbitals of single $\mathrm{Pt}$ atoms resulting from electron transfer from $\mathrm{Pt}$ atoms to $\mathrm{FeO}_{x}$ surfaces can lead to positively charged $\mathrm{Pt}$ atoms, which ultimately accounts for the excellent catalytic activity of $\mathrm{Pt}_{1} / \mathrm{FeO}_{x}$ catalysts (Fig. 6f).

Furthermore, new techniques to utilize synchrotron radiation are continuously being developed to probe single atoms under conditions more relevant to catalytic processes. For example, in situ synchrotron radiation has been designed as a technique to precisely present the chemistry of single atoms during catalytic measurements in which Tao et al. [82] in situ studied the surface chemistry and structure of $\mathrm{Rh}_{1} /$ $\mathrm{Co}_{3} \mathrm{O}_{4}$ nanorods in a mixture of reactant gases $\left(\mathrm{NO}\right.$ and $\left.\mathrm{H}_{2}\right)$ using a combination of in situ EXAFS, XANES and ambient pressure X-ray photoelectron spectroscopy (APXPS). Here, the in situ studies revealed that this catalyst can maintain its single dispersion of $\mathrm{Rh}$ atoms during catalysis, although a restructuring of the surface of $\mathrm{Rh}_{1} / \mathrm{Co}_{3} \mathrm{O}_{4}$ occurred in which the surface of $\mathrm{Rh}_{1} / \mathrm{Co}_{3} \mathrm{O}_{4}$ with singly dispersed $\mathrm{Rh}$ atoms 
was restructured into $\mathrm{RhCo}_{n}$ nanoclusters singly dispersed in the surface layer of $\mathrm{Co}_{3} \mathrm{O}_{4}$. As a result, the restructured $\mathrm{RhCo}_{n} / \mathrm{Co}_{3} \mathrm{O}_{4}$ catalyst exhibited much better catalytic performances as compared with $\mathrm{Rh}_{1} / \mathrm{Co}_{3} \mathrm{O}_{4}$ without restructuring.

\subsection{Scanning Tunneling Microscopy}

Atomic-resolution scanning tunneling microscopy (STM) is an excellent technique to image-supported individual metal atoms [83-85]. And to improve the resolution of STM to examine single atoms, STM usually operates at low temperatures under ultrahigh vacuums (UHV) $[86,87]$ in which Lucci et al. [88] used STM to successfully identify single $\mathrm{Pt}$ atoms supported on $\mathrm{Cu}(111)$ surfaces. In this study, the obtained STM images revealed that Pt atoms were incorporated directly into $\mathrm{Cu}(111)$ terraces and in the areas above the surface step edges through place exchange (Fig. 7a, b). The most prominent advantage of STM imaging is the ability to allow for visualizations of the atomic-scale structure of surfaces around single atoms during reactions, which can allow for the investigation of reaction mechanisms and single-atom sintering. For example, low-temperature STM (LT-STM) can be used to directly image $\mathrm{H}$ atoms on $\mathrm{Cu}$ surfaces [88] and reveal that $\mathrm{H}$ atoms at $\mathrm{Pd}$ monomer sites can enhance the appearance of $\mathrm{Pd}$ atoms on $\mathrm{Au}(111)$ surfaces in agreement with temperature-programmed desorption (TPD) results [89]. Furthermore, Flytzani-Stephanopoulos et al. [90] probed the atomic-scale interactions of $\mathrm{CO}$ and $\mathrm{H}$ with Pt catalytic sites on Pt-Cu (111) SAA surfaces using STM (Fig. 7c-e) and found evidence that the selective adsorption of $\mathrm{CO}$ onto $\mathrm{Pt}$ sites and $\mathrm{H}$ adatoms is capable of diffusing into $\mathrm{Cu}$ sites and away from $\mathrm{Pt}$ dissociation sites.
Fig. 7 a STM image of $0.02 \mathrm{ml}$ $\mathrm{Pt} / \mathrm{Cu}(111)$ SAA surface in which Pt atoms appear as isolated protrusions substituted into the $\mathrm{Cu}(111)$ surface. Scale bar, $1 \mathrm{~nm}$. b STM image showing $\mathrm{H}$ atom spillover onto $\mathrm{Cu}$ in which $\mathrm{H}$ atoms appear as depressions and cluster into small mobile islands. $\mathrm{Pt}$ sites appear in STM images as protrusions. c-e STM images showing the co-adsorption of $\mathrm{H}$ and $\mathrm{CO}$ on a $\mathrm{Pt}-\mathrm{Cu}(111) \mathrm{SAA}$ surface and STM tip-induced adsorbate removal to reveal the binding sites beneath. a, b Adapted with permission from Ref. [88]. Copyright 2015,

Nature Publishing Group. c-e Adapted with permission from Ref. [90]. Copyright 2016, American Chemical Society
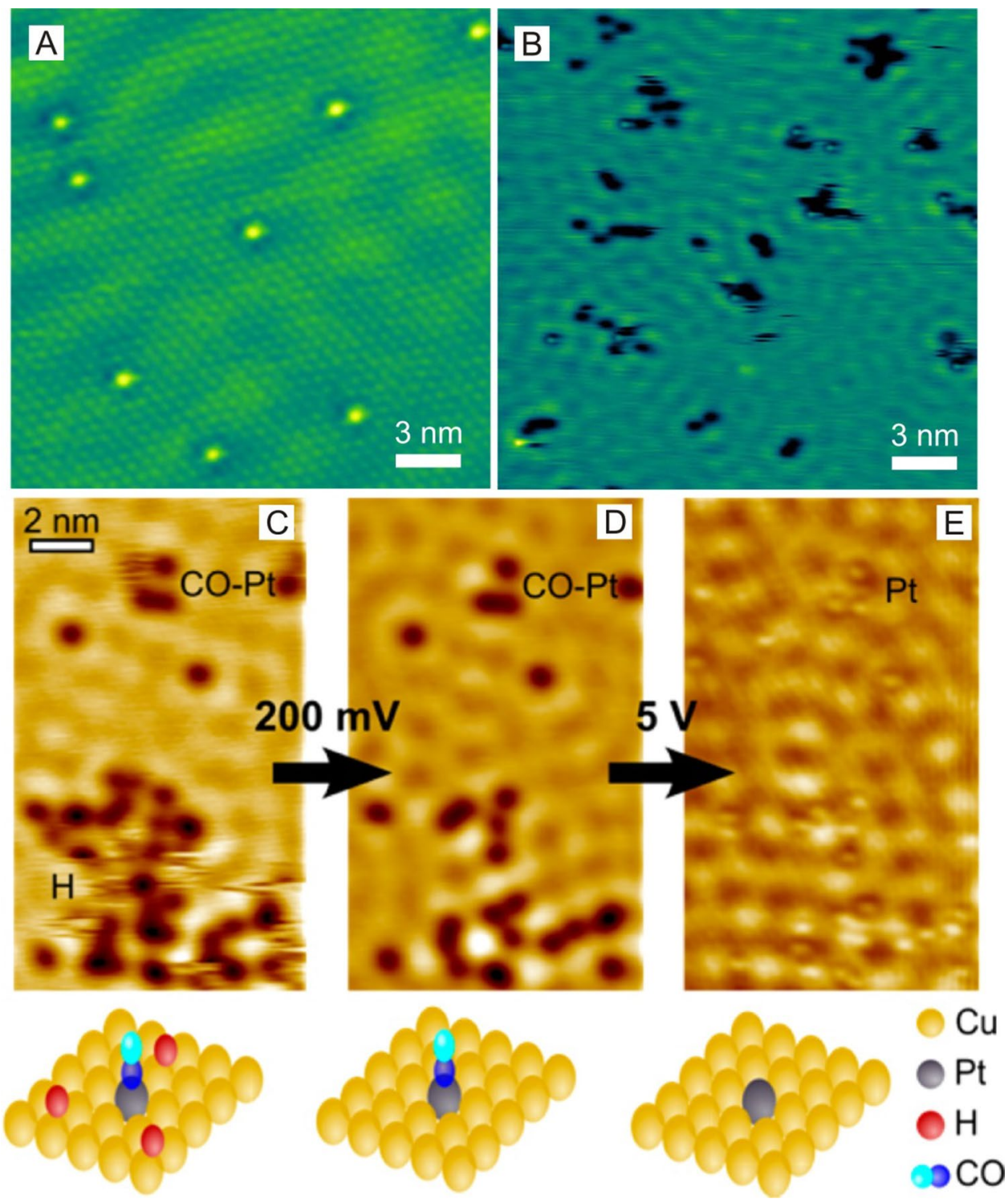


\subsection{Infrared (IR) Spectroscopy}

Probe molecule infrared (IR) spectroscopy is a powerful site-specific characterization technique that can provide insights into the local structure, oxidation state and coordination environment of supported metals [91]. This is because as bonds form between adsorbed molecules, their adsorption sites on supported metals become sensitive to local geometric and electronic environments. Here, probing molecules can be introduced to adsorb onto different types of supported metal sites to induce change in the vibrational frequency and bandwidth of the IR spectra of the adsorbed molecules. For example, IR spectroscopy with $\mathrm{CO}$ is widely used to identify precious metal structures on various supports based on the peak position of $\mathrm{CO}_{\mathrm{ad}}$. Based on this, DeRita et al. [92] used the IR spectra of $\mathrm{CO}$ adsorbed onto $\mathrm{Pt}$ on $\mathrm{TiO}_{2}$ with different $\mathrm{Pt}$ loadings to distinguish between $\mathrm{Pt}_{\text {iso }}$ and $\mathrm{Pt}_{\text {metal. }}$. In this study, a correlated IR-STEM analysis was also conducted to support the IR assignment of $\mathrm{CO}$ adsorbed onto $\mathrm{Pt}$ on $\mathrm{TiO}_{2}$ in which for $0.05 \mathrm{wt} \% \mathrm{Pt} / \mathrm{TiO}_{2}$, the stretching band of the IR spectra of the $\mathrm{CO}$ saturated sample was observed at $2112 \mathrm{~cm}^{-1}$ and assigned to $\mathrm{CO}$ adsorption onto single $\mathrm{Pt}$ atoms on $\mathrm{TiO}_{2}$, which was in excellent agreement with obtained STEM images identifying $\mathrm{Pt}_{\text {iso }}$ species. And as compared with the $0.05 \mathrm{wt} \% \mathrm{Pt} / \mathrm{TiO}_{2}$, the IR spectra of the $\mathrm{CO}$ saturated $0.15 \mathrm{wt} \% \mathrm{Pt} / \mathrm{TiO}_{2}$ catalyst showed increased relative intensity for the $\mathrm{CO}$ stretching band at 2040-2090 $\mathrm{cm}^{-1}$ and was assigned to CO adsorbed onto Pt clusters as confirmed by STEM analysis. Furthermore, these researchers reported that as Pt loading increased to $1 \mathrm{wt} \%$, the CO stretching band at $2112 \mathrm{~cm}^{-1}$ disappeared and that an exclusively broad $\mathrm{CO}$ stretching band intensity appeared between 2040 and $2090 \mathrm{~cm}^{-1}$, which the researchers assigned to $\mathrm{CO}$ adsorption in a linear geometry to $\mathrm{Pt}_{\text {metal }}$ sites, which was also in excellent agreement with STEM analysis in which the $\mathrm{Pt}_{\text {metal }}$ sites consisted predominantly of clusters with an average diameter of $1.1 \mathrm{~nm}$ and a few larger particles with an average diameter of $4.3 \mathrm{~nm}$.

In addition to the identification of precious metal structures, time/temperature-dependent IR spectra of $\mathrm{CO}$ can also be used to study the activity, stability and reaction mechanisms of SACs by identifying changes in spectra during catalytic reactions [93-96]. For example, Ding et al. [94] used time/temperature-dependent IR spectra to investigate $\mathrm{CO}$ adsorbed on both $\mathrm{Pt}_{\text {metal }}$ and $\mathrm{Pt}_{\text {iso }}$ species $(2.6 \mathrm{wt} \% \mathrm{Pt} /$ HZSM-5) and $\mathrm{Pt}_{\text {iso }}$ (0.5 wt\% Pt/HZSM-5) species as confirmed by STEM analysis (Fig. 6d, e) and reported that the IR peak at $2115 \mathrm{~cm}^{-1}$ corresponding to $\mathrm{CO}$ adsorbed on single Pt atoms (green area) remained unchanged during the oxidation process, whereas the IR peak between 2070 and $2090 \mathrm{~cm}^{-1}$ assigned to CO adsorbed on Pt NPs (green area) can be oxidized and subsequently desorbed as $\mathrm{CO}_{2}$ at reaction temperatures below $100{ }^{\circ} \mathrm{C}$, clearly suggesting that Pt NPs on HZSM-5 possessed higher activities for CO oxidation as compared with single-atom HZSM-5. However, DeRita et al. [92] reported that on $\mathrm{TiO}_{2}$ supports, the order of $\mathrm{CO}$ adsorption energy $\left(\mathrm{Pt}_{\text {iso }} \ll \mathrm{Pt}_{\text {metal }}<\mathrm{Pt}_{\mathrm{ox}}\right)$ using IR spectra revealed that $\mathrm{Pt}_{\text {iso }}$ species can exhibit a twofold greater turnover frequency for $\mathrm{CO}$ oxidation as compared with $1 \mathrm{~nm}$ Pt clusters, whereas adsorbed $\mathrm{CO}$ on $\mathrm{Pt}_{\mathrm{ox}}$ was essentially inactive for $\mathrm{CO}$ oxidation below $\sim 200{ }^{\circ} \mathrm{C}$. Here, the researchers proposed a possible mechanism in which single $\mathrm{Pt}$ atoms can exhibit optimal reactivity because every atom is exposed for catalysis and can form interfacial sites with $\mathrm{TiO}_{2}$.

\subsection{DFT Calculations}

DFT calculations are vital in the development of SACs and the understanding of the specific catalytic reaction mechanisms of supported single metal atoms. For example, Zhang et al. [11] successfully anchored single Pt atoms onto iron oxide surfaces and achieved high activity and stability for CO oxidation. However, because the conventional Langmuir-Hinshelwood scheme ( $\mathrm{L}-\mathrm{H}$ scheme) requires at least one $\mathrm{Pt}-\mathrm{Pt}$ bond for $\mathrm{CO}$ oxidation [97], there is interest in how single Pt atoms can act as active sites. To address this, Zhang et al. [11] proposed a reaction mechanism for $\mathrm{CO}$ oxidation on $\mathrm{Pt}_{1} / \mathrm{FeO}_{x}$ (Fig. 8) based on a modified $\mathrm{L}-\mathrm{H}$ scheme using DFT calculations and experiments in which the active sites for $\mathrm{CO}$ oxidation are single $\mathrm{Pt}$ atoms coordinated with two or three oxygen atoms embedded in an iron oxide system instead of only single Pt atoms. Here, the researchers proposed that the iron oxide support can participate in $\mathrm{CO}$ oxidation and that the oxygen provided by the iron oxide support can facilitate the oxidation of $\mathrm{CO}$ adsorbed on Pt atoms. Furthermore, DFT calculations suggested that single $\mathrm{Pt}$ atoms embedded onto $\mathrm{Fe}_{2} \mathrm{O}_{3}$ surfaces possess a high oxidation state due to coordination with two or three surface $\mathrm{O}$ atoms of the iron oxide support, leading to lower reaction activation barriers for the rate-determining step of $\mathrm{CO}$ oxidation on single Pt atoms $(0.79 \mathrm{eV})$ as compared with Pt (111) $(\sim 1 \mathrm{eV})$ (Fig. 8a). Furthermore, Liang et al. [29] proposed a catalytic mechanism for $\mathrm{CO}$ oxidation on $\mathrm{Ir}_{1} / \mathrm{FeO}_{x}$ using periodic DFT calculations in which $\mathrm{Ir}_{1} /$ $\mathrm{FeO}_{x}$ catalysts possessed lower activity for $\mathrm{CO}$ oxidation than $\mathrm{Pt}_{1} / \mathrm{FeO}_{x}$ catalysts as confirmed by experimental results (Fig. 8b). Here, the calculations revealed that the reaction activation barrier of the rate-determining step in the catalytic cycle of $\mathrm{CO}$ oxidation was $0.62 \mathrm{eV}$ higher and the adsorption energy for $\mathrm{CO}$ molecules was $0.69 \mathrm{eV}$ higher for $\mathrm{Ir}_{1} / \mathrm{FeO}_{x}$ catalysts as compared with $\mathrm{Pt}_{1} / \mathrm{FeO}_{x}$ catalysts, accounting for the lower activity of the $\mathrm{Ir}_{1} / \mathrm{FeO}_{x}$ catalysts. Moreover, in the search for low-cost catalysts for $\mathrm{CO}$ oxidation, Liang et al. [98] used DFT calculations to predict that single Ni atoms anchored onto $\mathrm{FeO}_{x}$ possessed higher catalytic activities at 
Fig. 8 a-c Proposed reaction pathways for $\mathrm{CO}$ oxidation on a $\mathrm{Pt}_{1} / \mathrm{FeO}_{x}, \mathbf{b ~} \mathrm{Ir}_{1} / \mathrm{FeO}_{x}$ and $\mathbf{c}$ $\mathrm{Ni}_{1} / \mathrm{FeO}_{x}$ catalysts. d Reaction pathway of $\mathrm{CO}$ oxidation on oxygen-defective $\mathrm{M}_{1} / \mathrm{FeO}_{x}$ $(\mathrm{M}=\mathrm{Pt}, \mathrm{Rh}, \mathrm{Pd}, \mathrm{Co}$ and $\mathrm{Cu})$ via the Langmuir-Hinshelwood mechanism. e Energetic alignment (in eV) of the surfacebound $\mathrm{H}$ and Kubas-coordinated $\mathrm{H}$ intermediates for $\mathrm{V}$ and $\mathrm{Mo}$. f Energetic alignment (in $\mathrm{eV}$ ) of the Kubas-coordinated $\mathrm{H}$, intermediate dissociated $\mathrm{H}_{2}$, and surface-bound $\mathrm{H}$ intermediates for Pt and Mo along the pathway. a Adapted with permission from Ref. [11]. Copyright 2011, Nature Publishing Group. b Adapted with permission from Ref. [29]. Copyright 2014, American Chemical Society. c Adapted with permission from Ref. [98]. Copyright 2016, Royal Society of Chemistry. d Adapted with permission from Ref. [99]. Copyright 2015, American Chemical Society. e Adapted with permission from Ref. [100]. Copyright 2015, Wiley-VCH

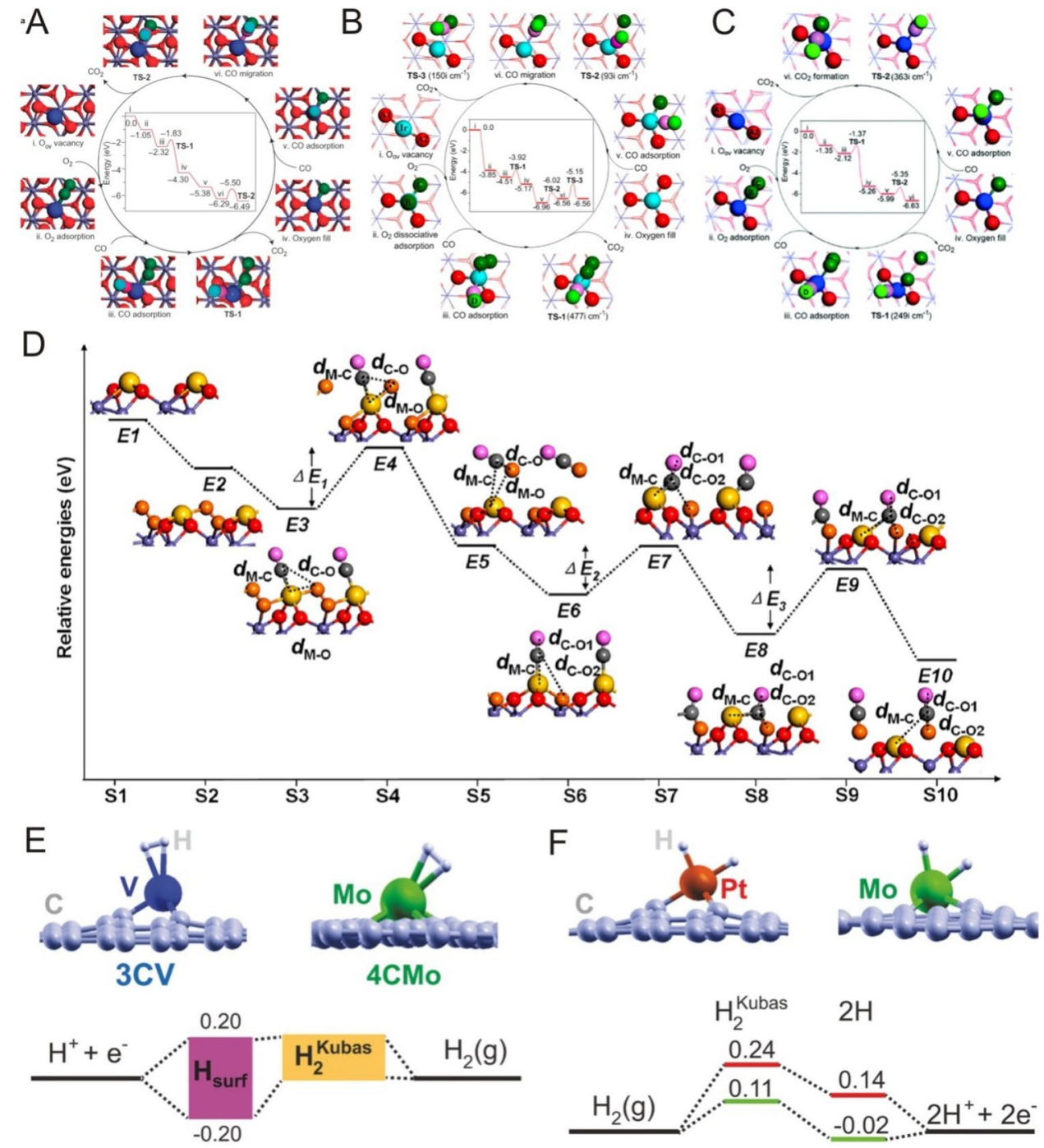

room temperature for $\mathrm{CO}$ oxidation that were comparable to that of $\mathrm{Pt}_{1} / \mathrm{FeO}_{x}$ catalysts and were considerably higher than that of $\operatorname{Ir}_{1} / \mathrm{FeO}_{x}$ catalysts in which the high activity for $\mathrm{CO}$ oxidation of the $\mathrm{Ni}_{1} / \mathrm{FeO}_{x}$ catalyst at room temperature was attributed to the low energy barrier of the rate-determining step (Fig. 8c). Here, the researchers reported that the adsorption states of $\mathrm{O}_{2}$ on $\mathrm{Pt}_{1}, \mathrm{Ir}_{1}$ and $\mathrm{Ni}_{1}$ single atoms are different in which $\mathrm{O}_{2}$ can be molecularly adsorbed onto $\mathrm{Ni}_{1}$ and $\mathrm{Pt}_{1}$ single atoms in $\mathrm{Ni}_{1} / \mathrm{FeO}_{x}$ catalysts and $\mathrm{Pt}_{1} / \mathrm{FeO}_{x}$ catalysts, whereas it is dissociatively absorbed in $\mathrm{Ir}_{1} / \mathrm{FeO}_{x}$ catalysts, with DFT calculations indicating that $\mathrm{CO}$ oxidation required a slightly higher activation energy $(0.75 \mathrm{eV})$ on $\mathrm{Ni}_{1} / \mathrm{FeO}_{x}$ catalysts as compared with $\mathrm{Pt}_{1} / \mathrm{FeO}_{x}$ catalysts $(0.49 \mathrm{eV})$ and $\mathrm{Ir}_{1} / \mathrm{FeO}_{x}$ catalysts $(0.59 \mathrm{eV})$ in the formation of the first $\mathrm{CO}_{2}$ (TS-1). However, these researchers also reported that the energy barrier of the rate-determining step in the formation of $\mathrm{CO}_{2}$ was obviously different on $\mathrm{Pt}_{1}, \mathrm{Ir}_{1}$ and $\mathrm{Ni}_{1}$ single atoms in which the calculated barrier of $\mathrm{CO}_{\mathrm{ad}}+\mathrm{O}_{\mathrm{c}} \rightarrow \mathrm{CO}_{2}$ (TS-2) on $\mathrm{Ni}_{1} / \mathrm{FeO}_{x}$ catalysts $(0.64 \mathrm{eV})$ was much lower than that on $\mathrm{Pt}_{1} / \mathrm{FeO}_{x}$ catalysts $(0.79 \mathrm{eV})$ and $\mathrm{Ir}_{1} / \mathrm{FeO}_{x}$ catalysts $(1.41 \mathrm{eV})$, suggesting that $\mathrm{Ni}_{1} / \mathrm{FeO}_{x}$ catalysts possessed the highest activity for $\mathrm{CO}$ oxidation among these $\mathrm{SACs}$ at room temperature.

Inspired by the discovery of highly active $\mathrm{CO}$ oxidation in $\mathrm{Pt}_{1} / \mathrm{FeO}_{x}$ catalysts [11] and to develop more efficient and low-cost catalysts for $\mathrm{CO}$ oxidation, Chen et al. [99] recently applied DFT calculations to systemically investigate the catalytic activity of various metal single atoms ( $\mathrm{Rh}, \mathrm{Pd}, \mathrm{Au}$, $\mathrm{Co}, \mathrm{Cu}, \mathrm{Ru}$ and $\mathrm{Ti}$ ) supported on iron oxide surfaces and reported that among the various metal single-atom systems, the $\mathrm{CO}$ oxidation catalytic performances of oxygen-defective $\mathrm{Rh}_{1} / \mathrm{FeO}_{x}, \mathrm{Pd}_{1} / \mathrm{FeO}_{x}$ and $\mathrm{Ru}_{1} / \mathrm{FeO}_{x}$ catalysts (Fig. 8d) with or without oxygen vacancies and vacancy-free $\mathrm{Ti}_{1} / \mathrm{FeO}_{x}$ and $\mathrm{Co}_{1} / \mathrm{FeO}_{x}$ catalysts approached or exceeded the overall catalytic performance of the $\mathrm{Pt}_{1} / \mathrm{FeO}_{x}$ catalyst based on a $\mathrm{LH}$ mechanism and that in particular, $\mathrm{Co}_{1} / \mathrm{FeO}_{x}$ and $\mathrm{Ti}_{1} / \mathrm{FeO}_{x}$ catalysts with non-precious metals possessed very low activation energies for $\mathrm{CO}$ oxidation. 
In addition to elucidating catalytic reaction mechanisms of supported single metal atoms, DFT calculations can also be used to identify SACs. For example, Ogitsu et al. [100] performed a computational search of hydrogen catalysts composed of TM atoms embedded within graphitic carbon (TMEGs) (Fig. 8). And based on various criteria including stability, activity and resistance to poisoning, these researchers identified ten materials that showed promise as highly efficient HER catalysts, two of which were also viable for HOR. In addition, several of the proposed materials were composed entirely of earth-abundant elements, providing significant synthetic and cost advantages. For example, a catalyst composed of Mo atoms embedded within divacancy sites in graphene (4CMo) appeared to be particularly promising for HOR catalysis in addition to HER and is an excellent candidate for inclusion in proton exchange membrane fuel cell anodes (Fig. 8e, f) .

Overall, to fully understand the enhanced catalytic activity of SACs, it is important to develop more advanced and accurate instruments to identify SAC structures and unravel reaction mechanisms. In addition, the development of in situ characterization methods is essential to determine the structure-function relationships of SACs in catalytic processes. Furthermore, advancements in theoretical approaches can enable the modeling of more complex systems and the prediction of SACs with extraordinary catalytic activities.

\section{The Activity of Single-Atom Catalysts}

As novel heterogeneous catalysts, SACs possess unique interfacial configurations that can provide maximized atomic utilization and single, highly active sites. In addition, SACs are not only catalytically active but are also stable during catalytic reactions in many cases primarily due to strong bonding between single metal atoms and corresponding anchoring sites on support surfaces. Based on this, representative studies as well as advances in single-atom catalysis are summarized in this section.

\subsection{Electrochemical Reactions}

\subsubsection{Oxygen Reduction Reaction (ORR)}

The inherently sluggish kinetics of the oxygen reduction reaction (ORR) and the instability of Pt at cathodes are foremost challenges hindering the widespread commercialization of polymer electrolyte membrane fuel cells (PEMFCs) $[101,102]$. In addition, because Pt is prohibitively expensive due to its scarcity, the development of highly active, stable and inexpensive ORR electrocatalysts is extremely desirable. Here, researchers report that as Pt nanoparticles downsize into single atoms, supports play a significant role in the performance of corresponding catalysts. However, researchers also report that $\mathrm{Pt}$ single atoms do not show good ORR activity because ORR requires $\mathrm{Pt}$ ensemble sites in acid media [20], with similar results found for Pt single atoms anchored onto sulfur-doped ZTC (HSC) [22] in which Pt single atoms anchored onto HSC do not follow a conventional four electron pathway to produce $\mathrm{H}_{2} \mathrm{O}$, but selectively produce $\mathrm{H}_{2} \mathrm{O}_{2}$ over extended periods of time without significant declines in activity (Fig. 9a, b). Despite this, Liu et al. [103] reported that $\mathrm{Pt}$ single atoms deposited onto $\mathrm{N}$-doped carbon black can exhibit excellent ORR performances in which the ORR activity of $\mathrm{Pt}_{1}-\mathrm{N} / \mathrm{BP}$ with $0.4 \mathrm{wt} \% \mathrm{Pt}$ loading in acid was close to that of traditional state-of-art Pt-NP-based $\mathrm{Pt} / \mathrm{C}$ with much higher Pt loadings (Fig. 9c). In addition, these researchers reported that in acidic $\mathrm{H}_{2} / \mathrm{O}_{2}$ fuel cell tests, cells with $\mathrm{Pt}_{1}-\mathrm{N} / \mathrm{BP}$ as the cathode and commercial $\mathrm{Pt} / \mathrm{C}$ as the anode showed a remarkable Pt utilization efficiency of $0.13 \mathrm{~g}_{\mathrm{Pt}} \mathrm{kW}^{-1}$, which was higher than cells using commercial Pt/C as both the cathode and anode $\left(0.26 \mathrm{~g}_{\mathrm{Pt}} \mathrm{kW}^{-1}\right)$ (Fig. 9d). Here, these researchers found that pyridinic $\mathrm{N}$ sites were strong anchoring points for the deposition of $\mathrm{Pt}$ atoms and enhanced the stability of $\mathrm{Pt}_{1}-\mathrm{N} / \mathrm{BP}$ in which according to DFT calculations, single pyridinic nitrogen atom-anchored single $\mathrm{Pt}$ atom centers were the main active sites and greatly improved electrochemical performances.

In addition to Pt catalysts, Pt-free single atoms have also been developed for ORR. For example, Zhang et al. [104] reported that single niobium atoms trapped within graphitic layers demonstrated good ORR activities in alkaline media in which the advanced structure of the trapped single atoms not only enhanced overall conductivity to accelerate ion and electron exchange, but also suppressed the chemical/ thermal coarsening of active particles. In addition, experimental and theoretical studies revealed that single niobium atoms can produce a redistribution of d-band electrons, thus becoming surprisingly active for $\mathrm{O}_{2}$ adsorption and dissociation and exhibit high stability. In another example, Wang et al. [56] prepared a highly reactive and stable isolated single-atom $\mathrm{Fe} / \mathrm{N}$-doped porous carbon (ISA Fe/ $\mathrm{CN})$ catalyst with Fe loadings up to $2.16 \mathrm{wt} \%$ and reported that the catalyst showed excellent ORR performances with a half-wave potential $\left(E_{1 / 2}\right)$ of $0.900 \mathrm{~V}$ that outperformed commercial Pt/C (Fig. 9e, f). Recently, Li et al. [105] also fabricated bimetallic $\mathrm{Fe}-\mathrm{Co}$ dual sites embedded onto $\mathrm{N}$-doped porous carbon for ORR and reported that as compared with Fe SAs/N-C, Co SAs/N-C and commercial Pt/C catalysts, the well-defined $(\mathrm{Fe}, \mathrm{Co}) / \mathrm{N}-\mathrm{C}$ catalyst exhibited a high ORR activity with an $E_{1 / 2}$ of $0.863 \mathrm{~V}$ and an $E_{\text {onset }}$ of $1.06 \mathrm{~V}$. In addition, Wu et al. [106] synthesized an efficient ORR catalyst consisting of atomically dispersed nitrogencoordinated single Mn sites on partially graphitic carbon (Mn-N-C) through a two-step synthesis strategy involving doping and adsorption and reported high activities for the 
Fig. 9 a ORR activity and b $\mathrm{H}_{2} \mathrm{O}_{2}$ production selectivity of Pt/HSC catalysts. c ORR polarization curves of $\mathrm{BP}, \mathrm{N} /$ $\mathrm{BP}, \mathrm{Pt}_{1} / \mathrm{BP}, \mathrm{Pt}_{1}-\mathrm{N} / \mathrm{BP}$ and commercial Pt/C in $\mathrm{O}_{2}$-saturated $0.1 \mathrm{M} \mathrm{HClO}_{4}$ with a scan rate of $5 \mathrm{mV} \mathrm{s}^{-1}$ and a rotation speed of $1600 \mathrm{rpm}$. d Voltages and power densities of $\mathrm{H}_{2} / \mathrm{O}_{2}$ fuel cells with $\mathrm{Pt}_{1}-\mathrm{N} / \mathrm{BP}$ and commercial Pt/C (marked with stars) as cathodes in acid. $\mathbf{e}$ ORR polarization curves of $\mathrm{Fe}$ single atoms. f $J_{\mathrm{k}}$ at $0.85 \mathrm{~V}$ and $E_{1 / 2}$ for Fe SACs. a, b Adapted with permission from Ref. [22]. Copyright 2016, Nature Publishing Group. c, d Adapted with permission from Ref. [103]. Copyright 2017, Nature Publishing Group. e, f Adapted with permission from Ref. [56]. Copyright 2017, Wiley-VCH
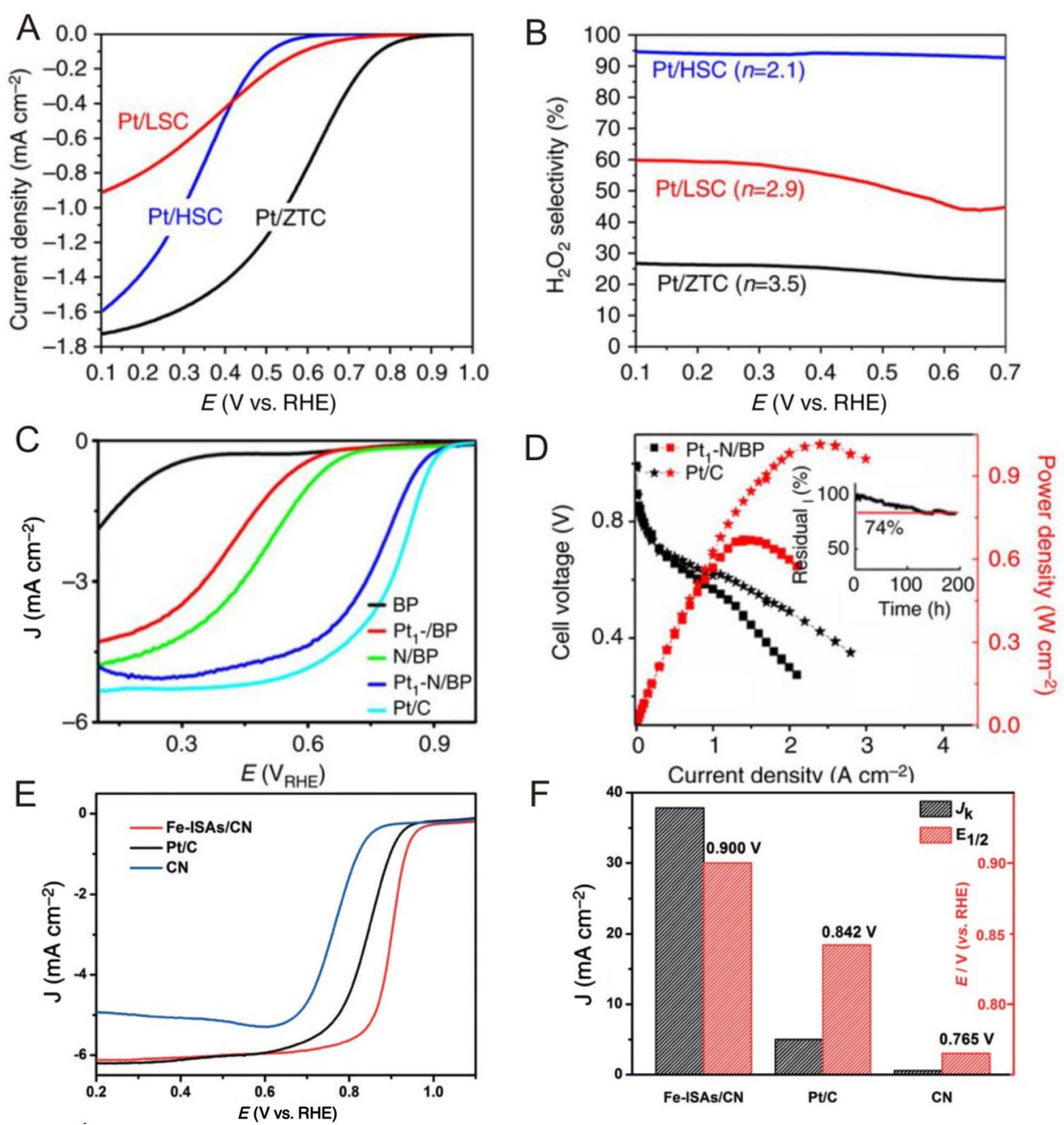

resulting $\mathrm{Mn}-\mathrm{N}-\mathrm{C}$ catalyst as evidenced by a commendable $E_{1 / 2}$ of $0.80 \mathrm{~V}$ versus RHE in acids as well as the fact that the formed $\mathrm{MnN}_{4}$ sites can enhance stability during durability tests in acidic media.

\subsubsection{Methanol Oxidation Reaction (MOR)}

Direct methanol fuel cells (DMFCs) are attractive power sources for portable and vehicular applications due to the simplicity of the systems and the adaptability of the liquid fuels in which precious metal (i.e., Pt) NPs supported on carbon black are the most commonly employed anode catalysts for MOR. Here, the downsizing of precious metal catalyst particles is vital to maximize efficiency and decrease costs. For example, Sun et al. [38] recently deposited single Pt atoms onto graphene nanosheets through ALD and used this approach to vary the Pt content from isolated single atoms to sub-nanometer sized clusters up to Pt nanoparticles in which the single Pt atom catalyst exhibited significantly enhanced MOR catalytic activities (up to 10 times) in comparison with state-of-the-art commercial Pt/C catalysts. In addition, these researchers reported that this single Pt atom catalyst demonstrated superior $\mathrm{CO}$ tolerances as compared with conventional $\mathrm{Pt} / \mathrm{C}$ catalysts and suggested that the increased MOR activity on ALD50-Pt/GNS can be mainly attributed to the small size of the catalyst, resulting in significantly enhanced utilization of Pt atoms. Furthermore, these researchers conducted XAFS studies and suggested that the low-coordination and partially unoccupied $5 d$ orbitals of the Pt atoms were responsible for the excellent activity.

\subsubsection{Hydrogen Evolution Reaction (HER)}

Pt-based catalysts are generally considered to be the most effective electrocatalysts for hydrogen evolution reactions (HER) [107, 108]. However, Pt is expensive and scarce, limiting the commercial potential of such catalysts. Therefore, the development of active, stable and inexpensive electrocatalysts for water splitting is key in the realization of a hydrogen economy based on the use of molecular hydrogen for energy storage. To address this, Sun et al. [109] recently proposed a practical synthesis method to produce isolated 
Fig. 10 a HER polarization curves for ALDPt/NGNs and $\mathrm{Pt} / \mathrm{C}$ catalysts. b Mass activity at $0.05 \mathrm{~V}$ (versus RHE) of ALDPt/NGNs and Pt/C catalysts for HER. c HER polarization curves of NF, NT-NF, PtSA-NT-NF and $\mathrm{Pt} / \mathrm{C}$ acquired in $\mathrm{N}_{2}$-saturated $1 \mathrm{M}$ PBS. d Pt mass activities of PtSA-NT-NF and Pt/C at $0.05 \mathrm{~V}$. e HER polarization curves of DG, Ni@DG, A-Ni@ $\mathrm{DG}$ and $\mathrm{Pt} / \mathrm{C}$ performed in $0.5 \mathrm{M} \mathrm{H}_{2} \mathrm{SO}_{4}$ electrolyte. $\mathbf{f}$ Turnover frequency curve of A-Ni@DG and other catalysts reported in the literature for hydrogen evolution. $\mathbf{a}, \mathbf{b}$ Adapted with permission from Ref. [109]. Copyright 2016, Nature Publishing Group. c, d Adapted with permission from Ref. [110]. Copyright 2017, Wiley-VCH. e, f Adapted with permission from Ref. [113]. Copyright 2018, Cell Press
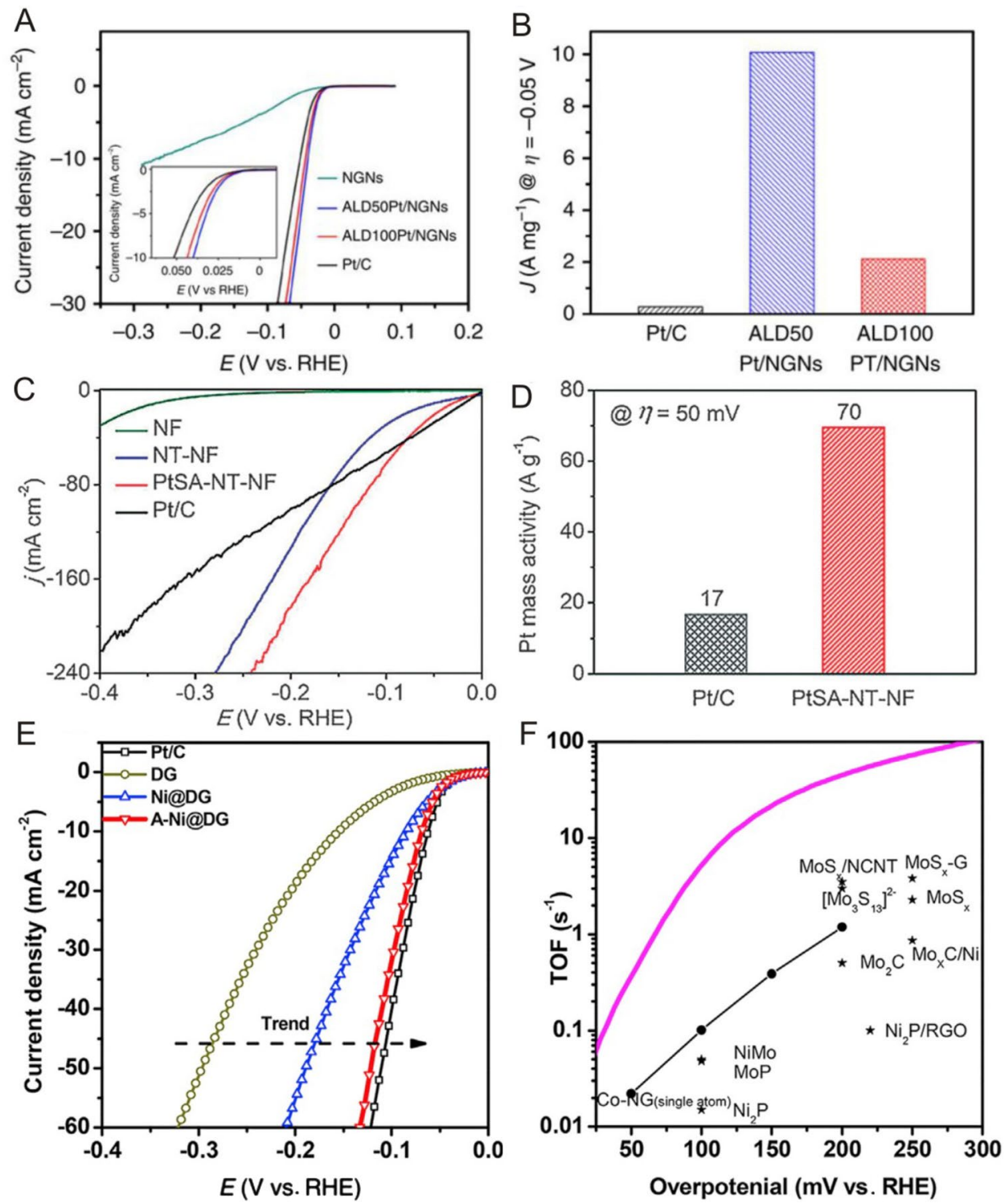

single Pt atoms on N-doped graphene using ALD (Fig. 10a, b) and reported that the single Pt atom catalyst exhibited significantly enhanced HER catalytic activities (up to 37 times improvement) and stability in comparison with state-of-theart commercial $\mathrm{Pt} / \mathrm{C}$ catalysts in which the researchers found that the interaction between metal atoms and support played a vital role in stabilization through synchrotron and DFT analyses. Here, first-principles calculations showed that the interaction energy between single $\mathrm{Pt}$ atoms and $\mathrm{N}$-dopants was $\sim 5.3 \mathrm{eV}$, which was approximately $3.4 \mathrm{eV}$ larger than the bond strength between Pt atoms on graphene substrates, suggesting that $\mathrm{Pt}$ preferentially binds to $\mathrm{N}$ sites. In addition, this study revealed that the remarkable performance of the single Pt atom catalyst arose from its small size and unique electronic structure originating from the adsorption of single Pt atoms onto $\mathrm{N}$-doped graphene as confirmed by XANES and DFT analyses. Furthermore, to apply SACs to HER in neutral media, Liu et al. [110] prepared single $\mathrm{Pt}$ atoms onto CoP-based nanotube arrays supported by $\mathrm{Ni}$ foam (PtSA-NT-NF) using potential cycling and reported that the as-prepared Pt single-atom catalyst exhibited a four times higher mass activity than that of Pt/C (Fig. 10c, d).

Aside from Pt, single Co atoms anchored onto $\mathrm{N}$-doped graphene have also shown excellent catalytic performances for HER, making these catalysts promising candidates to replace $\mathrm{Pt}$ in water splitting applications [111, 112]. For example, Yao et al. [113] used graphene defects to trap atomic Ni species and reported that the as-prepared catalyst (A-Ni@DG) exhibited comparable HER performances to $\mathrm{Pt} / \mathrm{C}$ in which the overpotential required to reach a current density of $10 \mathrm{~mA} \mathrm{~cm} \mathrm{~cm}^{-2}$ for the A-Ni@DG was as low as $70 \mathrm{mV}$ (Fig. 10e, f) and that according to DFT results, the different coordination configurations of $\mathrm{Ni}$ atoms and defects demonstrated high catalytic preferences to facilitate HER. 
Fig. 11 a $\mathrm{FE}$ of $\mathrm{CO}_{2}$ reduction products in the gas phase for CoPc/CNT (2.5\%) (red) and $\mathrm{CoPc}$ (blue) at various potentials. b CO FE for Ni SACs on $\mathrm{N}$-doped graphene at various applied potentials. $\mathbf{c}$ FEs of $\mathrm{CO}$ and $\mathrm{H}_{2}$ at various applied potentials on $\mathrm{ZnN}_{x} / \mathrm{C}$ catalysts. d $\mathrm{CO}$ and $\mathrm{H}_{2}$ FEs of $\mathrm{N}-\mathrm{C}$, Co$\mathrm{N}-\mathrm{C}$ and $\mathrm{Fe}-\mathrm{N}-\mathrm{C}$ catalysts. a Adapted with permission from Ref. [114]. Copyright 2017, Nature Publishing Group. b Adapted with permission from Ref. [115]. Copyright 2018, Nature Publishing Group. c Adapted with permission from Ref. [116]. Copyright 2018, Wiley-VCH. d Adapted with permission from Ref. [117]. Copyright 2018, American Chemical Society
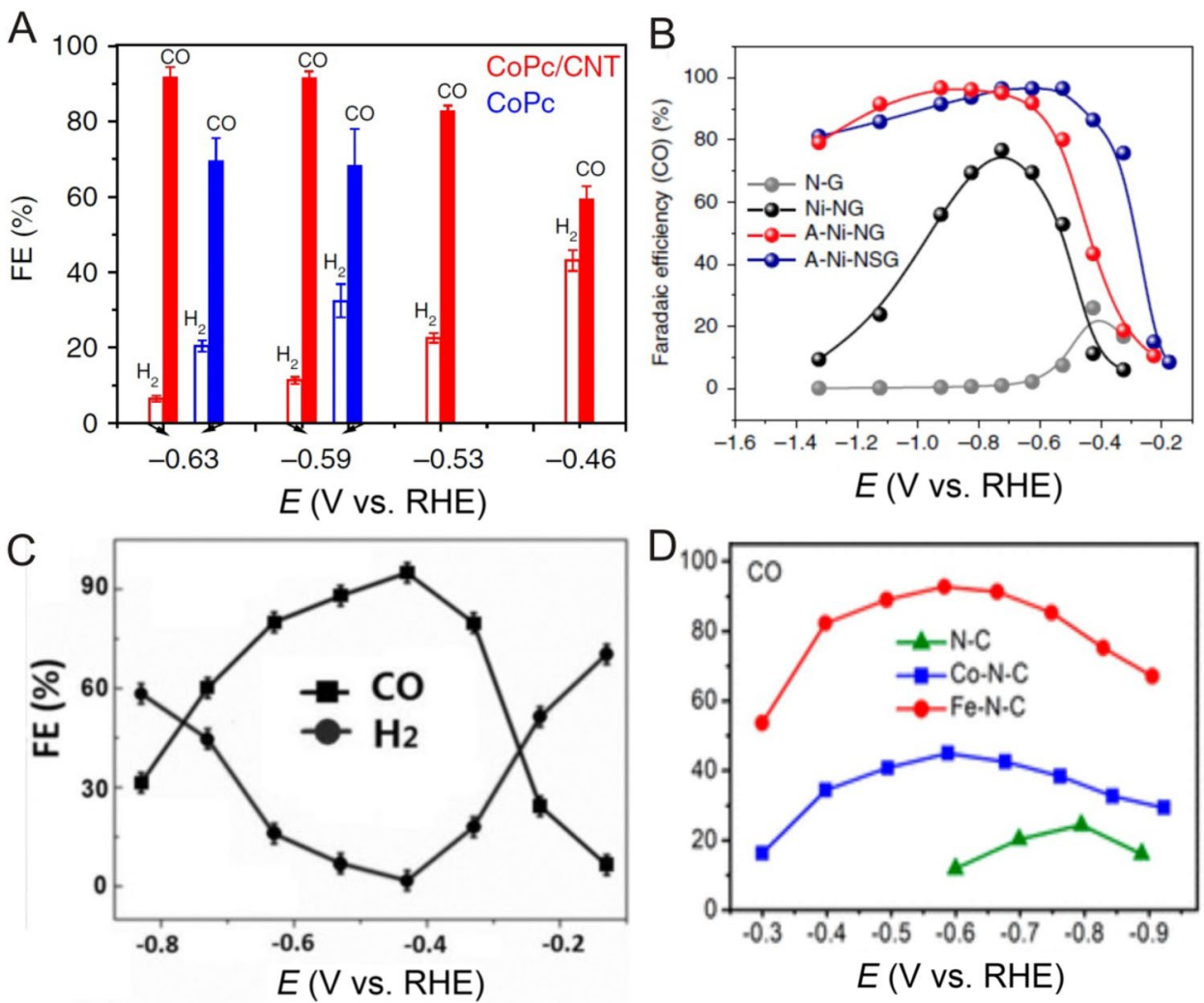

\subsubsection{Electrochemical Carbon Dioxide Reduction Reaction (CRR)}

With gradually increasing concentrations of carbon dioxide $\left(\mathrm{CO}_{2}\right)$ in the atmosphere, the development of effective routes for $\mathrm{CO}_{2}$ conversion into other carbon compounds is becoming urgent. However, $\mathrm{CO}_{2}$ is relatively stable and can only transform into other carbon compounds under harsh reaction conditions. Here, the electrochemical carbon dioxide reduction reaction (CRR) is an important transformation method with promising application prospects in which during the CRR process, the reaction rate and selectivity of the product is highly dependent on the catalyst. And recently, researchers have found that SACs can exhibit extremely high activities for $\mathrm{CO}_{2}$ reduction to $\mathrm{CO}$. For example, Liang et al. [114] prepared cobalt phthalocyanine $(\mathrm{CoPc})$ catalysts uniformly anchored onto carbon nanotubes in which ICP and Raman results showed that $\mathrm{CoPc}$ was dispersed onto CNTs at the molecular level and reported that at an overpotential of $0.52 \mathrm{~V}$ (vs. RHE) in $0.1 \mathrm{M} \mathrm{KHCO}_{3}$ aqueous solution, the $\mathrm{CoPc} / \mathrm{CNT}$ hybrid catalyst can provide a high and stable current density of over $10 \mathrm{~mA} \mathrm{~cm}^{-2}$ with a Faradaic efficiency (FE) of over $90 \%$ for $\mathrm{CO}_{2}$ reduction to $\mathrm{CO}$ (Fig. 11a). These researchers also reported that rapid electron transfer from the electrode to the surface CoPc molecules anchored onto CNTs can facilitate rapid and repetitive cycling between $\mathrm{Co}(\mathrm{II})$ and $\mathrm{Co}(\mathrm{I})$ to support $\mathrm{CO}_{2}$ conversion into $\mathrm{CO}$. In addition, these researchers also suggested that the uniform coverage of the CNT with CoPc molecules in the CoPc/ CNT catalyst structure can minimize exposure of the carbon surface to prevent the catalysis of hydrogen evolution rather than $\mathrm{CO}_{2}$ reduction.

In addition to metal complexes, Yang et al. [115] reported that a single Ni atom catalyst prepared by pyrolyzing a mixture of amino acids, melamine and nickel acetate in argon is active for CRR in which HAADF-STEM imaging revealed a SAC consisting of isolated, high-density and low-valent $\mathrm{Ni}(\mathrm{I})$ anchored onto $\mathrm{N}$-doped graphene, resulting in the asprepared Ni SAC achieving 97\% CO FE at $0.61 \mathrm{~V}$ (Fig. 11b). Here, operando XAS and DFT calculations demonstrated the delocalization of the unpaired electron in the $\mathrm{Ni} 3 \mathrm{~d}_{x^{2}-y^{2}}$ orbital and the spontaneous charge transfer from $\mathrm{Ni}(\mathrm{I})$ to the carbon $2 \mathrm{p}$ orbital in $\mathrm{CO}_{2}$, both of which can reduce the energy barrier for $\mathrm{CO}_{2}$ conversion into $\mathrm{CO}$. Aside from Ni single atoms, Yang et al. [116] also investigated Zn SACs for CRR in which the catalyst was synthesized through the pyrolysis of a mixture containing carbon black, urea and $\mathrm{Zn}$ at $1000{ }^{\circ} \mathrm{C}$. Here, the researchers reported that $\mathrm{Zn}$ atoms were anchored by $\mathrm{N}$ in a $\mathrm{Zn}-\mathrm{N}_{4}$ structure for the nitrogenanchored Zn SAC, allowing for a high selectivity (FE for $\mathrm{CO}$ ) of up to $95 \%$ at $0.43 \mathrm{~V}$ (Fig. 11c) and that their DFT results indicated that the $\mathrm{Zn}-\mathrm{N}_{4}$ structure can effectively reduce the energy barrier for the formation of $* \mathrm{COOH}$ and significantly enhance CRR performances. Furthermore, 
the CRR performance of MOF-derived Fe and Co SACs was also investigated in which Pan et al. [117] found that $\mathrm{Fe}-\mathrm{N}_{4}$ sites were intrinsically more active than $\mathrm{Co}-\mathrm{N}_{4}$ sites in $\mathrm{M}-\mathrm{N}-\mathrm{C}$ catalysts for $\mathrm{CO}_{2}$ reduction to $\mathrm{CO}$ and that for the $\mathrm{Fe}-\mathrm{N}-\mathrm{C}$ catalyst, a FE for $\mathrm{CO}$ can reach $93 \%$ at an overpotential of $0.47 \mathrm{~V}$ (Fig. 11d).

\subsection{Water-Gas Shift (WGS) Reactions}

The water-gas shift reaction, involving $\mathrm{CO}+\mathrm{H}_{2} \mathrm{O} \rightarrow \mathrm{CO}_{2}+\mathrm{H}_{2}$, forms the basis of heterogeneous catalysis and is critical to the generation of clean hydrogen energy for fuel cells, transportation fuels and ammonia manufacturing [118] and SACs are a promising new generation of WGS catalysts that can maximize both activity and catalytic efficiency $[14,119,120]$. For example, isolated $\mathrm{Au}$ species anchored onto $\mathrm{O}$ ligands to different supports such as ceria [121, 122] and titania [123] have been successfully prepared for WGS reactions and researchers have reported that atomically dispersed $\mathrm{Au}$ species with extra surrounding surface $\mathrm{OH}$ groups $\left[\mathrm{Au}-(\mathrm{OH})_{x}\right]$ can act as active sites for WGS reactions. In addition, researches have also reported that for "inert" oxide supports such as zeolites, alumina and silica, atomically dispersed metal species can be anchored on these supports through the addition of sodium-oxygen ligands $[124,125]$. As a result, these SACs can provide lower activation energies $E_{\mathrm{a}}$ for WGS reactions $\left(\sim 45 \mathrm{~kJ} \mathrm{~mol}^{-1}\right.$ for Auas compared with $\sim 75 \mathrm{~kJ} \mathrm{~mol}^{-1}$ for Pt) $[121,123]$.

Iron oxide-supported single Pt or Ir atoms are also active for WGS reactions $[11,118]$ and can exhibit remarkable activities that are $\sim$ one order of magnitude higher than clusters or nanoparticles in which iron oxide supports can participate in the reaction of $\mathrm{CO}$ oxidation and the oxygen provided by iron oxide can facilitate the oxidation of $\mathrm{CO}$ absorbed onto Pt atoms [11]. In addition, researchers have reported that Ir single atoms can greatly enhance the reducibility of $\mathrm{FeO}_{x}$ supports and the generation of oxygen vacancies, leading to excellent performances for $\mathrm{Ir}_{1} / \mathrm{FeO}_{x} \mathrm{SACs}$ [27].

\subsection{Hydrogenation Reactions}

SACs have been widely used in various hydrogenation reactions and have exhibited impressive catalytic performances. For example, Zhang et al. [31] reported that Pt single atoms anchored onto $\mathrm{FeO}_{x}$ nanocrystallites were highly active, chemoselective and reusable for the hydrogenation of a variety of substituted nitroarenes in which for the hydrogenation of 3 -nitrostyrene, the catalyst can yield a TOF of $\sim 1500 \mathrm{~h}^{-1}$, which is 20 -fold higher than optimal results reported in the literature, and a selectivity to 3 -aminostyrene close to $99 \%$. Here, the researchers attributed these superior performances to strong metal-support interactions that can significant enhance electron transfer from $\mathrm{Pt}$ atoms or ensembles to the $\mathrm{FeO}_{x}$ support and the presence of positively charged $\mathrm{Pt}$ centers, the absence of Pt-Pt metallic bonds and the appropriately reduced metal oxide surfaces, all of which favor the preferential adsorption of nitro groups, leading to significantly enhanced performances. Recently, Zeng et al. [45] also obtained high-ratio neighboring Pt monomers on $\mathrm{MoS}_{2}$ and found that neighboring Pt monomers can exhibit distinct performances as compared with isolated $\mathrm{Pt}$ monomers (Fig. 12a, b) in which for neighboring Pt monomers, $\mathrm{CO}_{2}$ can be converted stepwise to formic acid and methanol in $\mathrm{CO}_{2}$ hydrogenation, whereas isolated $\mathrm{Pt}$ monomers favor the conversion of $\mathrm{CO}_{2}$ to methanol without the formation of formic acid. Lu et al. [40] also reported that Pd single atoms anchored on graphene using ALD can show remarkable performances in the selective hydrogenation of 1,3-butadiene in which the $\mathrm{Pd}_{1} /$ graphene SAC demonstrated approximately $100 \%$ butene selectivity at $95 \%$ conversion in a mild reaction condition of $50{ }^{\circ} \mathrm{C}$ and attributed these performances to the changes in the 1,3-butadiene adsorption mode and the enhanced steric effect on the isolated Pd atoms (Fig. 12c, d). Here, the researchers speculated that butadiene can adsorb onto isolated $\mathrm{Pd}$ atoms through a mono- $\pi$-adsorption mode rather than a di- $\pi$-adsorption mode that usually requires a large ensemble of Pd surfaces (Fig. 12e). More importantly, excellent durability against deactivation through either aggregation of metal atoms or carbonaceous deposits for $100 \mathrm{~h}$ of reaction time on stream was also achieved. Vilé et al. [126] also synthesized Pd SACs by anchoring Pd atoms into mesoporous polymeric graphitic carbon nitride cavities and reported that the Pd SAC showed higher activity and selectivity for the flow hydrogenation of alkynes and nitroarenes as compared with supported Pd nanoparticle catalysts in which the Pd SAC surpassed the activity of conventional heterogeneous nanoparticle catalysts and maintained an outstanding degree of selectivity (>90\%) in which DFT calculations revealed that the high catalytic activity and selectivity can be attributed to the facile hydrogen activation and hydrocarbon adsorption of the atomically dispersed $\mathrm{Pd}$ sites.

\section{Single-Atom Alloys}

Single-atom alloy (SAA) catalysts have been shown to be active for a variety of processes, including selective hydrogenation reactions [127-130], dehydrogenation reactions [131-133],oxidation reactions [134, 135], hydrogenolysis [136] and coupling reactions [137] and have generated significant interest in recent years. Here, the creation of SAA catalysts is based on the deposition of isolated reactive metal adatoms into host metal surfaces (of a relatively inert metal). For examples, atomically dispersed $\mathrm{Pt}$ and Pd adatoms can 
Fig. 12 a, b Comparison of products obtained using atomically dispersed $\mathrm{Pt} / \mathrm{MoS}_{2}$ with different Pt loadings and Pt nanoparticles/MoS 2 . c, d Catalytic performances of $\mathrm{Pd}_{1} /$ graphene, $\mathrm{Pd}-\mathrm{NPs} /$ graphene, $\mathrm{Pd}-\mathrm{NPs} /$ graphene-500C and Pd/ carbon samples in the selective hydrogenation of 1,3-butadiene. e Schematic of the improvement of butene selectivity of $\mathrm{Pd}_{1} /$ graphene SACs. a, b Adapted with permission from Ref. [45]. Copyright 2017, Nature Publishing Group. c-e Adapted with permission from Ref. [40]. Copyright 2015, American Chemical Society
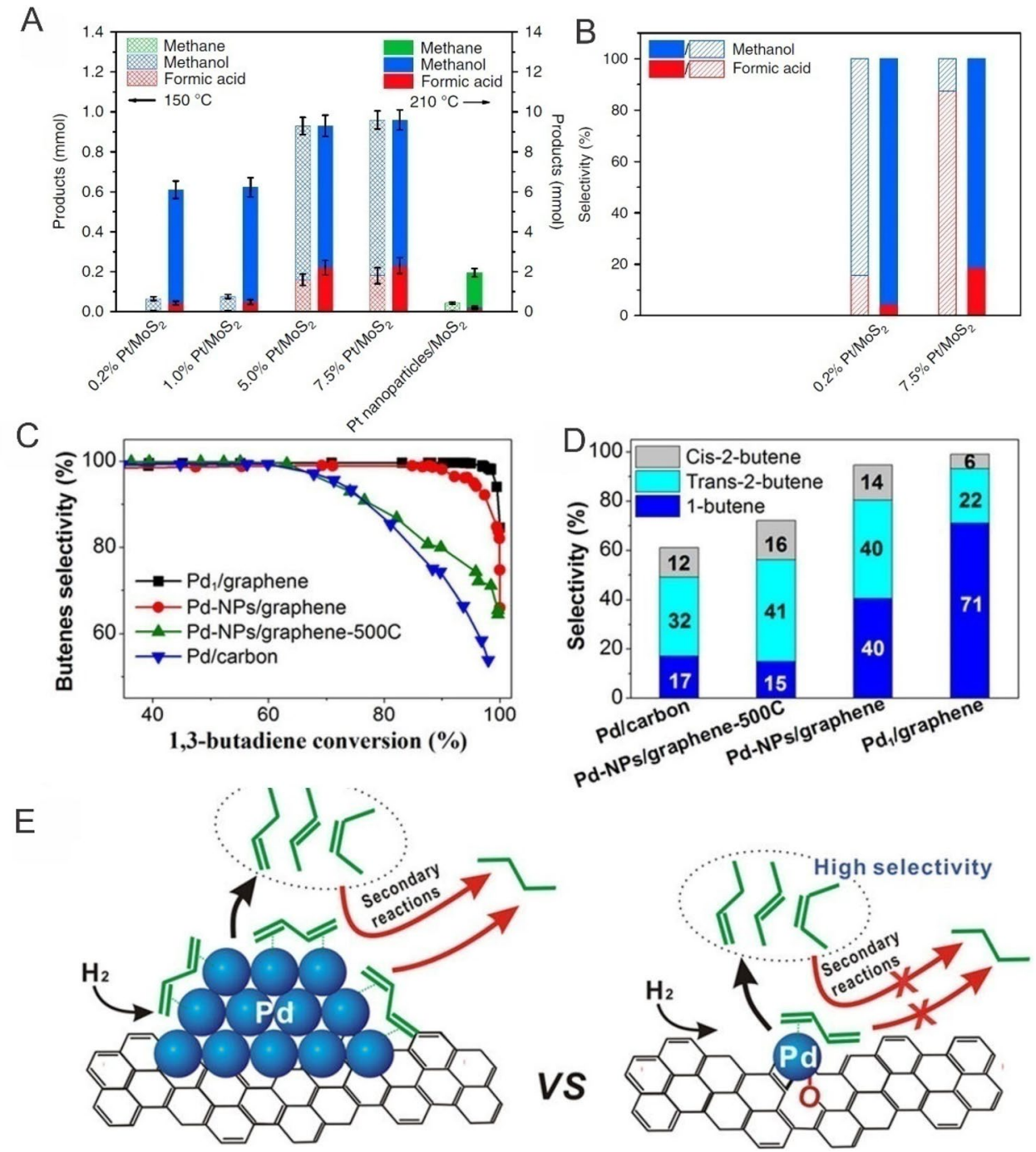

be deposited into a metallic copper host through galvanic replacement (GR) to catalyze selective hydrogenation reactions $[84,130]$. In addition, the catalytic properties of alloyed nanoparticles strongly depend on their composition and structure $[3,138]$. And because the structure of SAAs is different from normal alloyed nanoparticles, SAAs only interact with host metals with bonding occurring between its own atoms, resulting in different catalytic properties.

As an example, Lucci et al. [84] reported that Pt-Cu SAA catalysts can selectively hydrogenate 1,3-butadiene to butane under realistic flow reactor conditions, which is important in the transfer of SACs from ideal studies to practical catalytic reaction conditions. Here, the researchers reported that their SAA catalyst exhibited high stability and selectivity under realistic hydrogenation conditions and maintain stable butadiene conversion for $>46 \mathrm{~h}$ at $160{ }^{\circ} \mathrm{C}$ and attributed the selectivity increase to the inhibition of hydrocarbon decomposition that is commonly observed with Pt catalysts because SAA catalysts do not offer extended Pt ensembles to allow these unfavorable reactions to occur. Moreover, Shan et al. [133] reported that selectivity to formaldehyde on Pt-Cu SAA nanoparticle catalysts and $\mathrm{Pt}-\mathrm{Cu}$ (111) SAA model catalysts was both nearly $100 \%$. In addition, the $\mathrm{Pt}-\mathrm{Cu}$ SAA nanoparticle catalysts can also exhibit high selectivity and stability in water-catalyzed methanol dehydrogenation reactions and excellent stability in flow reactor tests and under UHV conditions. Furthermore, Lucci et al. [139] conducted a study of hydrogen activation and spillover in Pt-Cu SAA catalysts and found that the $\mathrm{Pt}-\mathrm{Cu}$ alloy containing only isolated $\mathrm{Pt}$ atoms was capable of facile $\mathrm{H}_{2}$ dissociation and spillover to $\mathrm{Cu}$ at temperatures as low as $85 \mathrm{~K}$ and possessed a reduced hydrogen desorption barrier as compared with monometallic $\mathrm{Pt}$ or $\mathrm{Cu}$. However, these researchers also reported that due to the stronger binding of $\mathrm{H}$ in the extended Pt ensembles, these larger Pt ensembles in $\mathrm{Cu}$ can exhibit higher temperature desorption profiles. Liu et al. [90] also used a Pt-Cu SAA catalyst recently to tackle the issue of $\mathrm{CO}$ poisoning in Pt catalysts and reported 
that the Pt-Cu SAA catalyst possessed excellent CO tolerances under realistic working conditions for $\mathrm{H}_{2}$ activation and acetylene hydrogenation. Here, the researchers attributed this tolerance to the weaker binding of Co to single $\mathrm{Pt}$ atoms in $\mathrm{Cu}$ as compared with larger Pt ensembles or monometallic Pt. Other researchers have also proposed that the improved $\mathrm{CO}$ tolerance of $\mathrm{Pt}-\mathrm{Cu}$ SAA catalysts can also be attributed to the unique structure of the SAA in which SAAs do not possess ensemble effects like traditional bimetallic alloys that have been shown to increase $\mathrm{CO}$ binding strengths at extended catalytic metal sites [140, 141]. And overall, these findings can guide the design of novel catalysts for low-temperature hydrogen fuel cells to avoid $\mathrm{CO}$ poisoning issues [142, 143].

Furthermore, through physical vapor deposition, Sykes et al. [144] dispersed single $\mathrm{Pd}$ atoms onto $\mathrm{Cu}$ (111) surfaces (Fig. 13a, b) and reported that the resulting Pd-Cu SAA catalyst showed higher efficiencies for the selective hydrogenation of styrene and acetylene in comparison with corresponding monometallic $\mathrm{Pd}$ and $\mathrm{Cu}$ catalysts in which the individual and isolated $\mathrm{Pd}$ atoms on $\mathrm{Cu}(111)$ surfaces can substantially lower hydrogen dissociation energy barriers and bind hydrogen adatoms weak enough to allow for spill over onto $\mathrm{Cu}$ surfaces (Fig. 13c), enabling the selective hydrogenation of styrene and acetylene as compared with pure $\mathrm{Cu}$ or $\mathrm{Pd}$ metal alone. Boucher et al. [130] also found that $\mathrm{Pd}_{0.18} \mathrm{Cu}_{15}$ nanoparticles prepared through GR possessed highly selective catalytic activity for hydrogenation reactions. Here, the alloying of $\mathrm{Pd}$ with $\mathrm{Cu}$ was confirmed using XPS and UV-visible spectroscopy measurements in which the prepared Pd-Cu SAA possessed over an order of magnitude higher activity for phenylacetylene hydrogenation as compared with monometallic $\mathrm{Cu}$ counterparts and maintained high selectivity to styrene for many hours at high conversion rates. In addition, DFT calculations by Fu et al. [145] suggested that the decreased activation energy of $\mathrm{H}_{2}$ dissociation plays an important role in the hydrogenation reactions of $\mathrm{Pd}-\mathrm{Cu}$ SAA catalysts in which $\mathrm{Pd}-\mathrm{Au}$ SAAs supported on ion-exchange resins possessed surface $\mathrm{Pd}$ sites that were totally isolated by $\mathrm{Au}$ atoms if $\mathrm{Au} / \mathrm{Pd} \geq 10$, allowing for exceptional activity and durability for Ullmann reactions of aryl chlorides [137]. Furthermore, Zhang et al. [134] reported that Pd host-supported single Au atom catalysts prepared through a successive reduction method can
Fig. 13 a, b STM images showing atomically dispersed $\mathrm{Pd}$ atoms on a $\mathrm{Cu}(111)$ surface and hydrogen atoms that have dissociated and spilled over onto the $\mathrm{Cu}$ surface. c Potential energy diagram depicting the mode of action of a Pd SAA surface compared with those of pure $\mathrm{Cu}(111)$ and $\mathrm{Pd}(111)$. d-e HAADF-STEM images showing the morphology of $\gamma-\mathrm{Al}_{2} \mathrm{O}_{3}$ supported $\mathrm{Pt} / \mathrm{Cu}$ SAA. a-c Adapted with permission from Ref. [144]. Copyright 2012,

American Association for the Advancement of Science. $\mathbf{d}-\mathbf{e}$ Adapted with permission from Ref. [147]. Copyright 2018, Nature Publishing Group
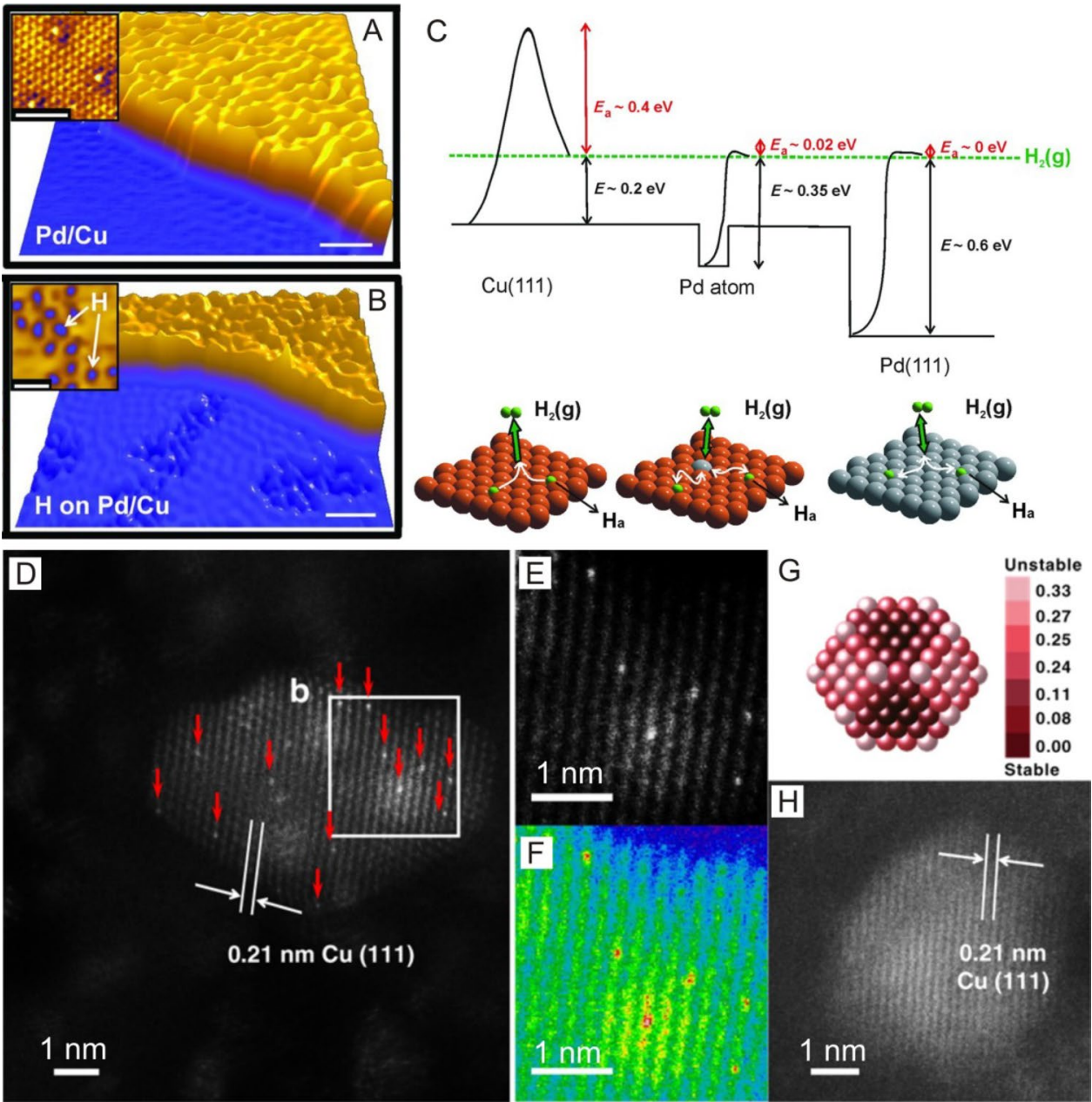
demonstrate glucose oxidation activities 17-40 times higher than that of monometallic Au and Pd nanoparticles and 5-8 times higher than that of Au/Pd alloy nanoparticles of the nearly same particle size. Here, the researchers attributed the high activity of the Au-Pd SAA catalyst to the presence of negatively charged single Au atoms that can form due to the charge polarization effect induced by charge transfer from $\mathrm{Pd}$ atoms to single $\mathrm{Au}$ atoms. Sykes et al. [89] also found that single $\mathrm{Pd}$ atoms in $\mathrm{Au}$ (111) surfaces can activate $\mathrm{H}_{2}$, which usually require two contiguous $\mathrm{Pd}$ atoms. Here, the researchers combined TPD with DFT calculations to elucidate the energetic landscape for $\mathrm{H}_{2}$ adsorption, activation and desorption for isolated $\mathrm{Pd}$ atoms and found a low-temperature pathway for $\mathrm{H}_{2}$ activation and release through $\mathrm{Pd}$ atoms with minimal spillover to $\mathrm{Au}$ in which the co-adsorption of $\mathrm{H}_{2}$ and $\mathrm{D}_{2}$ can lead to the complete scrambling of $\mathrm{H}$ and $\mathrm{D}$, supporting the dissociation of $\mathrm{H}_{2}$ and the transient existence of $\mathrm{H}$ atoms on $\mathrm{Au}$. Moreover, by using an opposite approach, Sykes et al. [146] alloyed small amounts of Ni onto Au (111) to produce a SAA catalyst and demonstrated that single $\mathrm{Ni}$ atoms on Au surfaces can increase the reactivity of substrates by creating single Ni sites to bind CO significantly stronger than Au.

To apply SAA catalysts to broader applications in higher temperatures, Gong et al. [147] synthesized $\mathrm{Pt} / \mathrm{Cu}$ SAAs supported on $\gamma$-alumina through atomic dilution and reported that their DFT results showed that the exposed isolated surface $\mathrm{Pt}$ atoms within $\mathrm{Cu}(111)$ facets of the $\mathrm{Pt} / \mathrm{Cu}$ SAA nanoparticles were more thermodynamically stable than other types of Pt species. Here, the structure of the Pt/ $\mathrm{Cu}$ SAA catalyst was obtained using AC-HAADF-STEM images in which single $\mathrm{Pt}$ atoms were distinguished from $\mathrm{Cu}$ atoms due to differences in Z-contrast (Fig. 13d-h). And in the catalytic dehydrogenation of propane, this Pt/Cu SAA catalyst with low Pt loading ( $0.1 \mathrm{wt} \%)$ displayed a propylene selectivity of $\sim 90 \%$ with high formation rates as well as excellent stability for $120 \mathrm{~h}$ on stream. In addition, DFT calculations showed that compared with conventional Pt alloys, this $\mathrm{Pt} / \mathrm{Cu}$ SAA broke the Pt-M alloy scaling relationship during $\mathrm{PDH}$ (propane dehydrogenation), displaying a negative difference between the desorption energy and the further dehydrogenation barrier of propylene.

\section{The Stability of Single-Atom Catalysts}

SACs show great potential for various heterogeneous reactions because atomically dispersed catalysts present optimal metal utilization geometries with the most exposed active sites in catalysis. However, the stabilization of supported highly dispersed single atoms during synthesis and catalysis is difficult due to the high surface-free energies and lowcoordination numbers of single metal atoms. And although many methods have been developed to prepare SACs to address stability issues, the loading of metal atoms is generally kept to less than $1.5 \mathrm{wt} \%$ to prevent the formation of metal nanocrystals through sintering. Another key aspect in the stabilization of SACs is the prevention of single atoms aggregating and agglomerating into clusters/nanoparticles due to atom migration as well as the reduction in metal atom loss through detachment in harsh operating conditions. Based on this, a deeper understanding of the stabilization mechanisms of single atoms on supports is needed to provide insights into the development of stable SACs for practical applications.

\subsection{The Anchoring Mechanism}

Metal-support interactions play a pivotal role in the performance of supported catalysts [148-150] by not only enhancing stability, but also by endowing improved catalytic properties such as significantly enhanced catalytic activities and selectivity due to altered electronic structures or synergetic catalytic effects [2,151-154]. And in SACs, this effect is more pronounced and is a determining factor in the performance of SACs due to contact between isolated metal atoms and supports [155]. Therefore, a thorough understanding of metal-support interactions is vital for the design of supported single atoms as catalysts for specific reactions in which appropriate substrates can strongly interact with metal atoms to form stable active site structures and anchor individual metal atoms firmly to prevent aggregation. To date, various metal oxides (e.g., $\mathrm{FeO}_{x}$ ), 2D materials (e.g., graphene, doped graphene, g- $\mathrm{C}_{3} \mathrm{~N}_{4}$ and $\mathrm{BN}$ ), crystalline metal surfaces and metal-organic frameworks have been investigated as supports for SACs in which different supports can provide different anchoring sites to stabilize single-atom metals due to different chemical bonding between metal atoms and supports, leading to different stabilization mechanisms and configurations. Based on this, this section will present stable active structures for SACs based on different supports.

\subsubsection{Metal Oxides}

Metal oxide materials such as reducible $\mathrm{FeO}_{x}, \mathrm{CeO}_{2}$ and $\mathrm{TiO}_{2}$ have widely been used as supports to stabilize single metal atoms through strong metal-support interactions. For example, single metal atoms can strongly interact with $\mathrm{FeO}_{x}$ by occupying the metal or oxygen vacancies on the surface of the metal oxide depending on the nature of the support and synthesis method, thus providing ultra-stability and remarkable catalytic performances in which metal-support interactions showing $\mathrm{Pt}-\mathrm{O}-\mathrm{Fe}$ bonding were observed on $\mathrm{FeO}_{x}$-supported $\mathrm{Pt}$ single atoms by researchers $[11,31]$. For example, EXAFS revealed $\mathrm{Pt}-\mathrm{O}$ and $\mathrm{Pt}-\mathrm{Fe}$ features 
at $\sim 2.01 \AA$ and $\sim 3.05 \AA$ originating from Pt atoms binding to the oxygen of the substrate and the interaction of $\mathrm{Pt}$ with the $\mathrm{Fe}$ of the substrate [31]. In addition, the increased $\mathrm{Pt}-\mathrm{Fe}$ coordination distance as compared with $\mathrm{Pt}-\mathrm{Fe}$ alloys (2.56 ̊) [156] suggests that Pt coordinates with Fe through bridging oxygen atoms (forming $\mathrm{Pt}-\mathrm{O}-\mathrm{Fe}$ boding) instead of direct coordination with Fe (Pt-Fe bonding) [11, 31]. Furthermore, Liu et al. [157] recently reported that isolated single $\mathrm{Au}$ atoms dispersed on iron oxide nanocrystallites $\left(\mathrm{Au}_{1} / \mathrm{FeO}_{x}\right)$ were much more resistant to sintering than $\mathrm{Au}$ nanostructures and can exhibit extremely high reaction stability for $\mathrm{CO}$ oxidation in a wide temperature range. Here, the researchers proposed that the highly positive charged single $\mathrm{Au}_{1}$ atoms can occupy $\mathrm{Fe}$ vacancy sites of the $\mathrm{FeO}_{x}$ nanocrystallites to lead to strong covalent metal-support bonding interactions in the form of $\mathrm{Au}-\mathrm{O}-\mathrm{Fe}$ bonding between single $\mathrm{Au}_{1}$ atoms and lattice oxygen atoms of $\mathrm{FeO}_{x}$ to account for the exceptional stability and remarkable catalytic activity of $\mathrm{Au}_{1} / \mathrm{FeO}_{x}$ during $\mathrm{CO}$ oxidation. However, $\mathrm{Pt}-\mathrm{Al}$ bonding was absent in the EXAFS of single $\mathrm{Pt}$ atoms supported on inert $\mathrm{Al}_{2} \mathrm{O}_{3}$ supports [97], suggesting that the stabilization mechanism of single atoms on inert supports is different from active supports such as $\mathrm{FeO}_{x}$.

Ceria are another widely used support to stabilize metal SACs through interactions between metal atoms and oxygen atoms of ceria as created by the structure of [meta-O-Ce]. For example, Datye et al. [158] found that the aging of Pt/ $\mathrm{Al}_{2} \mathrm{O}_{3}$ at $800{ }^{\circ} \mathrm{C}$ allowed for the transfer and trapping of $\mathrm{Pt}$ into ceria and that polyhedral and nanorodceria were more effective than ceria cubes at anchoring Pt (Fig. 14a-c). In addition, $\mathrm{Au}$ single atoms can also be stabilized by $\mathrm{CeO}_{2}$ in which researchers reported that HAADF-STEM images showed that $\mathrm{Au}_{1}$ atoms anchored onto $\mathrm{CeO}_{2}$ nanocrystals gained stability by occupying the surface $\mathrm{Ce}$ vacancies [159]. Furthermore, Lu et al. [160] revealed that single $\mathrm{Pt}$ atoms substituted into the surface $\mathrm{Ce}$ vacancies of $\mathrm{CeO}_{2}(110)$ gained stability as positively charged $\mathrm{Pt}$ atoms were stabilized by lattice oxygens through six $\mathrm{Pt}-\mathrm{O}$ bonds. Here, the researchers suggested that the most stable sites for the adsorption of mononuclear Pt species on ceria nanoparticles were at small nanofacets in which Pt can forms squareplanar coordination complexes $\left(\mathrm{Pt}-\mathrm{O}_{4}\right.$ moiety) with four $\mathrm{O}$ atoms from the ceria nanoparticle and that this $\mathrm{Pt}-\mathrm{O}_{4}$ moiety was likely to be responsible for the excellent overall stability. Moreover, these researchers proposed that in this $\mathrm{Pt}-\mathrm{O}_{4}$ moiety, $\mathrm{Pt}^{2+}$ instead of $\mathrm{Pt}^{0}$ was stabilized on the $\mathrm{CeO}_{2}$ support at the nanofacets through so-called $\mathrm{O}_{4}$ nanopockets in which $\mathrm{Pt}^{2+}$ ion scan coordinates in a square-planar complex with four oxygen anions as ligands. Here, $\mathrm{Pt}^{2+}$ cations can formed through the transfer of two electrons from Pt to ceria nanoparticles, resulting in the reduction in two ions from $\mathrm{Ce}^{4+}$ to $\mathrm{Ce}^{3+}[161,162]$. Researchers also found that the surface sites consisting of four $\mathrm{O}$ atoms in a square-planar geometry were on extended $\mathrm{CeO}_{2}$ (100) surfaces [163] and on the step edges of low-energy $\mathrm{CeO}_{2}$ (111) nanoislands [164].

$\mathrm{ZnO}$ can also be used to support single-atom metals in which researchers reported that precious metal atoms including $\mathrm{Pt}_{1}$ and $\mathrm{Au}_{1}$ together coordinated with lattice oxygens embedded into $\mathrm{ZnO}$ surfaces can provide single stable active sites for ethanol steam reforming [165]. Recently, Wang et al. [166] also generated $\mathrm{O}$ vacancies on the surface of $\mathrm{TiO}_{2}$ through $\mathrm{H}_{2}$ treatment at different temperatures (Fig. 14d) and reported that the isolated single $\mathrm{Au}$ atoms were atomically anchored onto defective $\mathrm{TiO}_{2}$ nanosheets and were twofold coordinated by $\mathrm{Ti}$ atoms to form a $\mathrm{Ti}-\mathrm{Au}-\mathrm{Ti}$ structure (Fig. 14e, f). Moreover, the two $\mathrm{O}_{2}$ molecules were considered to be adsorbed on either side of the Au sites to form a symmetrical structure in which ACSTEM results showed that single $\mathrm{Pt}$ atoms can occupy planar $\mathrm{O}$ vacancies of $\mathrm{TiO}_{2}$ (110) [72]. However, Thornton et al. [167] also presented direct evidence that single Au atoms can bind at bridging $\mathrm{O}$ vacancies on $\mathrm{TiO}_{2}$ (110) through a comparison of STEM images of the same area on the surface before and after dosing $\mathrm{Au}_{1}$. In addition, Batzill et al. [168] investigated the influence of hydroxyls on Pd atom mobility and clustering on rutile $\mathrm{TiO}_{2}$ and found that stable $\mathrm{Pd}$ atoms can be achieved on hydroxyl-modified $\mathrm{TiO}_{2}$ at room temperature, whereas much larger clusters formed under the same conditions on hydroxyl-free $\mathrm{TiO}_{2}$ surfaces in which the enhanced binding of adatoms to surface sites adjacent to hydroxyl groups and the associated increase in surface diffusion barriers were responsible for the initial suppression of Pd atom sintering.

\subsubsection{Carbon-Based Materials}

Carbon-based materials such as graphene and doped graphene are also important substrates to support single metal atoms. However, single metals atoms often drift on graphene surfaces to form aggregate particles because the interactions between pristine graphene and single-atom metals are weak due to the strong $\mathrm{sp}^{2}$ binding between carbon atoms in graphene sheets [109]. In addition, DFT calculations show that single atoms of transition metals can easily diffuse into pristine graphene to generate large metal clusters and reduce the performance of SACs. However, based on first-principles calculations, transition metal SACs embedded on graphene have been theoretically predicted as highly efficient catalysts for reactions such as $\mathrm{CO}$ oxidation, oxygen reduction and epoxidation of ethylene and propene, and include Au [169-172], Fe [173, 174], $\mathrm{Cu}$ [175] and Pt [176] supported by defective graphene. Here, single metal atoms can be stabilized on graphene through stronger interactions between metal atoms and carbon vacancies in defective graphene in which once incorporated into the graphene lattice, single metal atoms 
Fig. 14 a Schematic of Pt nanoparticle sintering showing how ceria can trap mobile Pt to suppress sintering. Cubes appear to be less effective than rods or polyhedral ceria. HAADFSTEM images of b $1 \mathrm{wt} \% \mathrm{Pt} /$ $\mathrm{CeO}_{2}$-rod and $\mathbf{c} 1 \mathrm{wt} \% \mathrm{Pt} /$ $\mathrm{CeO}_{2}$-polyhedra after aging at $800{ }^{\circ} \mathrm{C}$ for $10 \mathrm{~h}$ in flowing air. d Schematic of the formation $\mathrm{Au}$ single atoms on defective $\mathrm{TiO}_{2}$. e HAADF-STEM image of single atomic Au sites highlighted by red circles. f Elemental mappings showing the distribution of $\mathrm{Ti}$ (blue) and $\mathrm{Au}$ (red). a-c Adapted with permission from Ref. [158]. Copyright 2016, American Association for the Advancement of Science. $\mathbf{d}-\mathbf{f}$ Adapted with permission from Ref. [166]. Copyright 2018, Wiley-VCH
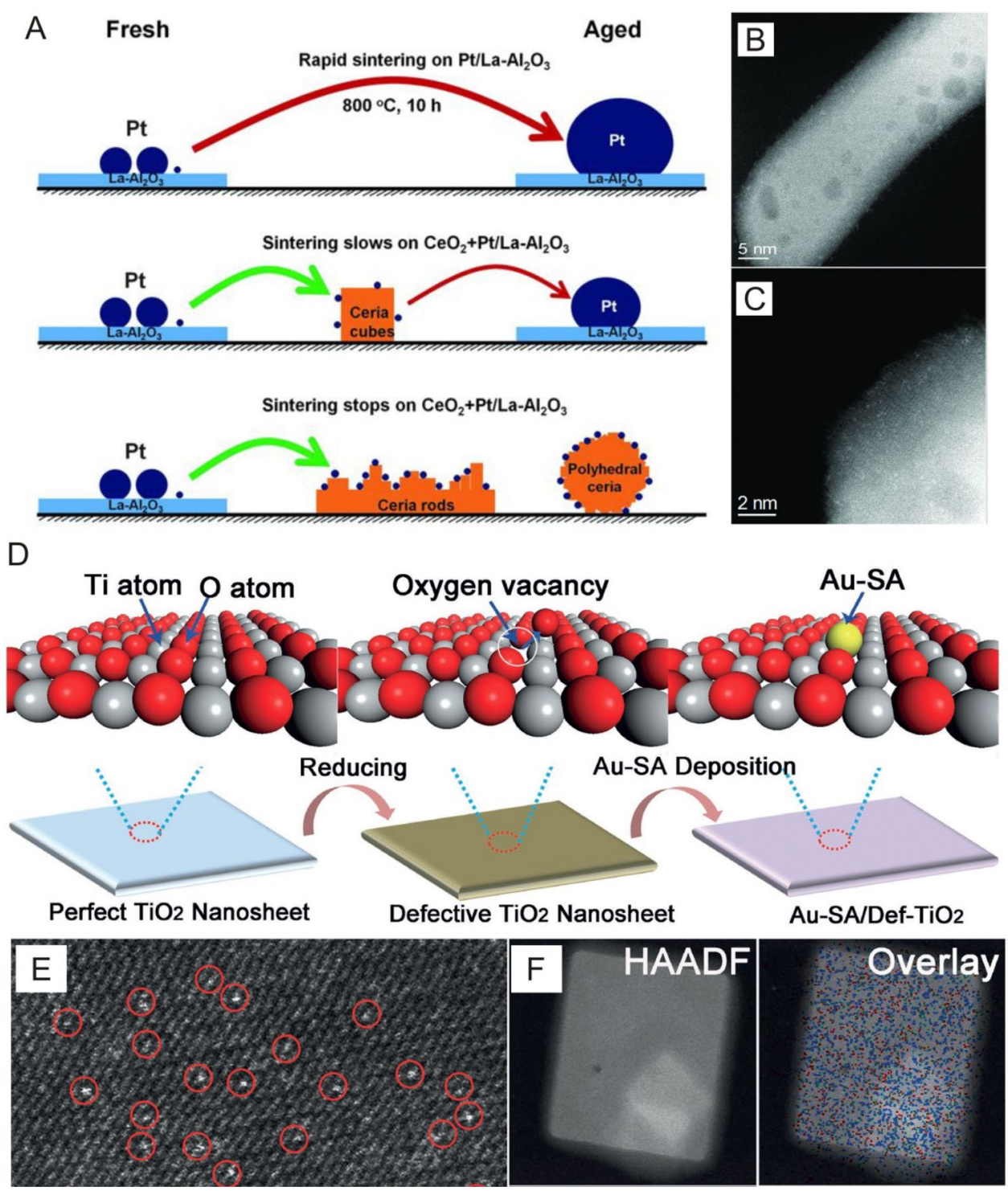

can transition to adjacent lattice positions and reversibly switch their bonding between three and four nearest neighbors [68]. And overall, theoretical studies predict that the activation energies for metal adatom adsorption and diffusion on perfect graphene are in the range of $0.14-0.8 \mathrm{eV}$ [177], whereas activation energies for diffusion in graphene are in the range of 2.1-3.6 eV for metal-monovacancies and $\sim 5 \mathrm{eV}$ for metal-divacancy complexes [178, 179]. Researchers also report that the migration barriers (activation energies) of metal atoms on graphene vacancies are much higher than that of pristine graphene and that the high binding energies of metal-vacancy complexes can ensure the high stability of SACs [180]. Furthermore, carbon vacancies can be deliberately introduced into carbon materials through irradiation [181-184] by knocking off carbon atoms with energetic particles such as electrons and ions [185]. Moreover, it is also possible to atomically disperse Co in a graphene matrix through a simple thermal treatment of $\mathrm{Co}^{2+}$ cations and graphene oxides in which carbon and oxygen at the surface of graphene can serve as anchoring sites for the coordination of Co atoms [186]. Similar results have also been found for $\mathrm{Pd}$ single atoms coordinated with defective $\mathrm{C}$ and phenolic $\mathrm{O}$ atoms on graphene surfaces as confirmed by XAFS analysis [40]. Chen et al. [73] also revealed different anchoring mechanisms for $\mathrm{Ni}$ atoms stabilized on graphene in which one $\mathrm{Ni}$ atom can substitute one $\mathrm{C}$ atom in a graphene lattice and chemically bond with three $\mathrm{C}$ atoms based on the investigation of HAADF-STEM, and Yao et al. [113] proposed that Ni atoms trapped in the divacancy of defect graphene (DG) can form a Ni- $\mathrm{C}_{4}$ structure, resulting in the DG-trapped $\mathrm{Ni}$ exhibiting excellent durability during electrochemical tests. Here, the researchers prepared Ni nanoparticles on DG through the dispersion of $\mathrm{Ni}^{2+}$ cations followed 
by annealing reduction and treatment in hydrochloric acid to remove redundant $\mathrm{Ni}$ and a leaching process to allow single $\mathrm{Ni}$ atoms to be trapped in the defects of DG (Fig. 15a, b). In addition to introducing defects onto graphene, Liu et al. [187] also proposed a new stabilizing strategy through the anchoring of single $\mathrm{Pt}$ atoms onto aniline-stacked graphene (Fig. 15c, d) in which XAS and DFT calculations elucidated that atomically isolated $\mathrm{Pt}$ can coordinate with the nitrogen of aniline to optimize the electronic structure of $\mathrm{Pt}$ as well as hydrogen adsorption energies, resulting in the as-prepared Pt SAC presenting excellent HER activity and stability as compared with commercial $\mathrm{Pt} / \mathrm{C}$.

Moreover, the introduction of foreign atoms such as nitrogen or sulfur into carbon supports is another effective method to enhance the interaction between metal atoms and supports through the formation of $\mathrm{M}-\mathrm{N}_{x}$ or $\mathrm{M}-\mathrm{S}_{x}$ structures with metal atom $(\mathrm{M}=\mathrm{Pt}, \mathrm{Pd}, \mathrm{Co}, \mathrm{Ni})$ centers and
Fig. 15 a Schematic of the fabrication of A-Ni@DG. b HADDF-STEM image of the defective area with atomic $\mathrm{Ni}$ trapped. c, d Schematic and HADDF-STEM image of Pt single atoms on aniline-stacked graphene. e-g Schematic and HAADF-STEM image of Co$\mathrm{N}_{5}$ SACs. a, b Adapted with permission from Ref. [113]. Copyright 2018, Cell Press. c, d Adapted with permission from Ref. [187]. Copyright 2019, Royal Society of Chemistry. $\mathbf{e}-\mathbf{g}$ Adapted with permission from Ref. [200]. Copyright 2018, American Chemical Society

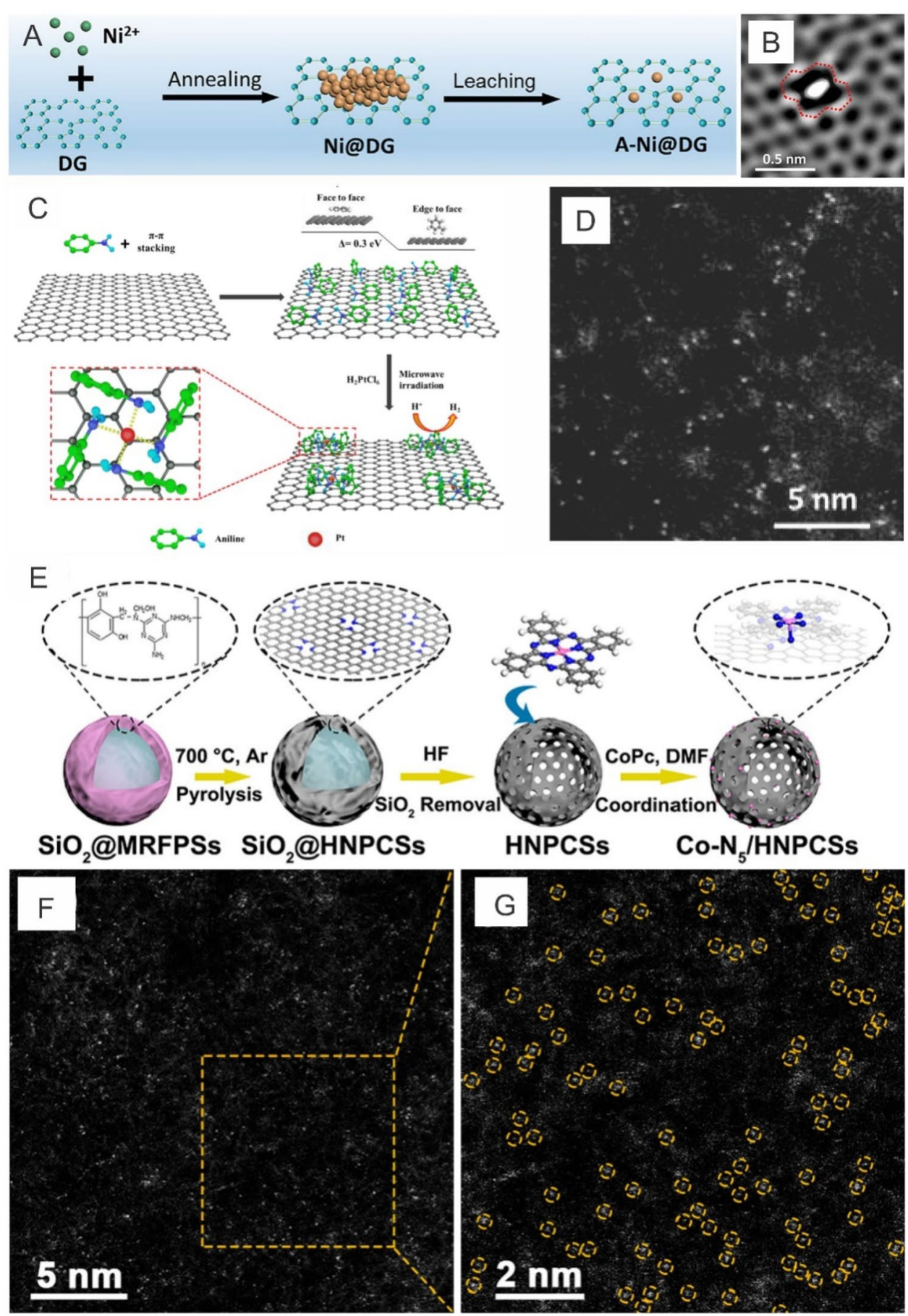


surrounding $\mathrm{N}$ or $\mathrm{S}$ atoms. Here, the atomic structures of $\mathrm{M}-\mathrm{N}_{x}$ are mainly fabricated through either the simple heating of mixtures of metal and nitrogen precursors on carbon supports [95, 188], the pyrolysis of mixtures of metal and $\mathrm{N}$, C-containing precursors $[189,190]$ or the direct carbonization of MOFs $[56,191]$ at high temperatures in which the introduction of $\mathrm{N}$ was found to be able to tune the electronic properties of carbon materials and facilitate the dispersion of metal atoms embedded in carbon materials through strong interactions between metals and supports. In addition, firstprinciples calculations showed that $\mathrm{N}$-doping can introduce localized defect states in the vicinity of the Fermi level of pristine graphene and that the calculated diffusion barrier of $\mathrm{Pt}$ atoms on $\mathrm{N}$-doped graphene $(2.97 \mathrm{eV})$ was much higher than that on pristine graphene $(\sim 0.14 \mathrm{eV})$, effectively stabilizing deposited Pt atoms [192]. Furthermore, N-doping configurations in graphene substrates were found to be able to affect the stability of Pt atoms on NG and that Pt-NG support interactions can be stronger than Pt-Pt interactions by picking appropriate doping configurations [193]. Recent calculations also indicated that single $\mathrm{Co}$ atoms embedded into pyridinic vacancy sites of nitrogen-doped graphene were more stable than that of Pt [194] as confirmed by experimental observations that showed that these bonded Co atoms by $\mathrm{N}$ atoms were stable and can function as highly active HER catalysts in both acid and base media [111].

The precise identification of the atomic structure of $\mathrm{M}-\mathrm{N}_{x}$ is critical for the understanding of the stabilization mechanisms of single metal atoms stabilized by $\mathrm{N}$ on carbon materials. Based on this, Suenaga et al. [195] found through the use of STEM that metal atoms were likely to be trapped at pyridinic $\mathrm{N}$ defects rather than at graphitic- $\mathrm{N}$ defects as pyridinic $\mathrm{N}$ exhibits higher chemical activity. In addition, $\mathrm{M}-\mathrm{N}_{4}$ moieties are believed to be stable structures for $\mathrm{N}$ functional carbon materials anchoring single atoms based on Ac-TEM, XAS and DFT calculations [189, 196]. Furthermore, Zhang et al. [197] identified a Co-N-C catalyst synthesized using a sacrificial support approach through AC-HAADF-STEM, XAS and DFT calculations and reported that the stable structure was identified to be $\mathrm{Co}-\mathrm{N}-\mathrm{C}-\mathrm{O}$ in which $\mathrm{Co}$ center atoms were coordinated with four pyridinic $\mathrm{N}$ atoms in the graphitic layer, whereas two oxygen molecules were weakly adsorbed on Co atoms perpendicular to the $\mathrm{Co}-\mathrm{N}_{4}$ plane. Bao et al. $[74,198]$ also systematically studied the atomic structure of $\mathrm{Fe}$ atoms embedded in graphene using HRTEM in combination with HAADF-STEM and low-temperature STM in which the structure of the single Fe atoms in the graphene matrix was first imaged as black dots using AC-HRTEM and subsequently confirmed using sub-angstrom resolution HAADF-STEM images as bright dots. Here, the electron energy loss atomic spectrum clearly showed the presence of both $\mathrm{Fe}$ and $\mathrm{N}$ elements in one bright dot, suggesting the formation of $\mathrm{Fe}-\mathrm{N}_{x}$ bonding. In addition, the atomic structure of the $\mathrm{FeN}_{4}$ centers embedded in the graphene matrix was also confirmed by low-temperature STM. Recently, Zhang et al. [199] also prepared an atomically dispersed self-supporting $\mathrm{Fe}-\mathrm{N}-\mathrm{C}$ catalyst using nano$\mathrm{MgO}$ as a sacrificial template and studied its structure using a combination of AC-HAADF-STEM, electron spin resonance (ESR), XAS and Mossbauer spectroscopy. Here, the researchers found the existence of four different species $(x=4-6)$ in the atomically dispersed $\mathrm{Fe}-\mathrm{N}-\mathrm{C}$ catalyst and that the relative concentrations of each species were dependent on pyrolysis temperatures in which the $\mathrm{Fe}-\mathrm{N}-\mathrm{C}$ catalyst sample treated at $700{ }^{\circ} \mathrm{C}$ was composed of highspin $\mathrm{FeN}_{6}(28.3 \%)$, low-spin $\mathrm{FeN}_{6}(53.8 \%)$ and mediumspin $\mathrm{FeN}_{5}$ (17.9\%) species. Chen et al. [200] also proposed a $\mathrm{Co}-\mathrm{N}_{5}$ structure anchored onto polymer-derived hollow $\mathrm{N}$-doped porous carbon spheres (Fig. 15e-g) in which the $\mathrm{Co}-\mathrm{N}_{5}$ sites were found to be active centers for $\mathrm{CO}_{2}$ activation and the rapid formation of key reaction intermediate $\mathrm{COOH}^{*}$ as well as the desorption of $\mathrm{CO}$.

More recently, graphitic carbon nitride; a new class of 2D conjugated polymers, has gained immense attention as a single-atom substrate due to its unique structure and high surface-area substrate containing "cavities" that can trap catalytically active metal atoms in an isolated form [201-203]. In addition, graphitic carbon nitride $\left(\mathrm{g}-\mathrm{C}_{3} \mathrm{~N}_{4}\right)$ is a promising support to anchor single metal atoms [204] because $\mathrm{g}_{-} \mathrm{C}_{3} \mathrm{~N}_{4}$ possesses more specific $\mathrm{N}$ species and larger $\mathrm{N}$-coordinating cavities as compared with $\mathrm{N}$-doped graphene and can provide more abundant and uniform nitrogen coordinators in which theoretical studies of g- $\mathrm{C}_{3} \mathrm{~N}_{4}$-supported single $\mathrm{Pt}$ or Pd atoms [205] found that the exsistance of significant charge transfer between metal atoms and neighboring pyridinic nitrogen atoms for both $\mathrm{Pd} / \mathrm{g}-\mathrm{C}_{3} \mathrm{~N}_{4}$ and $\mathrm{Pt} / \mathrm{g}-\mathrm{C}_{3} \mathrm{~N}_{4}$, indicating strong interactions between the lone pair electrons of neighboring pyridinic nitrogen atoms and isolated metal atoms. Researchers have also proposed that single metal atoms can be stabilized through anchoring into the center of the sixfold cavity of g- $\mathrm{C}_{3} \mathrm{~N}_{4}[126,205]$ in which the metal atoms were believed to move to a corner of the sixfold cavity in $\mathrm{g}_{-} \mathrm{C}_{3} \mathrm{~N}_{4}$ once reactant/intermediates were adsorbed during reactions [205]. Alternatively, Wu et al. [19] proposed a different stable structure involving $\mathrm{Pt}$ atoms located on the top of the five-membered rings of a $\mathrm{C}_{3} \mathrm{~N}_{4}$ network. In addition, Yao et al. [206] stated that atomically dispersed Co atoms can successfully be grafted by covalently forming a Co- $\mathrm{N}_{4}$ structure on $\mathrm{g}-\mathrm{C}_{3} \mathrm{~N}_{4}$ nanosheets through ALD and Qiao et al. [207] reported that isolated single Co atoms can be atomically anchored into g- $\mathrm{C}_{3} \mathrm{~N}_{4}$ matrixes through the formation of $\mathrm{Co}-\mathrm{N}_{2}$ coordination moieties after thorough XANES analysis and DFT computation. 


\subsection{Strategies to Enhance the Interactions Between Single Atoms and Supports}

The manipulation of interactions between metal atoms and different supports to achieve high stability in singleatom catalysis is vital, and researchers have proposed several strategies to enhance the interactions between metal atoms and supports to stabilize single atoms and design robust SACs for practical application. For example, several recent studies have reported that noble metal SACs (Pt and $\mathrm{Au}$ ) for WGS reactions can be stabilized through the use of alkali metals (Na, K and Li) as promoters (Fig. 16a) [208-210] in which alkali promotion can be understood as a means of stabilizing and providing oxygen containing $(\mathrm{OH})$ species to metal atoms and that the role of alkali metals is not simply to create $\mathrm{OH}$ sites in close contact with dispersed metal through the modification of support properties. In addition, single noble metal atoms can be stabilized by alkali metals through interactions and the formation of several structures [124, 125, 208], including alkali atoms linked to noble metal atoms through $-\mathrm{O}$ ligands, $-\mathrm{O}$ ligands bound directly to central noble metal atoms and $\mathrm{OH}$ groups primarily bound on alkali metal sites that surround noble metal atoms (Fig. 16b). And in these supported SACs stabilized by alkali metal, the active sites are noble metal- $\mathrm{O}(\mathrm{OH})_{x}$-species instead of the single noble metal atom itself in which noble metal- $\mathrm{O}(\mathrm{OH})_{x}$-species stabilized by alkali metals can demonstrate high stability for WGS reactions. For example, Zhai et al. [208] reported that single-site active $\mathrm{Pt}-\mathrm{O}(\mathrm{OH})_{x}-(\mathrm{Na} \text { or } \mathrm{K})_{y}$ species on silica and alumina were activate at low temperatures $\left(\sim 100{ }^{\circ} \mathrm{C}\right)$ for WGS reactions and were stable in temperatures exceeding $300{ }^{\circ} \mathrm{C}$ for many hours (Fig. 16c, d) [208]. In another example, Yang et al. [124] reported that good stability was found for alkali ion (sodium or potassium) stabilized Au atoms on KLTL-zeolite and mesoporous MCM-41 silica for WGS up to $200{ }^{\circ} \mathrm{C}$.

\section{Conclusion and Perspectives}

Single-atom catalysts can exhibit fascinating characteristics such as high activity, selectivity and optimal atomic utilization due to a low-coordination status, the quantum size effect and SMSIs. As a result, single-atom catalysis has been proven to be a powerful and effective solution in many typical heterogeneous catalytic reactions, including electrochemical reactions, water-gas shift reactions, hydrogenation reactions, etc. [211-217] and in particular, SACs obtained through scalable synthesis methods have potential industrial applications. In addition, SACs have established a bridge to link homogeneous and heterogeneous catalysis by providing single active sites on solid surfaces.
Fig. 16 a HADDF-STEM image of Na-containing Pt catalysts. b Bader charge of $\mathrm{Pt}$ in $\mathrm{PtK}_{6} \mathrm{O}_{x}(\mathrm{OH})_{y}$ cluster sites. c WGS profiles (steady-state data) measured over the $1 \mathrm{Pt}-$ $3 \mathrm{Na}-\mathrm{SiO}_{2}$ sample in the $2 \%$ $\mathrm{CO}-10 \% \mathrm{H}_{2} \mathrm{O}-\mathrm{He}$ gas mixture, contact time of $0.09 \mathrm{~g} \mathrm{~s} \mathrm{~cm}^{-3}$. d Arrhenius-type plot of reaction rates of Na-free and Na-containing samples in a simulated reformate gas mixture. a, $\mathbf{d}$ Adapted with permission from Ref. [125]. Copyright 2015, American Chemical Society. b, c Adapted with permission from Ref. [208]. Copyright 2010, American Association for the Advancement of Science
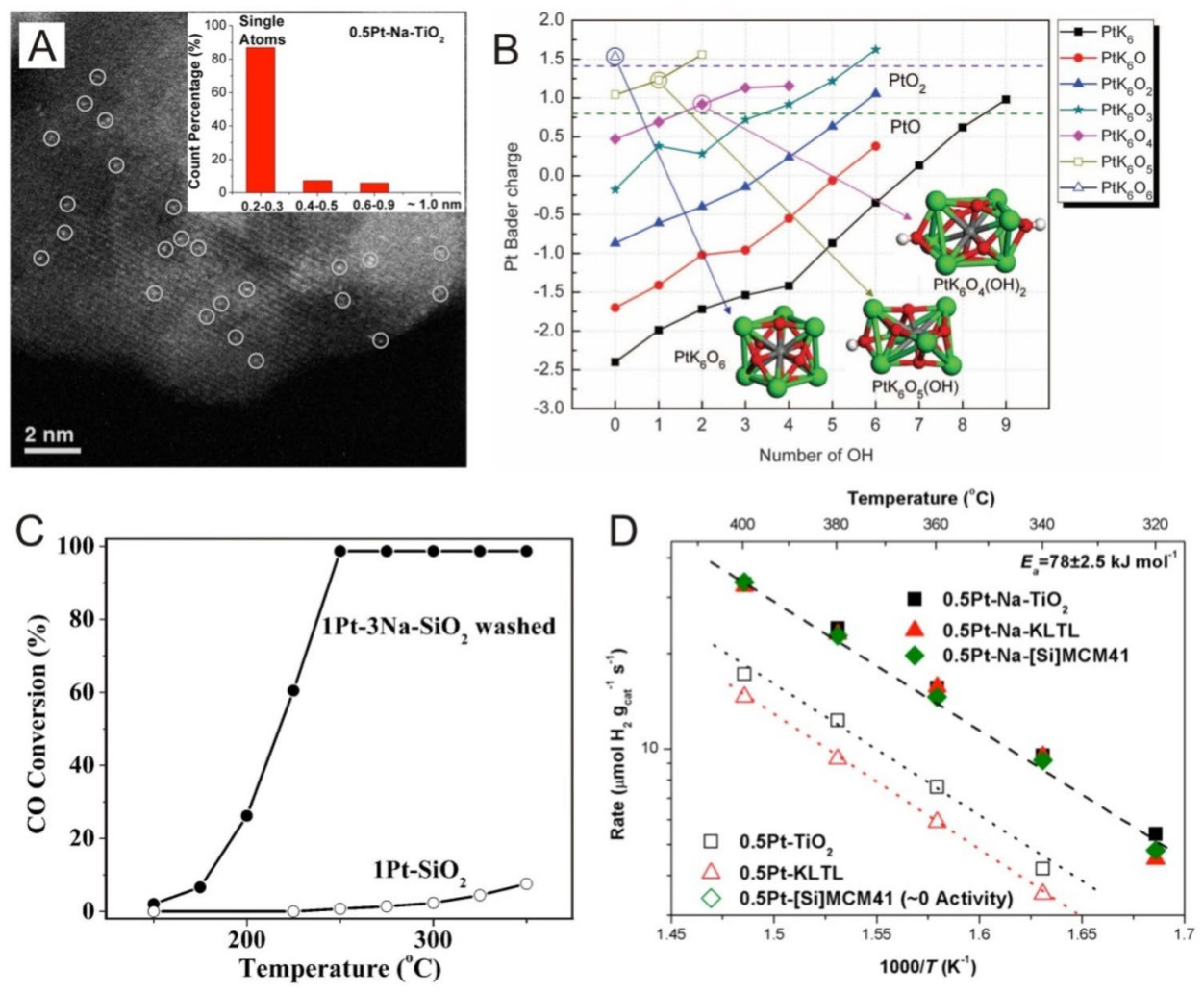
Fig. 17 a Schematic of the formation of $\mathrm{Zn}-\mathrm{Co}$ dimers. b-d AC-HAADF-STEM images and statistical $\mathrm{Zn}-\mathrm{Co}$ distances of $\mathrm{Zn}-\mathrm{Co}$ dimer catalysts. Adapted with permission from Ref. [213]. Copyright 2019, Wiley-VCH

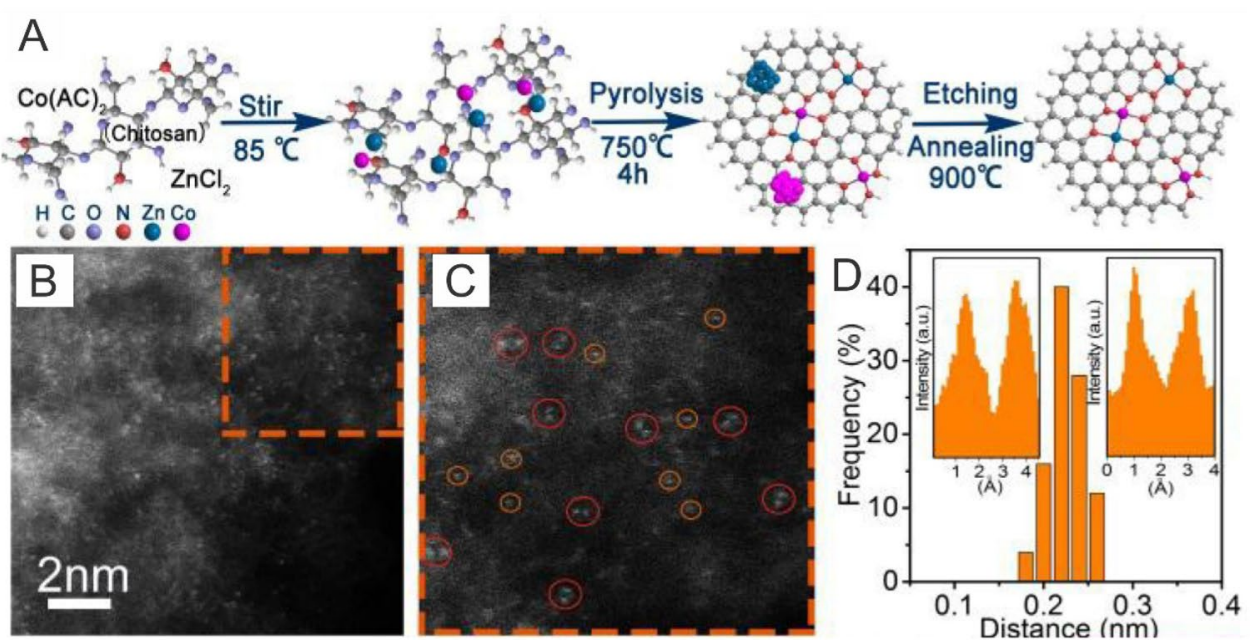

Overall, SACs possess considerable promise in industrial applications. And to meet the stringent requirements for industry, the following future research efforts are proposed:

1. Support materials SAC supports play an important role in the performance of atomically dispersed metal catalysts because single metal atoms can strongly bond to support surface atoms through bonding between metal atoms and support surfaces. In addition, the choice of supports and corresponding properties are important for the design of novel SACs because different supports can provide different anchoring sites to stabilize single metal atoms and provide different activities [218-222]. Furthermore, not only can supports stabilize single metal atoms, they can also actively participate in catalytic reactions. For example, both $\mathrm{TiC}$ and $\mathrm{TiN}$ supports can stabilize single Pt atoms and corresponding catalysts show significantly different catalytic activity, product selectivity and stability for electrochemical $\mathrm{H}_{2} \mathrm{O}_{2}$ production due to differences in the oxygen adsorption energies of TiC and TiN [223]. Moreover, to achieve high loading of single metal atoms on supports, high surface area and robust supports with large numbers of anchor sites are needed in which anchor sites on support materials can determine the active and stability of metal SACs. Support surfaces with different functional groups or defects can also form different SAC structures, which can not only affect the stability of SACs but will also affect the activity and selectivity. For example, Shibata et al. [72] identified five anchoring sites for Pt atoms on $\mathrm{TiO}_{2}(110)$ surfaces using AC-STEM and found that the most favorable Pt adsorption sites were on the vacancy sites of basal oxygen atoms located in the subsurface positions. More recently, Liu et al. [224] found that $\mathrm{Pt}$ atoms preferred to occupy $\mathrm{Fe}$ cation positions with low $\mathrm{Pt}$ loading, whereas Pt atoms preferred to occupy both
Fe positions and $\mathrm{O}$ positions on $\mathrm{Fe}_{2} \mathrm{O}_{3}$ surfaces with high metal loading. Despite these results, more work is needed to identify preferential support sites for metal anchoring and to understand how SAC precursors react with support surfaces and how these atoms incorporate themselves into anchor sites. Overall, the understanding of these key features will allow for the improved design of novel supports for stable, high-loading SACs for practical applications.

2. Synthesis methods economically scalable synthesis methods are essential for the large-scale application of SACs in industry. And although many synthesis methods have been presented in this review to prepare SACs, it is difficult for these methods to produce high-loading SACs on a scale beyond laboratory settings. Furthermore, almost all studies currently reported are focused on SACs with only one element and the synthesis of bimetallic dimer structures remains challenging. However, researchers predict that the properties of SACs can be further promoted through the rational design of bimetallic dimers due to synergistic effects between different elements. For example, Zhao et al. [225] recently developed a competitive complexation strategy to construct a novel electrocatalyst with $\mathrm{Zn}-\mathrm{Co}$ atomic dimers coordinated on N-doped carbon support (Fig. 17) in which due to similar coordination abilities, a $\mathrm{Zn}-\mathrm{Co}$ dimer structure can be synthesized after pyrolysis. As a result, the as-prepared dimer structure exhibited outstanding ORR performances in both alkaline and acidic conditions. Such methods can allow for the flexible implementation of alternative SACs such as multi-element dimers, which can also offer promising implementation in industry. Moreover, the direct conversion of bulk metal to SACs is another promising synthesis strategy. For example, Li et al. [226] developed a simple strategy to synthesize atomically dispersed Pt from bulk Pt metal using a 
thermal emitting method and reported that the resulting Pt SAC showed superior performances for HER and the oxidation of various organo-silanes. Overall, synthesis methods must not only provide strong performance results but must also be cost effective and scalable for the broader adoption of SACs.

3. Stability a major challenge to the broad application of SACs is their stabilization under realistic working conditions. Here, the true structures of the active sites of SACs must be identified and understood because they can hinder the fundamental understanding of these catalysts and the design of novel ones. The identification and investigation of SACs require advanced atomicresolution characterization techniques; primarily in real working conditions, and theoretical calculations. For example, atomic-scale information on the diffusion of single atoms on supports and the evolution of SAC structures during reactions is extremely useful to establish sintering mechanisms of SACs. Overall, the enhancement or tuning of interactions between metals and supports is vital in the stabilization of single metal atoms and the increase in activity and selectivity as well as the development of high-loading SACs. In addition, the understanding of the correlation between singleatom coordination structures, degree of metal-support interactions and support properties is also important to the stabilization of SACs. Here, a deep understanding of both sintering mechanisms and active mechanisms for single metal atoms under working conditions can provide insights into the design of high-performance catalytic systems and provide useful criteria for the design of industrial catalysts.

4. Characterization methods advanced characterization methods such as HAADF-STEM, STM, XAS spectroscopy and IR spectroscopy are essential to develop highly active and stable SACs. And although significant improvements in the understanding of catalytic mechanisms of SACs have been made, these are mainly based on ex situ characterization techniques such as HAADF-STEM and XAS as well as theoretical calculations conducted primarily on idealized systems. Alternatively, in situ characterization techniques can not only provide direct images of supported single atoms to reveal the location of single-atom anchored supports and the interfaces of single atoms and supports, but more importantly, will also help in the understanding of stabilization mechanisms and reveal the behaviors of single atoms for different reactions. Based on this, the development of in situ/operando characterization methods to observe SACs under "real" reaction conditions is vital for the development of SACs for industrial applications.
Acknowledgements This work was supported by the Natural Sciences and Engineering Research Council of Canada (NSERC), the Canada Research Chair (CRC) Program, the Canada Foundation for Innovation (CFI) and the University of Western Ontario.

\section{Compliance with Ethical Standards}

Conflict of interest The authors declare that they have no conflict of interest.

Open Access This article is distributed under the terms of the Creative Commons Attribution 4.0 International License (http://creativeco mmons.org/licenses/by/4.0/), which permits unrestricted use, distribution, and reproduction in any medium, provided you give appropriate credit to the original author(s) and the source, provide a link to the Creative Commons license, and indicate if changes were made.

\section{References}

1. Stratakis, M., Garcia, H.: Catalysis by supported gold nanoparticles: beyond aerobic oxidative processes. Chem. Rev. 112, 4469-4506 (2012)

2. Yu, W., Porosoff, M.D., Chen, J.G.: Review of Pt-based bimetallic catalysis: from model surfaces to supported catalysts. Chem. Rev. 112, 5780-5817 (2012)

3. Wang, Y.J., Zhao, N., Fang, B., et al.: Carbon-supported Pt-based alloy electrocatalysts for the oxygen reduction reaction in polymer electrolyte membrane fuel cells: particle size, shape, and composition manipulation and their impact to activity. Chem. Rev. 115, 3433-3467 (2015)

4. Chen, M.S., Goodman, D.W.: The structure of catalytically active gold on titania. Science 306, 252-255 (2004)

5. Herzing, A.A., Kiely, C.J., Carley, A.F., et al.: Identification of active gold nanoclusters on iron oxide supports for $\mathrm{CO}$ oxidation. Science 321, 1331-1335 (2008)

6. Turner, M., Golovko, V.B., Vaughan, O.P., et al.: Selective oxidation with dioxygen by gold nanoparticle catalysts derived from 55-atom clusters. Nature 454, 981-983 (2008)

7. Tyo, E.C., Vajda, S.: Catalysis by clusters with precise numbers of atoms. Nat. Nanotechnol. 10, 577-588 (2015)

8. Liang, S., Hao, C., Shi, Y.: The power of single-atom catalysis. ChemCatChem 7, 2559-2567 (2015)

9. Yang, X., Wang, A., Qiao, B., et al.: Single-atom catalysts: a new frontier in heterogeneous catalysis. Acc. Chem. Res. 46, 1740-1748 (2013)

10. Liu, J.: Catalysis by supported metal single atoms. ACS Catal. 7, 34-59 (2017)

11. Qiao, B., Wang, A., Yang, X., et al.: Single-atom catalysis of CO oxidation using $\mathrm{Pt}_{1} / \mathrm{FeO}_{x}$. Nat. Chem. 3, 634-641 (2011)

12. Zhu, C., Fu, S., Shi, Q., et al.: Single-atom electrocatalysts. Angew. Chem. Int. Ed. 56, 13944-13960 (2017)

13. Zhang, H., Liu, G., Shi, L., et al.: Single-atom catalysts: emerging multifunctional materials in heterogeneous catalysis. Adv. Energy Mater. 8, 1701343 (2018)

14. Flytzani-Stephanopoulos, M., Gates, B.C.: Atomically dispersed supported metal catalysts. Annu. Rev. Chem. Biomol. Eng. 3, 545-574 (2012)

15. Corma, A., et al.: Exceptional oxidation activity with size-controlled supported gold clusters of low atomicity. Nat. Chem. 5, 775-781 (2013) 
16. Moliner, M., Concepción, P., Boronat, M., et al.: Reversible transformation of $\mathrm{Pt}$ nanoparticles into single atoms inside highsilica chabazite zeolite. J. Am. Chem. Soc. 138, 15743-15750 (2016)

17. Peterson, E.J., DeLaRiva, A.T., Lin, S., et al.: Low-temperature carbon monoxide oxidation catalysed by regenerable atomically dispersed palladium on alumina. Nat. Commun. 5, 4885 (2014)

18. Wang, X., Cheng, X., Thomas, A., et al.: Metal-containing carbon nitride compounds: a new functional organic-metal hybrid material. Adv. Mater. 21, 1609-1612 (2009)

19. Li, X., et al.: Single-atom Pt as Co-catalyst for enhanced photocatalytic $\mathrm{H}_{2}$ evolution. Adv. Mater. 28, 2427-2431 (2016)

20. Yang, S., Bi, W., Zhang, L., et al.: Single-atom catalyst of platinum supported on titanium nitride for selective electrochemical reactions. Angew. Chem. Int. Ed. 55, 2058-2062 (2016)

21. Schwarz, J.A., Contescu, C., Contescu, A.: Methods for preparation of catalytic materials. Chem. Rev. 95, 477-510 (1995)

22. Choi, C.H., Kim, M., Kwon, H.C., et al.: Tuning selectivity of electrochemical reactions by atomically dispersed platinum catalyst. Nat. Commun. 7, 10922 (2016)

23. Ahn, T., Kim, J.H., Yang, H.M., et al.: Formation pathways of magnetite nanoparticles by coprecipitation method. J. Phys. Chem. C 116, 6069-6076 (2012)

24. Laurent, S., Forge, D., Port, M., et al.: Magnetic iron oxide nanoparticles: synthesis, stabilization, vectorization, physicochemical characterizations, and biological applications. Chem. Rev. 108, 2064-2110 (2008)

25. Lu, A.H., Salabas, E.L., Schuth, F.: Magnetic nanoparticles: synthesis, protection, functionalization, and application. Angew. Chem. Int. Ed. 46, 1222-1244 (2007)

26. Shi, Y., Zhao, C., Wei, H., et al.: Single-atom catalysis in mesoporous photovoltaics: the principle of utility maximization. Adv. Mater. 26, 8147-8153 (2014)

27. Lin, J., Wang, A., Qiao, B., et al.: Remarkable performance of $\mathrm{Ir}_{1} / \mathrm{FeO}_{x}$ single-atom catalyst in water gas shift reaction. J. Am. Chem. Soc. 135, 15314-15317 (2013)

28. Lin, J., Qiao, B., Liu, J., et al.: Design of a highly active Ir/ $\mathrm{Fe}(\mathrm{OH})_{x}$ catalyst: versatile application of Pt-group metals for the preferential oxidation of carbon monoxide. Angew. Chem. Int. Ed. 51, 2920-2924 (2012)

29. Liang, J.X., Lin, J., Yang, X.F., et al.: Theoretical and experimental investigations on single-atom catalysis: $\mathrm{Ir}_{1} / \mathrm{FeO}_{x}$ for $\mathrm{CO}$ oxidation. J. Phys. Chem. C 118, 21945-21951 (2014)

30. Lin, J., Qiao, B., Li, N., et al.: Little do more: a highly effective $\mathrm{Pt}_{1} / \mathrm{FeO}_{x}$ single-atom catalyst for the reduction of $\mathrm{NO}$ by $\mathrm{H}_{2}$. Chem. Comm. 51, 7911-7914 (2015)

31. Wei, H.S., Liu, X., Wang, A., et al.: $\mathrm{FeO}_{x}$-supported platinum single-atom and pseudo-single-atom catalysts for chemoselective hydrogenation of functionalized nitroarenes. Nat. Commun. 5, 5634 (2014)

32. George, S.M.: Atomic layer deposition: an overview. Chem. Rev. 110, 111-131 (2010)

33. Liu, J., Sun, X.: Elegant design of electrode and electrode/ electrolyte interface in lithium-ion batteries by atomic layer deposition. Nanotechnology 26, 024001 (2015)

34. O’Neill, B.J., Jackson, D.H.K., Lee, J., et al.: Catalyst design with atomic layer deposition. ACS Catal. 5, 1804-1825 (2015)

35. Hamalainen, J., Ritala, M., Leskela, M.: Atomic layer deposition of noble metals and their oxides. Chem. Mater. 26, 786-801 (2014)

36. Lu, J.L., Elam, J.W., Stair, P.C.: Synthesis and stabilization of supported metal catalysts by atomic layer deposition. Acc. Chem. Res. 46, 1806-1815 (2013)

37. Cheng, N., Shao, Y., Liu, J., et al.: Electrocatalysts by atomic layer deposition for fuel cell applications. Nano Energy 29, 220-242 (2016)
38. Sun, S.H., Zhang, G., Gauquelin, N., et al.: Single-atom catalysis using $\mathrm{Pt} /$ graphene achieved through atomic layer deposition. Sci. Rep. 3, 1775 (2013)

39. Yan, H., Li, Y., Wu, H., et al.: Bottom-up precise synthesis of stable platinum dimers on graphene. Nat. Commun. 8, 1070 (2017)

40. Yan, H., Cheng, H., Yi, H., et al.: Single-atom $\mathrm{Pd}_{1} /$ graphene catalyst achieved by atomic layer deposition: remarkable performance in selective hydrogenation of 1,3-butadiene. J. Am. Chem. Soc. 137, 10484-10487 (2015)

41. Setthapun, W., Williams, W.D., Kim, S.M., et al.: Genesis and evolution of surface species during Pt atomic layer deposition on oxide supports characterized by in situ XAFS analysis and watergas shift reaction. J. Phys. Chem. C 114, 9758-9771 (2010)

42. Gould, T.D., Lubers, A.M., Corpuz, A.R., et al.: Controlling nanoscale properties of supported platinum catalysts through atomic layer deposition. ACS Catal. 5, 1344-1352 (2015)

43. Stambula, S., Gauquelin, N., Bugnet, M., et al.: Chemical structure of nitrogen-doped graphene with single platinum atoms and atomic clusters as a platform for the PEMFC electrode. J. Phys. Chem. C 118, 3890-3900 (2014)

44. Liu, P., Zhao, Y., Qin, R., et al.: Photochemical route for synthesizing atomically dispersed palladium catalysts. Science $\mathbf{3 5 2}$, 797-800 (2016)

45. Li, H., Wang, L., Dai, Y., et al.: Synergetic interaction between neighbouring platinum monomers in $\mathrm{CO}_{2}$ hydrogenation. Nat. Nanotechnol. 13, 411-417 (2018)

46. Lu, J., Aydin, C., Browning, N.D., et al.: Imaging isolated gold atom catalytic sites in zeolite NaY. Angew. Chem. Int. Ed. 51, 5842-5846 (2012)

47. Kistler, J.D., Chotigkrai, N., Xu, P., et al.: A single-site platinum CO oxidation catalyst in zeolite KLTL: microscopic and spectroscopic determination of the locations of the platinum atoms. Angew. Chem. Int. Ed. 53, 8904-8907 (2014)

48. He, T., Chen, S., Ni, B., et al.: Zirconium-porphyrin-based metal-organic framework hollow nanotubes for immobilization of noble-metal single atoms. Angew. Chem. Int. Ed. 57, 3493$3498(2018)$

49. Wang, X., Chen, W., Zhang, L., et al.: Uncoordinated amine groups of metal-organic frameworks to anchor single Ru sites as chemoselective catalysts toward the hydrogenation of quinoline. J. Am. Chem. Soc. 139, 9419-9422 (2017)

50. Zhang, H., Wei, J., Dong, J., et al.: Efficient visible-light-driven carbon dioxide reduction by a single-atom implanted metalorganic framework. Angew. Chem. Int. Ed. 7, 14310-14314 (2016)

51. Chen, Y., Ji, S., Chen, C., et al.: Single-atom catalysts: synthetic strategies and electrochemical applications. Joule 2, 1242-1264 (2018)

52. Kamiya, K., Kamai, R., Hashimoto, K., et al.: Platinum-modified covalent triazine frameworks hybridized with carbon nanoparticles as methanol-tolerant oxygen reduction electrocatalysts. Nat. Commun. 5, 5040 (2014)

53. Zhang, W., Jiang, P., Wang, Y., et al.: Bottom-up approach to engineer a molybdenum-doped covalent-organic framework catalyst for selective oxidation reaction. RSC Adv. 4, 51544-51547 (2014)

54. Yin, P., Yao, T., Wu, Y., et al.: Single cobalt atoms with precise $\mathrm{N}$-coordination as superior oxygen reduction reaction catalysts. Angew. Chem. Int. Ed. 55, 10800-10805 (2016)

55. Wang, X., Chen, Z., Zhao, X., et al.: Regulation of coordination number over single Co sites: triggering the efficient electroreduction of $\mathrm{CO}_{2}$. Angew. Chem. Int. Ed. 57, 1944-1948 (2018)

56. Chen, Y., Ji, S., Wang, Y., et al.: Isolated single iron atoms anchored on $\mathrm{N}$-doped porous carbon as an efficient electrocatalyst 
for the oxygen reduction reaction. Angew. Chem. Int. Ed. 56, 3941-6937 (2017)

57. Zhao, C., Dai, X., Yao, T., et al.: Ionic exchange of metal-organic frameworks to access single nickel sites for efficient electroreduction of $\mathrm{CO}_{2}$. J. Am. Chem. Soc. 139, 8078-8081 (2017)

58. Ji, S., Chen, Y., Fu, Q., et al.: Confined pyrolysis within metalorganic frameworks to form uniform $\mathrm{Ru}_{3}$ clusters for efficient oxidation of alcohols. J. Am. Chem. Soc. 139, 9795-9798 (2017)

59. Wei, S., Li, A., Liu, J.C., et al.: Direct observation of noble metal nanoparticles transforming to thermally stable single atoms. Nat. Nanotechnol. 13, 856-861 (2018)

60. Yang, J., Qiu, Z., Zhao, C., et al.: In situ thermal atomization to convert supported nickel nanoparticles into surface-bound nickel single-atom catalysts. Angew. Chem. Int. Ed. 57, 14095-14100 (2018)

61. Varela, M., Findlay, S.D., Lupini, A.R., et al.: Spectroscopic imaging of single atoms within a bulk solid. Phys. Rev. Lett. 92, 095502 (2004)

62. Pennycook, S.J., Chisholm, M.F., Lupini, A.R., et al.: Aberration-corrected scanning transmission electron microscopy: from atomic imaging and analysis to solving energy problems. Philos. Trans. Royal Soc. A367, 3709-3733 (2009)

63. Allard, L.F., Flytzani-Stephanopoulos, M., Overbury, S.H.: Behavior of Au species in $\mathrm{Au} / \mathrm{Fe}_{2} \mathrm{O}_{3}$ catalysts characterized by novel in situ heating techniques and aberration-corrected STEM imaging. Microsc. Microanal. 16, 375-385 (2010)

64. Zhu, Y., Inada, H., Nakamura, K., et al.: Imaging single atoms using secondary electrons with an aberration-corrected electron microscope. Nat. Mater. 8, 808-812 (2009)

65. Nellist, D., Pennycookm, S.J.: Direct imaging of the atomic configuration of ultradispersed catalysts. Science 274, 413-415 (1996)

66. Fultz, B., Howe, J.: High-Resolution STEM and Related Imaging Techniques. Springer, Berlin (2013)

67. Wang, H.T., Li, K., Cheng, Y., et al.: Interaction between single gold atom and the graphene edge: a study via aberration-corrected transmission electron microscopy. Nanoscale 4, 29202925 (2012)

68. Robertson, A.W., Montanari, B., He, K., et al.: Dynamics of single Fe atoms in graphene vacancies. Nano Lett. 13, 1468-1475 (2013)

69. Zhao, J., Deng, Q., Avdoshenko, S.M., et al.: Direct in situ observations of single $\mathrm{Fe}$ atom catalytic processes and anomalous diffusion at graphene edges. Proc. Natl. Acad. Sci. U.S.A. 111, 15641-15646 (2014)

70. Bradley, S.A., Sinkler, W., Blom, D.A., et al.: Behavior of Pt atoms on oxide supports during reduction treatments at elevated temperatures, characterized by aberration corrected stem imaging. Catal. Lett. 142, 176-182 (2012)

71. Pennycook, S.J.: Structure determination through Z-contrast microscopy. Adv. Imag. Elect. Phys. 123, 173-206 (2002)

72. Chang, T.Y., Tanaka, Y., Ishikawa, R., et al.: Direct imaging of Pt single atoms adsorbed on $\mathrm{TiO}_{2}(110)$ surfaces. Nano Lett. 14, 134-138 (2014)

73. Qiu, H.J., Ito, Y., Cong, W., et al.: Nanoporous graphene with single-atom nickel dopants: an efficient and stable catalyst for electrochemical hydrogen production. Angew. Chem. Int. Ed. 54, 14031-14035 (2015)

74. Deng, D., Chen, X., Yu, L., et al.: A single iron site confined in a graphene matrix for the catalytic oxidation of benzene at room temperature. Sci. Adv. 1, e1500462 (2015)

75. Chang, H., Saito, M., Nagai, T., et al.: Single adatom dynamics at monatomic steps of free-standing few-layer reduced graphene. Sci. Rep. 4, 6037 (2014)

76. Muller, D.A.: Structure and bonding at the atomic scale by scanning transmission electron microscopy. Nat. Mater. 8, 263-270 (2009)
77. Krivanek, O.L., Chisholm, M.F., Nicolosi, V., et al.: Atom-byatom structural and chemical analysis by annular dark-field electron microscopy. Nature 464, 571-574 (2010)

78. Krivanek, O.L., Zhou, W., Chisholm, M.F., et al.: Gentle STEM of single atoms: low keV imaging and analysis at ultimate detection limits. Wiley, Hoboken (2012)

79. Narula, C.K., Moses-DeBusk, M.: Catalysis by materials with well-defined structures. Elsevier, Amsterdam (2015)

80. Banis, M.N., Sun, S., Meng, X., et al.: $\mathrm{TiSi}_{2} \mathrm{O}_{x}$ coated N-doped carbon nanotubes as Pt catalyst support for the oxygen reduction reaction in PEMFCs. J. Phys. Chem. C 117, 15457-15467 (2013)

81. Ho, V.T.T., Pan, C.J., Rick, J., et al.: Nanostructured $\mathrm{Ti}_{0.7} \mathrm{Mo}_{0.3} \mathrm{O}_{2}$ support enhances electron transfer to Pt: high-performance catalyst for oxygen reduction reaction. J. Am. Chem. Soc. 133, 11716-11724 (2011)

82. Wang, L., Zhang, S., Zhu, Y., et al.: Catalysis and in situ studies of $\mathrm{Rh}_{1} / \mathrm{Co}_{3} \mathrm{O}_{4}$ nanorods in reduction of $\mathrm{NO}$ with $\mathrm{H}_{2}$. ACS Catal. 3, 1011-1019 (2013)

83. Ternes, M., Heinrich, A.J., Schneider, W.D.: Spectroscopic manifestations of the Kondo effect on single adatoms. J. Phys.Condens. Mat. 21, 053001 (2009)

84. Wiesendanger, R.: Single-atom magnetometry. Curr. Opin. Solid St. M. 15, 1-7 (2011)

85. Yang, F., Goodman, D.W.: Scanning tunneling microscopy in surface science. Wiley-VCH Verlag GmbH \& Co. KGaA, Weinheim (2010)

86. Krenner, W., Klappenberger, F., Kühne, D., et al.: Positioning of single Co atoms steered by a self-assembled organic molecular template. J. Phys. Chem. Lett. 2, 1639-1645 (2011)

87. Zhou, X., Yang, W., Chen, Q., et al.: Stable Pt single atoms and nanoclusters on ultrathin $\mathrm{CuO}$ film and their performances in $\mathrm{CO}$ oxidation. J. Phys. Chem. C 120, 1709-1715 (2016)

88. Lucci, F.R., Liu, J., Marcinkowski, M.D., et al.: Selective hydrogenation of 1,3-butadiene on platinum-copper alloys at the single-atom limit. Nat. Commun. 6, 8550 (2015)

89. Lucci, F.R., Darby, M.T., Mattera, M.F.G., et al.: Controlling hydrogen activation, spillover, and desorption with $\mathrm{Pd}-\mathrm{Au}$ single-atom alloys. J. Phys. Chem. Lett. 7, 480-485 (2016)

90. Liu, J., Lucci, F.R., Yang, M., et al.: Tackling CO poisoning with single-atom alloy catalysts. J. Am. Chem. Soc. 138, 6396-6399 (2016)

91. Asokan, C., DeRita, L., Christopher, P.: Using probe molecule FTIR spectroscopy to identify and characterize Pt-group metal based single atom catalysts. Chinese J. Catal. 38, 1473-1480 (2017)

92. DeRita, L., Dai, L., Lopez-Zepeda, K., et al.: Catalyst architecture for stable single atom dispersion enables site-specific spectroscopic and reactivity measurements of $\mathrm{CO}$ adsorbed to $\mathrm{Pt}$ atoms, oxidized Pt clusters, and metallic Pt clusters on $\mathrm{TiO}_{2}$. J. Am. Chem. Soc. 139, 14150-14165 (2017)

93. Yang, D., Xu, P., Browning, N.D., et al.: Tracking Rh atoms in zeolite HY: first steps of metal cluster formation and influence of metal nuclearity on catalysis of ethylene hydrogenation and ethylene dimerization. J. Phys. Chem. Lett. 7, 2537-2543 (2016)

94. Ding, K., Gulec, A., Johnson, A.M., et al.: Identification of active sites in CO oxidation and water-gas shift over supported Pt catalysts. Science 350, 189-192 (2015)

95. Matsubu, J.C., Yang, V.N., Christopher, P.: Isolated metal active site concentration and stability control catalytic $\mathrm{CO}_{2}$ reduction selectivity. J. Am. Chem. Soc. 137, 3076-3084 (2015)

96. Hoffman, A.S., Fang, C.Y., Gates, B.C.: Homogeneity of surface sites in supported single-site metal catalysts: assessment with band widths of metal carbonyl infrared spectra. J. Phys. Chem. Lett. 7, 3854-3860 (2016)

97. Moses-DeBusk, M., Yoon, M., Allard, L.F., et al.: CO oxidation on supported single Pt atoms: experimental and ab initio 
density functional studies of $\mathrm{CO}$ interaction with $\mathrm{Pt}$ atom on theta- $\mathrm{Al}_{2} \mathrm{O}_{3}(010)$ surface. J. Am. Chem. Soc. 135, 12634-12645 (2013)

98. Liang, J.X., Yang, X.F., Wang, A., et al.: Theoretical investigations of non-noble metal single-atom catalysis: $\mathrm{Ni}_{1} / \mathrm{FeO}_{x}$ for $\mathrm{CO}$ oxidation. Catal. Sci. Technol. 6, 6886-6892 (2016)

99. Li, F., Li, Y., Zeng, X.C., et al.: Exploration of high-performance single-atom catalysts on support $\mathrm{M}_{1} / \mathrm{FeO}_{x}$ for $\mathrm{CO}$ oxidation via computational study. ACS Catal. 5, 544-552 (2015)

100. Choi, W.I., Wood, B.C., Schwegler, E., et al.: Combinatorial search for high-activity hydrogen catalysts based on transitionmetal-embedded graphitic carbons. Adv. Energy Mater. 5, 1501423 (2015)

101. Cheng, N.C., et al.: Atomic scale enhancement of metal-support interactions between $\mathrm{Pt}$ and $\mathrm{ZrC}$ for highly stable electrocatalysts. Energy Environ. Sci. 8, 1450-1455 (2015)

102. Cheng, N., Banis, M.N., Liu, J., et al.: Extremely stable platinum nanoparticles encapsulated in a zirconia nanocage by area-selective atomic layer deposition for the oxygen reduction reaction. Adv. Mater. 27, 277-281 (2015)

103. Liu, J., Jiao, M., Lu, L., et al.: High performance platinum single atom electrocatalyst for oxygen reduction reaction. Nat. Comm. 8, 15938 (2017)

104. Zhang, X., Guo, J., Guan, P., et al.: Catalytically active singleatom niobium in graphitic layers. Nat. Commun. 4, 1924 (2013)

105. Wang, J., Huang, Z., Liu, W., et al.: Design of N-coordinated dual-metal sites: a stable and active Pt-free catalyst for acidic oxygen reduction reaction. J. Am. Chem. Soc. 139, 17281-17284 (2017)

106. Li, J., Chen, M., Cullen, D.A., et al.: Atomically dispersed manganese catalysts for oxygen reduction in proton-exchange membrane fuel cells. Nat. Catal. 1, 935-945 (2018). https://doi. org/10.1038/s41929-018-0164-8

107. Subbaraman, R., Tripkovic, D., Strmcnik, D., et al.: Enhancing hydrogen evolution activity in water splitting by tailoring $\mathrm{Li}^{+}-$ $\mathrm{Ni}(\mathrm{OH})_{2}-\mathrm{Pt}$ interfaces. Science 334, 1256-1260 (2011)

108. Yin, H., Zhao, S., Zhao, K., et al.: Ultrathin platinum nanowires grown on single-layered nickel hydroxide with high hydrogen evolution activity. Nat. Commun. 6, 6430 (2015)

109. Cheng, N., Stambula, S., Wang, D., et al.: Pt single-atom/cluster catalysis of the hydrogen evolution reaction. Nat. Commun. 7, 13638 (2016)

110. Zhang, L., Han, L., Liu, H., et al.: Potential-cycling synthesis of single platinum atoms for efficient hydrogen evolution in neutral media. Angew. Chem. Int. Ed. 56, 13694-13698 (2017)

111. Fei, H., Dong, J., Arellano-Jiménez, M.J., et al.: Atomic cobalt on nitrogen-doped graphene for hydrogen generation. Nat Commun 6, 8668 (2015)

112. Stephens, I.E.L., Chorkendorff, I.: Minimizing the use of platinum in hydrogen-evolving electrodes. Angew. Chem. Int. Ed. 50, 1476-1477 (2011)

113. Zhang, L., Jia, Y., Gao, G., et al.: Graphene defects trap atomic $\mathrm{Ni}$ species for hydrogen and oxygen evolution reactions. Chem 4, 285-297 (2018)

114. Zhang, X., Wu, Z., Zhang, X., et al.: Highly selective and active $\mathrm{CO}_{2}$ reduction electrocatalysts based on cobalt phthalocyanine/ carbon nanotube hybrid structures. Nat. Commun. 8, 14675 (2017)

115. Yang, H.B., Hung, S.F., Liu, S., et al.: Atomically dispersed Ni(I) as the active site for electrochemical $\mathrm{CO}_{2}$ reduction. Nat. Energy 3, 140-147 (2018)

116. Yang, F., Song, P., Liu, X., et al.: Highly efficient $\mathrm{CO}_{2}$ electroreduction on $\mathrm{ZnN}_{4}$-based single-atom catalyst. Angew. Chem. Int. Ed. 57, 12303-12307 (2018)
117. Pan, F., Zhang, H., Liu, K., et al.: Unveiling active sites of $\mathrm{CO}_{2}$ reduction on nitrogen-coordinated and atomically dispersed iron and cobalt catalysts. ACS Catal. 8, 3116-3122 (2018)

118. Gai, L., Yoshida, K., Ward, M.R., et al.: Visualisation of single atom dynamics in water gas shift reaction for hydrogen generation. Catal. Sci. Technol. 6, 2214-2227 (2016)

119. Thomas, J.M., Saghi, Z., Gai, P.L.: Can a single atom serve as the active site in some heterogeneous catalysts? Top. Catal. 54, 588-594 (2011)

120. Flytzani-Stephanopoulos, M.: Gold atoms stabilized on various supports catalyze the water-gas shift reaction. Acc. Chem. Res. 47, 783-792 (2014)

121. Fu, Q., Saltsburg, H., Flytzani-Stephanopoulos, M.: Active nonmetallic Au and Pt species on ceria-based water-gas shift catalysts. Science 301, 935-938 (2003)

122. Fu, Q., Deng, W., Saltsburg, H., et al.: Activity and stability of low-content gold-cerium oxide catalysts for the water-gas shift reaction. Appl. Catal. B-Environ. 56, 57-68 (2005)

123. Yang, M., Allard, L.F., Flytzani-Stephanopoulos, M.: Atomically dispersed $\mathrm{Au}-(\mathrm{OH})_{\mathrm{x}}$ species bound on titania catalyze the low-temperature water-gas shift reaction. J. Am. Chem. Soc. 135, 3768-3771 (2013)

124. Yang, M., Li, S., Wang, Y., et al.: Catalytically active Au$\mathrm{O}(\mathrm{OH})_{x}$-species stabilized by alkali ions on zeolites and mesoporous oxides. Science 346, 1498-1501 (2014)

125. Yang, M., Liu, J., Lee, S., et al.: A common single-site Pt(II)$\mathrm{O}(\mathrm{OH})_{x}$-species stabilized by sodium on "Active" and "Inert" supports catalyzes the water-gas shift reaction. J. Am. Chem. Soc. 137, 3470-3473 (2015)

126. Vilé, G., Albani, D., Nachtegaal, M., et al.: A stable single-site palladium catalyst for hydrogenations. Angew. Chem. Int. Ed. 54, 11265-11269 (2015)

127. Pei, G.X., Liu, X.Y., Wang, A., et al.: Ag alloyed Pd singleatom catalysts for efficient selective hydrogenation of acetylene to ethylene in excess ethylene. ACS Catal. 5, 3717-3725 (2015)

128. Pei, G.X., Liu, X.Y., Wang, A., et al.: Promotional effect of Pd single atoms on Au nanoparticles supported on silica for the selective hydrogenation of acetylene in excess ethylene. New J. Chem. 38, 2043-2051 (2014)

129. Aich, P., Wei, H., Basan, H., et al.: Single-atom alloy Pd-Ag catalyst for selective hydrogenation of acrolein. J. Phys. Chem. C 119, 18140-18148 (2015)

130. Boucher, M.B., Zugic, B., Cladaras, G., et al.: Single atom alloy surface analogs in $\mathrm{Pd}_{0.18} \mathrm{Cu}_{15}$ nanoparticles for selective hydrogenation reactions. Phys. Chem. Chem. Phys. 15, 12187-12196 (2013)

131. Cao, X.R., Ji, Y.F., Luo, Y.: Dehydrogenation of propane to propylene by a $\mathrm{Pd} / \mathrm{Cu}$ single-atom catalyst: insight from firstprinciples calculations. J. Phys. Chem. C 119, 1016-1023 (2015)

132. Boucher, M.B., Marcinkowski, M.D., Liriano, M.L., et al.: Molecular-scale perspective of water-catalyzed methanol dehydrogenation to formaldehyde. ACS Nano 7, 6181-6187 (2013)

133. Shan, J.J., Lucci, F.R., Liu, J., et al.: Water co-catalyzed selective dehydrogenation of methanol to formaldehyde and hydrogen. Surf. Sci. 650, 121-129 (2016)

134. Zhang, H.J., Kawashima, K., Okumura, M., et al.: Colloidal Au single-atom catalysts embedded on Pd nanoclusters. J. Mater. Chem. A 2, 13498-13508 (2014)

135. Cheng, X., Zhao, Y., Li, F., et al.: Catalytic mechanisms of $\mathrm{Au}_{11}$ and $\mathrm{Au}_{11-n} \mathrm{Pt}_{n}(n=1-2)$ clusters: a DFT investigation on the oxidation of $\mathrm{CO}$ by $\mathrm{O}_{2}$. J. Mol. Model. 21, 1-11 (2015)

136. Yao, Y.X., Goodman, D.W.: New insights into structure-activity relationships for propane hydrogenolysis over $\mathrm{Ni}-\mathrm{Cu}$ bimetallic catalysts. RSC Adv. 5, 43547-43551 (2015) 
137. Zhang, L., Wang, A., Miller, J.T., et al.: Efficient and durable Au alloyed Pd single-atom catalyst for the Ullmann reaction of aryl chlorides in water. ACS Catal. 4, 1546-1553 (2014)

138. Wu, J., Shan, S., Petkov, V., et al.: Composition-structure-activity relationships for palladium-alloyed nanocatalysts in oxygen reduction reaction: an ex situ/in situ high energy X-ray diffraction study. ACS Catal. 5, 5317-5327 (2015)

139. Lucci, F.R., Marcinkowski, M.D., Lawton, T.J., et al.: $\mathrm{H}_{2}$ activation and spillover on catalytically relevant $\mathrm{Pt}-\mathrm{Cu}$ single atom alloys. J. Phys. Chem. C 119, 24351-24357 (2015)

140. Pedersen, M.O., Helveg, S., Ruban, A., et al.: How a gold substrate can increase the reactivity of a Pt overlayer. Surf. Sci. 426, 395-409 (1999)

141. Ruff, M., Takehiro, N., Liu, P., et al.: Size-specific chemistry on bimetallic surfaces: a combined experimental and theoretical study. ChemPhysChem 8, 2068-2071 (2007)

142. Takeguchi, T., Yamanaka, T., Asakura, K., et al.: Evidence of nonelectrochemical shift reaction on a CO-tolerant high-entropy state Pt-Ru anode catalyst for reliable and efficient residential fuel cell systems. J. Am. Chem. Soc. 134, 14508-14512 (2012)

143. Nagahara, Y., Sugawara, S., Shinohara, K.: The impact of air contaminants on PEMFC performance and durability. J. Power Sources 182, 422-428 (2008)

144. Kyriakou, G., Boucher, M.B., Jewell, A.D., et al.: Isolated metal atom geometries as a strategy for selective heterogeneous hydrogenations. Science 335, 1209-1212 (2012)

145. Cao, X., Fu, Q., Luo, Y.: Catalytic activity of Pd-doped Cu nanoparticles for hydrogenation as a single-atom-alloy catalyst. Phys. Chem. Chem. Phys. 16, 8367-8375 (2014)

146. Wang, Z.T., Darby, M.T., Therrien, A.J., et al.: Preparation, structure, and surface chemistry of Ni-Au single atom alloys. J. Phys. Chem. C 120, 13574-13580 (2016)

147. Sun, G., Zhao, Z.J., Mu, R., et al.: Breaking the scaling relationship via thermally stable $\mathrm{Pt} / \mathrm{Cu}$ single atom alloys for catalytic dehydrogenation. Nat. Commun. 9, 4454 (2018)

148. Cargnello, M., Doan-Nguyen, V.V.T., Gordon, T.R., et al.: Control of metal nanocrystal size reveals metal-support interface role for ceria catalysts. Science 341, 771-773 (2013)

149. Frenkel, A.I., Cason, M.W., Elsen, A., et al.: Critical review: effects of complex interactions on structure and dynamics of supported metal catalysts. J. Vac. Sci. Technol., A 32, 020801 (2014)

150. Farmer, J.A., Campbell, C.T.: Ceria maintains smaller metal catalyst particles by strong metal-support bonding. Science 329, 933-936 (2010)

151. Campbell, T.: Catalyst-support interactions: electronic perturbations. Nat. Chem. 4, 597-598 (2012)

152. Shi, J.L.: On the synergetic catalytic effect in heterogeneous nanocomposite catalysts. Chem. Rev. 113, 2139-2181 (2013)

153. Tang, H.L., Wei, J., Liu, F., et al.: Strong metal-support interactions between gold nanoparticles and nonoxides. J. Am. Chem. Soc. 138, 56-59 (2016)

154. Kou, R., Shao, Y., Mei, D., et al.: Stabilization of electrocatalytic metal nanoparticles at metal-metal oxide-graphene triple junction points. J. Am. Chem. Soc. 133, 2541-2547 (2011)

155. Zhang, Z., Zhu, Y., Asakura, H., et al.: Thermally stable single atom $\mathrm{Pt} / \mathrm{m}-\mathrm{Al}_{2} \mathrm{O}_{3}$ for selective hydrogenation and $\mathrm{CO}$ oxidation. Nat. Commun. 8, 16100 (2017)

156. Wieckowski, A.: Interfacial electrochemistry: theory, experiment, and applications. Marcel Dekker Inc, New York (1999)

157. Qiao, B., Liang, J.X., Wang, A., et al.: Ultrastable single-atom gold catalysts with strong covalent metal-support interaction (CMSI). Nano Res. 8, 2913-2924 (2015)

158. Jones, J., Xiong, H., DeLaRiva, A.T., et al.: Thermally stable single-atom platinum-on-ceria catalysts via atom trapping. Science 353, 150-154 (2016)
159. Qiao, B., Liu, J., Wang, Y.G., et al.: Highly efficient catalysis of preferential oxidation of $\mathrm{CO}$ in $\mathrm{H}_{2}$-rich stream by gold singleatom catalysts. ACS Catal. 5, 6249-6254 (2015)

160. Wang, C., Gu, X.K., Yan, H., et al.: Water-mediated Mars-Van Krevelen mechanism for $\mathrm{CO}$ oxidation on ceria-supported singleatom Pt1 catalyst. ACS Catal. 7, 887-891 (2017)

161. Bruix, A., Lykhach, Y., Matolínová, I., et al.: Maximum noblemetal efficiency in catalytic materials: atomically dispersed surface platinum. Angew. Chem. Int. Ed. 53, 10525-10530 (2014)

162. Aleksandrov, H.A., Neyman, K.M., Vayssilov, G.N.: The structure and stability of reduced and oxidized mononuclear platinum species on nanostructured ceria from density functional modeling. Phys. Chem. Chem. Phys. 17, 14551-14560 (2015)

163. Pan, Y., Nilius, N., Stiehler, C., et al.: Ceria nanocrystals exposing wide (100) facets: structure and polarity compensation. Adv. Mater. Interfaces 1, 1400404 (2014)

164. Kozlov, S.M., Viñes, F., Nilius, N., et al.: Absolute surface step energies: accurate theoretical methods applied to ceria nanoislands. J. Phys. Chem. Lett. 3, 1956-1961 (2012)

165. Gu, X.K., Qiao, B., Huang, C.Q., et al.: Supported single $\mathrm{Pt}_{1} / \mathrm{Au}_{1}$ atoms for methanol steam reforming. ACS Catal. 4, 3886-3890 (2014)

166. Wan, J., Chen, W., Jia, C., et al.: Defect effects on $\mathrm{TiO}_{2}$ nanosheets: stabilizing single atomic site $\mathrm{Au}$ and promoting catalytic properties. Adv. Mater. 30, 1705369 (2018)

167. Mellor, A., Humphrey, D., Yim, C.M., et al.: Direct visualization of $\mathrm{Au}$ atoms bound to $\mathrm{TiO}_{2}(110) \mathrm{O}$-vacancies. J. Phys. Chem. C 121, 24721-24725 (2017)

168. Addou, R., Senftle, T.P., O'Connor, N., et al.: Influence of hydroxyls on $\mathrm{Pd}$ atom mobility and clustering on rutile $\mathrm{TiO}_{2}(011)-2 \times 1$. ACS Nano 8, 6321-6333 (2014)

169. Lu, Y.H., Zhou, M., Zhang, C., et al.: Metal-embedded graphene: a possible catalyst with high activity. J. Phys. Chem. C 113, 20156-20160 (2009)

170. Zhang, T., Xue, Q., Shan, M., et al.: Adsorption and catalytic activation of $\mathrm{O}_{2}$ molecule on the surface of Au-doped graphene under an external electric field. J. Phys. Chem. C 116, 1991819924 (2012)

171. Liu, X., Yang, Y., Chu, M., et al.: Defect stabilized gold atoms on graphene as potential catalysts for ethylene epoxidation: a first-principles investigation. Catal. Sci. Technol. 6, 1632-1641 (2016)

172. Pulido, A., Boronat, M., Corma, A.: Propene epoxidation with $\mathrm{H}_{2} / \mathrm{H}_{2} \mathrm{O} / \mathrm{O}_{2}$ mixtures over gold atoms supported on defective graphene: a theoretical study. J. Phys. Chem. C 116, 19355-19362 (2012)

173. Li, Y., Zhou, Z., Yu, G., et al.: CO catalytic oxidation on ironembedded graphene: computational quest for low-cost nanocatalysts. J. Phys. Chem. C 114, 6250-6254 (2010)

174. Wannakao, S., Nongnual, T., Khongpracha, P., et al.: Reaction Mechanisms for CO Catalytic Oxidation by $\mathrm{N}_{2} \mathrm{O}$ on Fe-Embedded Graphene. J. Phys. Chem. C 116, 16992-16998 (2012)

175. Song, E.H., Wen, Z., Jiang, Q.: CO catalytic oxidation on copperembedded graphene. J. Phys. Chem. C 115, 3678-3683 (2011)

176. Tang, Y.A., Yang, Z.X., Dai, X.Q.: A theoretical simulation on the catalytic oxidation of $\mathrm{CO}$ on Pt/graphene. Phys. Chem. Chem. Phys. 14, 16566-16572 (2012)

177. Chan, K.T., Neaton, J.B., Cohen, M.L.: First-principles study of metal adatom adsorption on graphene. Phys. Rev. B 77, 235430 (2008)

178. Krasheninnikov, A.V., Lehtinen, P.O., Foster, A.S., et al.: Embedding transition-metal atoms in graphene: structure, bonding, and magnetism. Phys. Rev. Lett. 102, 126807 (2009)

179. Rodriguez-Manzo, J.A., Cretu, O., Banhart, F.: Trapping of metal atoms in vacancies of carbon nanotubes and graphene. ACS Nano 4, 3422-3428 (2010) 
180. Tang, Y.N., Yang, Z.X., Dai, X.Q.: Trapping of metal atoms in the defects on graphene. J. Chem. Phys. 135, 224704 (2011)

181. Wang, H., Wang, Q., Cheng, Y., et al.: Doping monolayer graphene with single atom substitutions. Nano Lett. 12, 141-144 (2012)

182. Rodriguez-Manzo, J.A., Banhart, F.: Creation of individual vacancies in carbon nanotubes by using an electron beam of 1 Angstrom diameter. Nano Lett. 9, 2285-2289 (2009)

183. Robertson, A.W., Allen, C.S., Wu, Y.A., et al.: Spatial control of defect creation in graphene at the nanoscale. Nat. Commun. 3, 1144 (2012)

184. Robertson, A.W., Montanari, B., He, K., et al.: Structural reconstruction of the graphene monovacancy. ACS Nano 7 , 4495-4502 (2013)

185. Banhart, F., Kotakoski, J., Krasheninnikov, A.V.: Structural defects in graphene. ACS Nano 5, 26-41 (2011)

186. Gao, C., Chen, S., Wang, Y., et al.: Heterogeneous single-atom catalyst for visible-light-driven high-turnover $\mathrm{CO}_{2}$ reduction: the role of electron transfer. Adv. Mater. 30, 1704624 (2018)

187. Ye, S., Luo, F., Zhang, Q., et al.: Highly stable single Pt atomic sites anchored on aniline-stacked graphene for the hydrogen evolution reaction. Energy Environ. Sci. (2019). https://doi. org/10.1039/C8EE02888E

188. Chen, Z., Zhou, T., Xing, L., et al.: Atomically dispersed ironnitrogen species as electrocatalysts for bifunctional oxygen evolution and reduction reactions. Angew. Chem. Int. Ed. 56, 610-614 (2017)

189. Han, A., Chen, W., Zhang, S., et al.: A polymer encapsulation strategy to synthesize porous nitrogen-doped carbon-nanosphere-supported metal isolated-single-atomic-site catalysts. Adv. Mater. 30, 1706508 (2018)

190. Zhu, C., Fu, S., Song, J., et al.: Self-assembled Fe-N-doped carbon nanotube aerogels with single-atom catalyst feature as high-efficiency oxygen reduction electrocatalysts. Small 13, 1603407 (2017)

191. Fan, L., Liu, P.F., Yan, X., et al.: Atomically isolated nickel species anchored on graphitized carbon for efficient hydrogen evolution electrocatalysis. Nat. Commun. 7, 10667 (2016)

192. Liu, X., Sui, Y., Duan, T., et al.: Monodisperse Pt atoms anchored on $\mathrm{N}$-doped graphene as efficient catalysts for $\mathrm{CO}$ oxidation: a first-principles investigation. Catal. Sci. Technol. 5, 1658-1667 (2015)

193. Zhang, X., Lu, Z., Xu, G., et al.: Single Pt atom stabilized on nitrogen doped graphene: $\mathrm{CO}$ oxidation readily occurs via the tri-molecular Eley-Rideal mechanism. Phys. Chem. Chem. Phys. 17, 20006-20013 (2015)

194. Zhang, X., Lu, Z., Yang, Z.: Single non-noble-metal cobalt atom stabilized by pyridinic vacancy graphene: an efficient catalyst for CO oxidation. J. Mol. Catal. A-Chem. 417, 28-35 (2016)

195. Lin, Y.C., Teng, P.Y., Yeh, P.Y., et al.: Structural and chemical dynamics of pyridinic-nitrogen defects in graphene. Nano Lett. 15, 7408-7413 (2015)

196. Cheng, Y., Zhao, S., Johannessen, B., et al.: Atomically dispersed transition metals on carbon nanotubes with ultrahigh loading for selective electrochemical carbon dioxide reduction. Adv. Mater. 30, 1706287 (2018)

197. Liu, W., Zhang, L., Yan, W., et al.: Single-atom dispersed Co-N$\mathrm{C}$ catalyst: structure identification and performance for hydrogenative coupling of nitroarenes. Chem. Sci. 7, 5758-5764 (2016)

198. Liu, Q., Liu, Y., Li, H., et al.: Towards the atomic-scale characterization of isolated iron sites confined in a nitrogen-doped graphene matrix. Applied Surf. Sci. 410, 111-116 (2017)

199. Liu, W.G., Zhang, L., Liu, X., et al.: Discriminating catalytically active $\mathrm{FeN}_{\mathrm{x}}$ species of atomically dispersed $\mathrm{Fe}-\mathrm{N}-\mathrm{C}$ catalyst for selective oxidation of the $\mathrm{C}-\mathrm{H}$ bond. J. Am. Chem. Soc. 139, 10790-10798 (2017)

200. Pan, Y., Lin, R., Chen, Y., et al.: Design of single-atom $\mathrm{Co}-\mathrm{N}_{5}$ catalytic site: a robust electrocatalyst for $\mathrm{CO}_{2}$ reduction with nearly $100 \%$ CO selectivity and remarkable stability. J. Am. Chem. Soc. 140, 4218-4221 (2018)

201. Ghosh, D., Periyasamy, G., Pandey, B., et al.: Computational studies on magnetism and the optical properties of transition metal embedded graphitic carbon nitride sheets. J. Mater. Chem. C 2, 7943-7951 (2014)

202. Kong, L., Dong, Y., Jiang, P., et al.: Light-assisted rapid preparation of a Ni/g- $\mathrm{C}_{3} \mathrm{~N}_{4}$ magnetic composite for robust photocatalytic $\mathrm{H}_{2}$ evolution from water. J. Mater. Chem. A 4, 9998-10007 (2016)

203. Li, X., Zhong, W., Cui, P., et al.: Design of efficient catalysts with double transition metal atoms on $\mathrm{C}_{2} \mathrm{~N}$ layer. J. Phys. Chem. Lett. 7, 1750-1755 (2016)

204. Chen, Z., Mitchell, S., Vorobyeva, E., et al.: Stabilization of single metal atoms on graphitic carbon nitride. Adv. Funct. Mater. 27, 1605785 (2017)

205. Gao, G., Jiao, Y., Waclawik, E.R., et al.: Single atom (Pd/Pt) supported on graphitic carbon nitride as an efficient photocatalyst for visible-light reduction of carbon dioxide. J. Am. Chem. Soc. 138, 6292-6297 (2016)

206. Cao, Y., Chen, S., Luo, Q., et al.: Atomic-level insight into optimizing the hydrogen evolution pathway over a $\mathrm{Co}_{1}-\mathrm{N}_{4}$ single-site photocatalyst. Angew. Chem. Int. Ed. 56, 12191-12196 (2017)

207. Zheng, Y., Jiao, Y., Zhu, Y., et al.: Molecule-level g- $\mathrm{C}_{3} \mathrm{~N}_{4}$ coordinated transition metals as a new class of electrocatalysts for oxygen electrode reactions. J. Am. Chem. Soc. 139, 3336-3339 (2017)

208. Zhai, Y., Pierre, D., Si, R., et al.: Alkali-stabilized Pt-OH ${ }_{x}$ species catalyze low-temperature water-gas shift reactions. Science 329, 1633-1636 (2010)

209. Zugic, B., Zhang, S., Bell, D.C., et al.: Probing the low-temperature water-gas shift activity of alkali-promoted platinum catalysts stabilized on carbon supports. J. Am. Chem. Soc. 136, 3238-3245 (2014)

210. Zhang, C.B., Liu, F., Zhai, Y., et al.: Alkali-metal-promoted Pt/ $\mathrm{TiO}_{2}$ opens a more efficient pathway to formaldehyde oxidation at ambient temperatures. Angew. Chem. Int. Ed. 51, 9628-9632 (2012)

211. Yuan, S., Pu, Z., Zhou, H., et al.: A universal synthesis strategy for single atom dispersed cobalt/metal clusters heterostructure boosting hydrogen evolution catalysis at all $\mathrm{pH}$ values. Nano Energy 59, 472-480 (2019)

212. Liang, Q., Jin, H., Wang, Z., et al.: Metal-organic frameworks derived reverse-encapsulation Co-NC@ $\mathrm{Mo}_{2} \mathrm{C}$ complex for efficient overall water splitting. Nano Energy 57, 746-752 (2019)

213. Jin, H., Zhou, H., He, D., et al.: MOF-derived 3D Fe-N-S codoped carbon matrix/nanotube nanocomposites with advanced oxygen reduction activity and stability in both acidic and alkaline media. Appl. Catal. B-Environ. 250, 143-149 (2019)

214. Qiao, Y., Yuan, P., Hu, Y., et al.: Sulfuration of an Fe-N-C catalyst containing $\mathrm{Fe}_{x} \mathrm{C} / \mathrm{Fe}$ species to enhance the catalysis of oxygen reduction in acidic media and for use in flexible $\mathrm{Zn}$-Air batteries. Adv. Mater. 30, 1804504 (2018)

215. Wang, Z., Jin, H., Meng, T., et al.: Fe, Cu-coordinated ZIFderived carbon framework for efficient oxygen reduction reaction and zinc-air batteries. Adv. Funct. Mater. 28, 1802596 (2018)

216. Guo, Y., Yuan, P., Zhang, J., et al.: Carbon nanosheets containing discrete $\mathrm{Co}-\mathrm{N}_{x}-\mathrm{By}-\mathrm{C}$ active sites for efficient oxygen electrocatalysis and rechargeable Zn-Air batteries. ACS Nano 12, 1894-1901 (2018)

217. Zheng, Y., Jiao, Y., Vasileff, A., et al.: The hydrogen evolution reaction in alkaline solution: from theory, single crystal models, 
to practical electrocatalysts. Angew. Chem. Int. Ed. 57, 75687579 (2018)

218. Vasileff, A., Xu, C., Jiao, Y., et al.: Surface and interface engineering in copper-based bimetallic materials for selective $\mathrm{CO}_{2}$ electroreduction. Chem 4, 1809-1831 (2018)

219. Liu, J., Zhu, D., Zheng, Y., et al.: Self-supported earth-abundant nanoarrays as efficient and robust electrocatalysts for energyrelated reactions. ACS Catal. 8, 6707-6732 (2018)

220. Jiao, Y., Zheng, Y., Chen, P., et al.: Molecular scaffolding strategy with synergistic active centers to facilitate electrocatalytic $\mathrm{CO}_{2}$ reduction to hydrocarbon/alcohol. J. Am. Chem. Soc. 139, 18093-18100 (2017)

221. Vasileff, A., Zheng, Y., Qiao, S.: Carbon solving carbon's problems: recent progress of nanostructured carbon-based catalysts for the electrochemical reduction of $\mathrm{CO}_{2}$. Adv Energy Mater. 7, 1700759 (2017)

222. Bayatsarmadi, B., Zheng, Y., Vasileff, A., et al.: Recent advances in atomic metal doping of carbon-based nanomaterials for energy conversion. Small 13, 1700191 (2017)

223. Yang, S., Tak, Y.J., Kim, J., et al.: Support effects in single-atom platinum catalysts for electrochemical oxygen reduction. ACS Catal. 7, 1301-1307 (2017)

224. Sibin, D., Rongming, W., Liu, J.: Stability investigation of a high number density $\mathrm{Pt}_{1} / \mathrm{Fe}_{2} \mathrm{O}_{3}$ single-atom catalyst under different gas environments by HAADF-STEM. Nanotechnology 29, 204002 (2018)

225. Lu, Z., Wang, B., Hu, Y., et al.: Isolated Zn-Co atomic pair for highly active and durable oxygen reduction. Angew. Chem. Int. Ed. 58, 2622-2626 (2019)

226. Qu, Y., Chen, B., Li, Z., et al.: Thermal emitting strategy to synthesize atomically dispersed Pt metal sites from bulk Pt metal. J. Am. Chem. Soc. 141, 4505-4509 (2019)

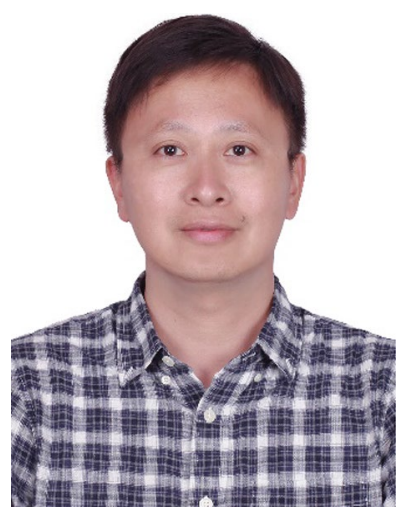

Dr. Niancai Cheng is a professor in the College of Materials Science and Engineering at Fuzhou University. Dr. Cheng received his Ph.D. in new energy materials at Wuhan University of technology in 2010. His research interests focus on materials science for electrochemical energy conversion and storage including fuel cells and batteries.

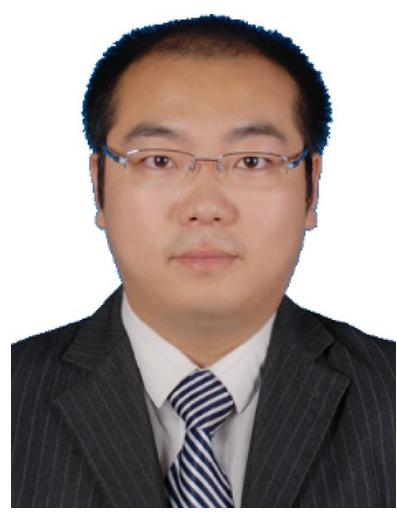

Dr. Lei Zhang received his B.S. degree in Chemistry (2008) and Ph.D. degree in Nanomaterial Chemistry (2014) from Xiamen University with Prof. Zhaoxiong
Xie. He was a visiting graduate student at Georgia Institute of Technology in Prof. Younan Xia's group from 2012 to 2014. From 2015 to 2016, he worked as a Postdoc at Collaborative Innovation Center of Chemical Science and Engineering in Tianjin University. He is currently a postdoctoral associate with Prof. Xueliang Sun at Western University. His research interests include the design and synthesis of metal nanomaterials and single-atom catalysts for fuel cells and water splitting devices.

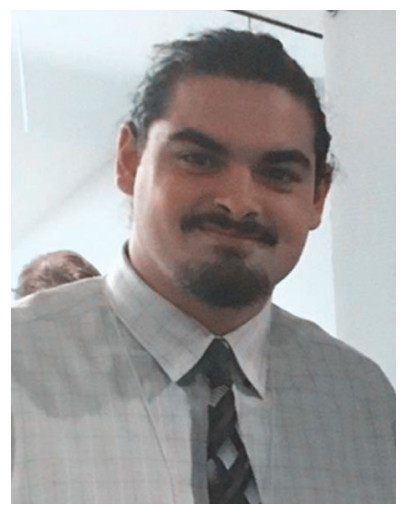

Kieran Doyle-Davis received his Honors B.Sc. in Physics from McMaster University in 2018, with research focus on process optimization for lithium-ion battery fabrication, and thin polymer films. Kieran is currently an M.E.Sc. candidate at the University of Western Ontario under the supervision of Prof. Xueliang Sun. His current research interests include the development of next-generation surface-modified 3-D current collectors for both solution and solid-state lithiumion batteries.

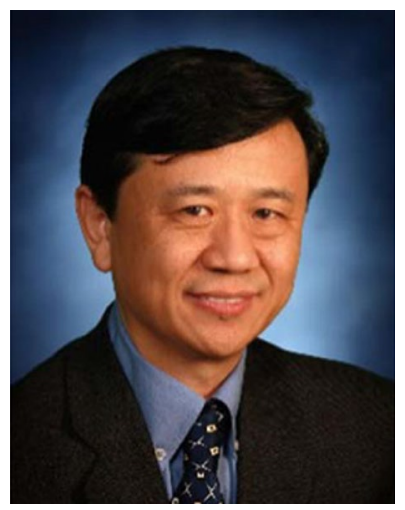

Xueliang Sun is a Canada Research Chair in Development of Nanomaterials for Clean Energy, Fellow of the Royal Society of Canada and Canadian Academy of Engineering and Full Professor at the University of Western Ontario, Canada. Dr. Sun received his Ph.D. in materials chemistry in 1999 from the University of Manchester, UK, which he followed up by working as a postdoctoral fellow at the University of British Columbia, Canada, and as a Research Associate at L'Institut National de la Recherche Scientifique (INRS), Canada. His current research interests are focused on advanced materials for electrochemical energy storage and conversion, including electrocatalysis in fuel cells and electrodes in lithium-ion batteries and metal-air battery. 